\title{
Bus transit equity among demographic groups considering monetary and travel time costs
}

\author{
Leonel Medellin \\ West Virginia University
}

Follow this and additional works at: https://researchrepository.wvu.edu/etd

\section{Recommended Citation}

Medellin, Leonel, "Bus transit equity among demographic groups considering monetary and travel time costs" (2007). Graduate Theses, Dissertations, and Problem Reports. 2795.

https://researchrepository.wvu.edu/etd/2795

This Dissertation is protected by copyright and/or related rights. It has been brought to you by the The Research Repository @ WVU with permission from the rights-holder(s). You are free to use this Dissertation in any way that is permitted by the copyright and related rights legislation that applies to your use. For other uses you must obtain permission from the rights-holder(s) directly, unless additional rights are indicated by a Creative Commons license in the record and/ or on the work itself. This Dissertation has been accepted for inclusion in WVU Graduate Theses, Dissertations, and Problem Reports collection by an authorized administrator of The Research Repository @ WVU.

For more information, please contact researchrepository@mail.wvu.edu. 


\title{
Bus Transit Equity Among Demographic Groups Considering Monetary And Travel Time Costs
}

\author{
Leonel Medellin
}

Dissertation submitted to the College of Engineering and Mineral Resources

at West Virginia University in partial fulfillment of the requirements

for the degree of

\author{
Doctor of Philosophy \\ in \\ Civil Engineering
}

\author{
David R. Martinelli, Ph.D., Chair \\ Darrell R. Dean, Jr., Ph.D. \\ Ronald W. Eck, Ph.D. \\ Lloyd Jim French III, Ph.D. \\ Santiago Pinto, Ph.D. \\ Department of Civil Engineering
}
Morgantown, West Virginia 2007

Keywords: transit equity, fare per mile, travel time per mile, distancebased fares, travel time-based fares, service-based fares, fare inequality Copyright 2007 Leonel Medellin 


\section{ABSTRACT \\ Bus Transit Equity among Demographic Groups Considering Monetary and Travel Time Costs}

\section{Leonel Medellin}

The generalized cost of a transit user depends mostly on time and money spent per trip. On the other hand, time and distance determine most of the transit agency's cost to provide service. These are important factors to consider in determining the equity performance of service provided to users of different demographic groups. The purpose of this study is to determine significant statistical differences in resources spent by bus users in two metropolitan areas. The study measures inequality among different socioeconomic groups of users in terms of travel time and money consumed per mile in using the service. Inequality is then compared between two case studies.

Transit subsidies represent a transfer of income from taxpayers to bus users. Past studies have found that benefits disproportionately accrue for consumers of long distance trips - mostly higher-income, White, older, and male. Since transit policies seek to attract both, transit dependents and choice riders, the situation raises questions regarding these conflicting objectives.

This study gives a closer look to transit equity by including, not only fare, but also travel time as a way to include quality of service in terms of speed. This approach answers the question: "are faster trips charged cheaper?" Therefore, the analysis focuses on the monetary and temporal resources spent by users of different demographic background.

Information from household travel surveys performed by two metropolitan areas, Columbus and Seattle, is analyzed here. The survey data includes distance, travel time and fare paid per trip, summarized by user and household, and then analyzed along with the demographic information, such as household income, household size, ethnicity, gender, and age. Statistical differences in resources spent are found by using the $t$-test analysis and inequity is determined by means of the Gini coefficient and the Theil and Atkinson indices of inequality.

Statistical differences were found between demographic groups and inequality was measured. Results support previous findings, showing that -in the two case studieslower income, minority, younger and female users pay more per mile of service.

Furthermore, it was found that in addition to higher fares per mile, they also receive an inferior quality service in terms of speed.

The analysis points to the conclusion that faster trips are charged at cheaper rates of fare per mile. Results found however, are applicable only to the two metropolitan areas analyzed here and during the time when the surveys were taken (1999). The approach can be a useful method to compare transit equity between cities and improvements within the same city through time. 


\section{DEDICATION}

I would like to dedicate this work to each and every one that had contributed to it, in one way or another, helping me reach up to this point. The list, however, would be definitely endless and I will just say: Thank you, God, for always being there. Thanks to my family for your help and support every single step during this journey. Special thanks go to my wife Lola Contreras, to my children Leonel Ivan and Diego Medellin, to my parents, siblings and in-laws. Thanks to my friends, thanks to my professors, and thanks to those who provided the means. Thank you all, sincerely. 


\section{ACKNOWLEDGMENTS}

Without the help, support and advice from my committee, this work would not have been possible. I want to acknowledge and thank David R. Martinelli, my advisor, for this research opportunity and his advice. I also want to thank Darrell R. Dean Jr., Ronald W. Eck, Jim French III and Santiago Pinto for their comments and encouragement that kept me motivated. Thank you.

This dissertation was possible in part thanks to Consejo Nacional de Ciencia y Tecnologia (Conacyt-Mexico) and to a grant from the Mid-Atlantic Universities Transportation Center (MAUTC). This work would not have been possible either without the valuable help provided by the Mid-Ohio Regional Planning Commission (MORPC) from Columbus, $\mathrm{OH}$ and the Puget Sound Regional Council (PSRC) from Seattle, WA. Their help is greatly appreciated. 


\section{TABLE OF CONTENTS}

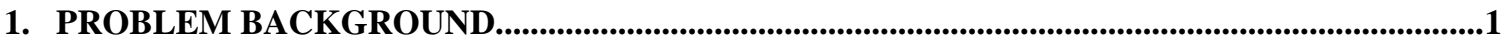

A. ACCESSIBILITY AND MobILITY - THE MAJor Problem......................................................... 1

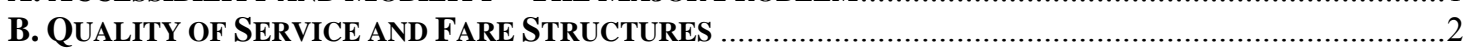

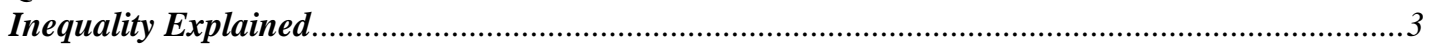

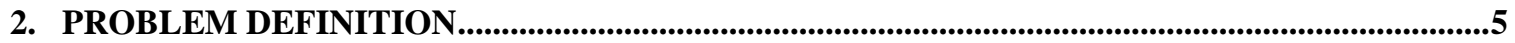

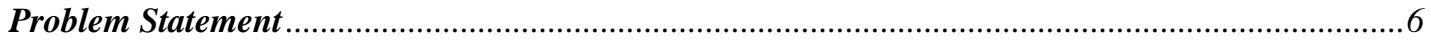

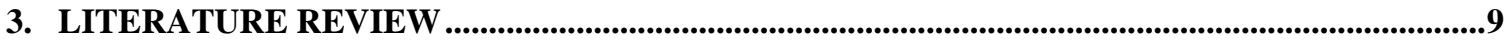

A. Different Approaches to Transit Pricing Analysis ......................................................

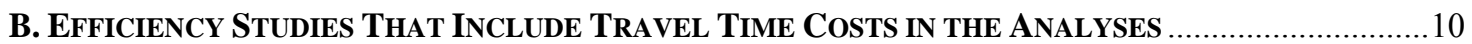

C. The NeEd to ANALyze Travel Time from an Equity PerSPeCtive ....................................13

D. TRANSIT EQUITY ANALYSIS - WHAT HAS BEEN STUdIED So FAR …......................................15

Group 1. Webber's analysis of tax incidence and ridership by income level .....................................19

Group 2. Distributional effects using demographic and basic service consumption data....................19

Group 3. Pucher's studies "who benefits from" and "who pays for" transit service ...........................20

Group 4. CRA cost allocation models to estimate fare, subsidies, and levels of crowding ..................21

Group 5. Cervero's models to estimate costs, fare, travel behavior, and crowding.............................21

Group 6. Analysis using cost allocation models, level of crowding, and tax incidence data ..............22

Group 7. Studies not included in the groups of Iseki \& Taylor's Review .............................................23

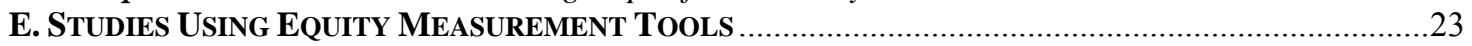

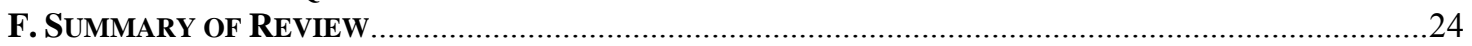

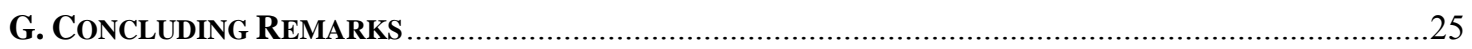

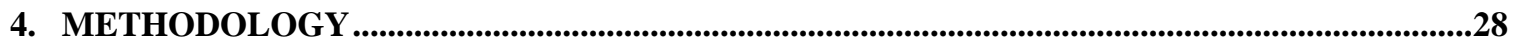

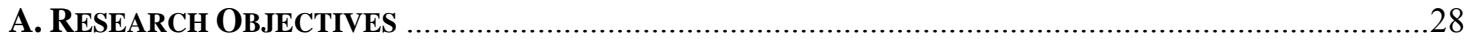

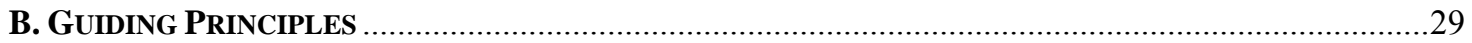

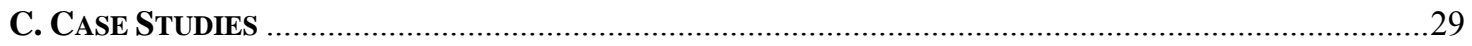

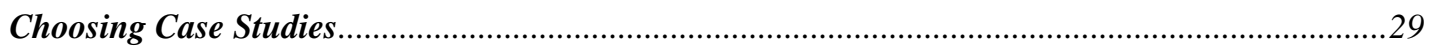

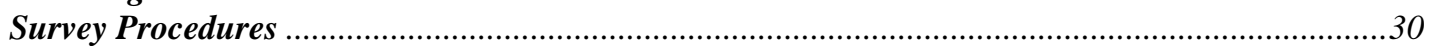

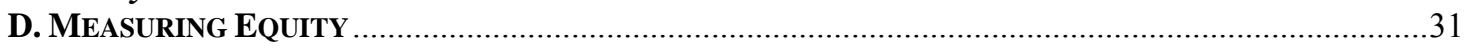

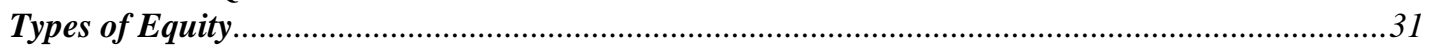

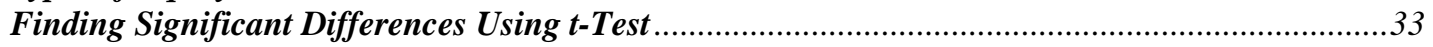

Tools to Measure Equity Performance .........................................................................................

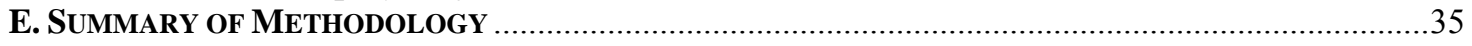

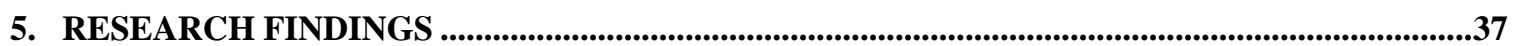

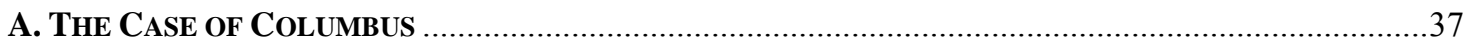

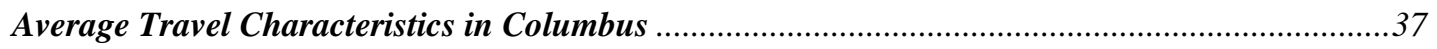

Statistical Differences by t-Statistics Analysis in Columbus ..........................................................40

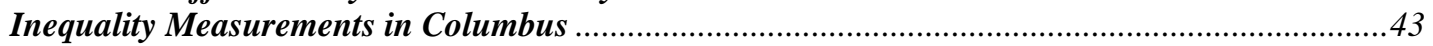

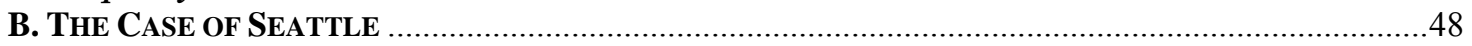

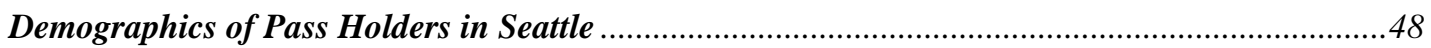

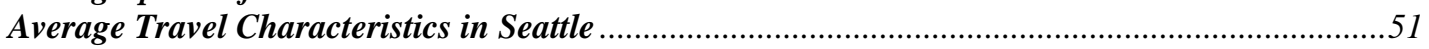

Statistical Differences by $t$-Statistics Analysis in Seattle .................................................................5

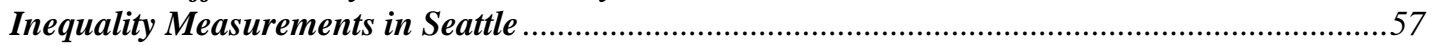

C. Contrast BetweEn Cities: Columbus vs. SEATTLE ……....................................................63

Comparing Overall Inequality Indices Between Cities..................................................................63

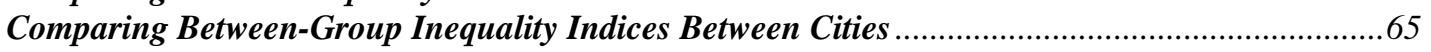

6. DISCUSSION OF RESULTS AND CONCLUSIONS ..................................................................68

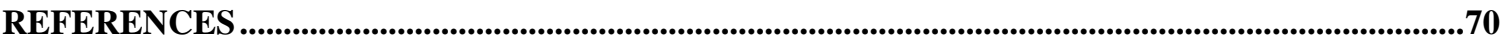

APPENDIX ...............................................................................................................................................74 


\section{LIST OF TABLES}

Table No. 3.1: Synthesis of the Approaches in Transit Equity Studies .............. 17

Table No. 3.2. Costs and Benefits from the Passenger Point of View .............. 18

Table No. 5.1. Travel Mode Split in Columbus ............................... 37

Table No. 5.2. Average Characteristics by Demographic Group of Bus Riders .... 39

Table No. 5.3. Statistical Differences by Demographic Group in Columbus ........ 40

Table No. 5.4. Inequality Measurements by Demographic Group in Columbus .... 46

Table No. 5.5. Travel Mode Split in Seattle ................................. 48

Table No. 5.6. Demographics of Pass-Holders, Survey Data vs. Sub-Sample ..... 50

Table No. 5.7. Average Characteristics by Demographic Group of Bus Riders ..... 53

Table No. 5.8. Statistical Differences by Demographic Group in Seattle ........... 55

Table No. 5.9. Inequality Measurements by Demographic Group in Seattle ....... 61

\section{LIST OF FIGURES}

Figure No. 4.1. Lorenz Curve........................................... 34

Figure No. 5.1. Comparative of Income Groups in Columbus ................. 38

Figure No. 5.2. Comparative of Ethnic, Gender, and Age Groups in Columbus ... 38

Figure No. 5.3. Comparative of Income Groups in Seattle ...................... 51

Figure No. 5.4. Comparative of Ethnic, Gender and Age Groups in Seattle ....... 52 


\section{PROBLEM BACKGROUND}

Equity issues in transportation have long been present in the United States. Fifty years ago -in 1955, Rosa Parks challenged the bus segregation ordinances in Montgomery, AL. Ten years later one of the worst riots in U.S. history erupted in Los Angeles. According to the McCone Commission, a lack of jobs and the inadequate transportation played a large role in creating the conditions that led to the urban unrest (O’Reagan \& Quigley, 1999). In 1992, once again in Los Angeles, more riots took place for similar reasons in addition to the initial trigger of the Rodney King verdict (Scott \& Brown, 1993). Unemployment rates remain high to these days in sectors of L.A. (Ong, 2005) and recent complaints from organizations of bus riders suggest that transportation issues continue.

For decades, the impacts of transit subsidies, service distribution, and fare structure on minority groups have had legal consequences. Even recently, "civil rights organizations (have) filed numerous administrative complaints and law suits against transit systems whose fare and service policies were seen as discriminating against minority riders" (Pucher, 2003). The transit problem -bus specifically, can be approached in different ways:

- No bus to ride on: No easy access to the transit network or no access at all; the analyses focus on accessibility and/or mobility issues, e.g. distance to the closest bus stop, automobile dependability, lack of mobility freedom, etc.

- Waiting for the bus: Poor quality of service, e.g. frequency of service, long waits between transfers, no service on weekends, no shelters, etc.

- Once on the bus: Discrimination of transit users, subsidies addressing those least in need, users spending unequal resources for similar service, etc. This approach, where this research is placed, centers on equity issues among different socioeconomic groups of users.

Even though this research does not address accessibility and mobility issues, it is worth mentioning key points on these perspectives to set the big picture of the transit problem.

\section{A. Accessibility and Mobility - The Major Problem}

These days, the equivalent to Rosa Parks may well be represented by the Bus Riders Union in Los Angeles. Riders complain about having to wait sometimes for an hour or two between buses. For elderly people, a visit to the doctor can take most of the day, and others may spend three or more hours a day commuting across town (Kelley, 1996). The Union is carrying a similar civil rights torch in a battle that could affect every large city in America. In fact, similar unions have emerged in other American and Canadian cities to make their voice heard ${ }^{1}$. The Bus Riders Union has become an influential voice on public transit issues and is getting its demands met. In 1996, it won a class action lawsuit against the Los Angeles County Metropolitan Transit Authority

\footnotetext{
${ }^{1}$ Tucson, AZ; San Francisco, CA; Atlanta, GA, and Vancouver, BC are some of them.
} 
(MTA). A U.S. District court judge ordered the MTA to make substantial improvements in bus service, including expanding the MTA's bus fleet and reducing fares (http://www.busridersunion.org).

Demands for a reliable and equitable transit system have been playing a major role for the last half century and users' claims for a better service have not been fulfilled (Gomez-Ibanez \& Meyer, 1993). As Mobile City Council president Rev. John Clinton put it, "Now, the question is not, can you ride in the front of the bus. The question is whether you can have a bus to ride on" (Kelley, 1996). There is a strong correlation between mobility and income inequality that has been pointed out since the late sixties and continues to be cited as a major social and economic problem (Altshuler, 1969; Pucher, 1998; Sanchez, 2002, 2003). The disadvantage of those without cars virtually forces many of the nation's poorest citizens to own a car to maintain a minimum level of accessibility (Pucher, 2003).

Public transportation needs more attention in order to meet the goals of, not only the Transportation Equity Act for the $21^{\text {st }}$ Century (TEA-21), but also Title VI of the Civil Rights Act of 1964. The Transportation Research Board has reported that one of the critical issues in transportation is the increasing burden of owning and operating vehicles for the lowest-income families (Transportation Research Board, 2001; 2006). These days transportation represents the second highest household expense. However, some lowincome suburban households spend as much as 25 percent of their total income for transportation expenses. For some, this is mostly a matter of choice but for low-income families transportation costs compete with those of housing. A Surface Transportation Policy Project found that in 1998 those in the lowest income quintile spent as much as 36 percent of their household budget on transportation (Sanchez, 2003).

\section{B. Quality of Service and Fare Structures}

Even though accessibility and mobility are critical issues in transportation, still those that do have access to the transit system might not receive a fair service. The focus of this research is on the impact of service quality and fare structures on different demographic groups (income, ethnicity, gender, and age). It also looks into the possibility to have the transit system as a way to redistribute income among users, given the alternatives that some of them have. Equity in resources spent is analyzed by measuring inequality in fare per mile and travel time per mile (fpm and tpm from now on). The analysis therefore, is considered once the users are on the bus.

The ability to pay for transportation needs varies among users and so do the reasons to commute. "Choice riders" have more than one option to make a trip; in contrast, "transit captives" have relatively few options. For those transit dependents, public transportation represents not only the best way to access jobs but also health services, schools, shopping centers, and entertainment. More importantly, reliable and reasonably priced transit means the opportunity to seek a better way of life for many people. Walking can only be the second best option if a number of variables are realized: 
the commuter is healthy and able to walk, the destination is within a reasonable walking distance, and there are safe pedestrian facilities as well as permissive weather conditions.

Just as with any other product or service, commuters try to minimize their generalized cost in transportation, which depends primarily on the time and money spent per trip (Yang, 2001). Trip distance is not a matter of concern for commuters; what they mostly care about is trip duration and the fare they have to pay $^{2}$ (Levinson, 2003). Instant and free would of course be the best alternative, if that was an option at all. However -as long as teletransportation is not an option, distance does matter to transit agencies and affects users directly, since both time and distance determine most of the agency's operating costs. According to Metro (Seattle's transit agency) nearly 75 percent of costs are time-based while 25 percent are distance-based (Hodge, 1988). Therefore fare, travel time, and trip distance are three of the most important trip attributes in the analysis of transit pricing.

As explained in the Literature Review section, studies have measured transit equity according to several parameters: fare per trip, fare per unit of distance, fare according to operating costs depending on time of day and levels of service, and fare depending on the source of subsidy among others. However, the parameter of travel time has not been included in equity analyses yet and it also matters since it is a resource that users pay as well. In fact, travel time has been a useful indicator for other equity analyses. The Global Urban Observatory (established by the United Nations Human Settlements Programme or UN-Habitat) for example, collects urban indicators from a sample of cities worldwide in order to report on progress and monitor social inequities within cities regarding access to essential services. Indeed, one of these urban indicators is travel time and refers to the average time in minutes for a one-way work trip, averaged over all modes of transportation. Therefore, a transit equity study that includes this indicator in particular is needed. Inequities in this indicator would be represented by inequalities that can be considered and qualified as unfair and avoidable. This research then, does not only consider inequality among bus users in fare spent per unit of distance (fpm), but also travel time spent per unit of distance $(t p m)$.

\section{Inequality Explained}

This research explores and measures inequality in transit service among different socioeconomic groups. Inequality among income and ethnic groups for instance can be explained in the following terms. In many American cities, minority and low-income groups are usually clustered in central areas while white, higher income groups are spread out in the suburbs. This situation is now commonly referred to as the spatial mismatch ${ }^{3}$, i.e. the "disconnect between the locations of housing and jobs suitable for lower-income people. In other words, those who most need entry-level jobs (primarily people of color)

\footnotetext{
${ }^{2}$ Other costs not considered here are comfort, safety, reliability, environmental (noise, pollution), etc.

${ }^{3}$ The spatial mismatch hypothesis was first identified by John Kain (1968). For details see Ihlanfeldt and Sjoquist, 1990, 1998; Pucher, 1998; Grengs, 2001; Sanchez, 2002, 2003; Ong, 2005.
} 
generally live in central cities while entry-level jobs are mostly in suburban locations that are not easily accessible from central cities" (Sanchez, 2003).

Because of this spatial mismatch, the national average of bus trip lengths is significantly different among users from different income and ethnic groups. Higher income users take longer trips on average due not only to uneven space distribution, but also because of different travel patterns ${ }^{4}$. On the other hand, average trip durations (anypurpose trips) may not differ much depending on transit speed. Because of express bus service, higher speeds in non-central areas, and congestion in central areas (thus slower speeds), different groups may spend similar average travel times on any-purpose bus trips. Travel time per mile (the inverse of speed) is therefore an important factor to consider in determining equitable resources spent by transit users too. Since a faster speed is related to a higher level of service, travel times need to be accounted for in equity analyses.

Similarly, there are important differences in travel behavior by age and gender. For instance, more women than men tend to be homemakers and/or work part-time, thus travel during off-peak hours for shopping and other non-work related trips. In fact, studies consistently have found that on average, consumers of short-distance local bus service are disproportionately low-income, non-whites, younger, and female, therefore receive less subsidy per trip than their counterparts (Iseki, 2001). For this reason, this analysis also includes demographic groups based on age and gender in addition to ethnicity and income level.

Nevertheless, transit equity analysis is controversial because it can be judged from many different perspectives. Conclusions depend on the factors at stake. The analysis may be from the transit authority, the tax payer, or the transit user point of view. Findings may be quite different in the context of equity among transit users or among the general population (users vs. non-users). This is further explained in the section devoted to the literature review. The approach here is from the user's experience and compares fare and travel time spent per unit of distance ( $f p m, t p m)$ by different demographic groups of bus riders. In other words: how much transit users spend (time and money) and how much they receive in return (miles traveled).

\footnotetext{
${ }^{4}$ Commuting to work is the most common trip purpose for the majority of higher income users; they usually travel from the suburbs to central areas. Lower income users, on the other hand, take shorter trips for multiple purposes; they have higher rates of unemployment and retirement, and fewer options to commute (Pucher 1981, 2003).
} 


\section{PROBLEM DEFINITION}

Quite a few studies have shown inequities in bus transit service ${ }^{5}$. With time being a resource that transit users also pay, there appears to be a gap in the literature dedicated to the equity analysis of passenger costs that includes travel time per mile of service (tpm). Since faster trips are of a better quality service - everything else being equal-, it is expected that these trips are charged at least similar fpm rates. It would be unfair if privileged groups were not only paying lower rates, but in addition receiving a better quality service -in terms of speed-for less. Therefore, it is desirable to have in the same study a comparison of how much tpm different demographic groups of users spend vis-àvis how much they pay per mile (fpm). While there is an extensive body of literature on transit equity, apparently little attention has been given to include tpm rates. This requires a study to be conducted in order to evaluate equity in such terms.

Since time-based operating costs are higher than distance-based costs (Hodge, 1988) and bus speeds are presumably higher off central areas, it might be argued that suburban residents should pay according to operating costs. However, faster service is related to a higher level of quality service which is not reflected in these operating costs. Fewer stops and lower traffic volumes in non-central areas lead to faster speeds, and faster speeds generate lower operating costs, mainly because these trips not only consume less distance-based costs per mile (gasoline, tires, oil, and lubricants) but also less timebased costs per mile (labor). Since the transit service is an integrated system, the transit agency might be concerned with the total cost of the entire system and the benefit (or service) that each rider receives. If, for instance, suburban users get better quality service (in terms of speed), then equity might call for them to pay according to the benefit they receive. That is, compared to slower trips, faster trips should be charged a higher proportion of the system's total cost. Two basic principles of equity apply here: the 'benefit principle' and the 'ability-to-pay principle'. The first principle states that the user should pay proportionally for the benefit received, and the second one establishes that the user should pay based on his/her ability to pay (Musgrave \& Musgrave, 1984).

Leutze \& Ugolik (1978), Cervero et al (1980), and Cervero (1981A, 1981B) reported that transit pricing systems that charge fares not based on trip distance allow higher income groups to pay less per mile compared to lower income groups. Since the underlying principle to subsidize transit is to provide mobility to the disadvantaged, this situation raises serious questions regarding the equality of current transit fare policies. The key questions that this research tries to answer are: Do transit fare structures impact differently the various socioeconomic groups of users? If so, how different? Which groups benefit/suffer from the status quo?

The study looks for statistical evidence of differences among groups and measures the inequality in resources spent (fpm and tpm) in two case studies. Specifically, the questions addressed in the study are:

\footnotetext{
${ }^{5}$ See literature review for a list of studies on the topic.
} 
- Which groups pay lower fares per mile for transit service?

- Which groups receive a better quality service in terms of speed?

- Are faster trips charged at least equal rates of fare per mile?

The findings are particular to the case studies analyzed here, since fare policies vary among transit agencies and locations, and are as good as the available data provided by the metropolitan planning organizations (MPOs). However, the analysis provides a straightforward technique applicable to other cities and circumstances to answer the aforementioned questions.

\section{Problem Statement}

With these key questions in mind, the purpose of this study is to:

\section{Determine significant differences and measure inequality in terms of fpm and tpm among different demographic groups of users. Also, compare inequality between case studies.}

The study indicates average distance, travel time and speed, as well as the average fpm and tpm that bus users of different groups spend in each case study. Information is not readily available in the literature comparing these two indicators that could answer the question "are faster trips charged cheaper?" These findings are measured up to what is already well documented in the literature: most transit pricing systems -which are not distance-based, charge lower fares per mile to longer trips. Specifically, flat-fare pricing systems in cities with spatial mismatch patterns stand for the worst case scenario. On average, this situation comes to the advantage of privileged groups of users. The relationship between fpm and tpm provides an idea as to whether faster trips (of higher quality) are being charged differently than slower trips (of lower quality). This approach to the analysis of equity (fairness) by measuring inequality (differences) in resources spent among groups of users can be a useful contribution for planning and pricing purposes.

The benefits of this work provide a guide to policy- and decision-makers, transit agencies, community leaders, and MPOs for transit pricing and planning purposes. The approach of this study, together with further research of conditions that correlate to successful fare policies, can assist in improving policies that seek more equitable conditions among demographic groups. Findings may well help community leaders to create support in the search of better conditions for those less favored. It can also be useful for transit agencies in the search of guidelines that lead to successful programs to increase transit ridership among specific groups. This however, can only be possible in conjunction with automobile-use disincentives and other travel demand management measures (TDM).

Most importantly, the study provides useful information to achieve environmental justice principles of federal transportation agencies. In particular, the results can assist in 
achieving two of the three environmental principles of the Federal Highway Administration and the Federal Transit Administration ${ }^{6}$ :

- To avoid, minimize, or mitigate disproportionately high and adverse human health and environmental effects, including social and economic effects, on minority populations and low-income populations, and

- To prevent the denial of, reduction in, or significant delay in the receipt of benefits by minority and low-income populations

Assuming that the study areas are in accordance with the spatial mismatch hypothesis, it is expected that at least significant differences in trip distance will be observed among ethnic and income groups of riders. Since minority, low-income groups would be clustered in urban areas, it is anticipated that they take shorter multi-purpose trips as opposed to their counterparts. Differences are also expected among different age and gender groups according to national averages ${ }^{7}$. Travel time may differ depending on travel speed; it may be similar if speeds are faster in non-central areas, but different if speeds are at most equal.

The study makes use of data from household travel surveys (HTS) performed by two major MPOs. These travel surveys, though not standard, provide information such as transportation mode, trip purpose, time of day, fare, trip duration, trip length, origindestination, and individual and household demographic characteristics (e.g. household size, income, ethnicity, age, gender, student and disability status, and so on). This information makes it possible to compare rates among different demographic groups and further comparison between cities.

The other side of the coin are the trade-offs that inevitably occur. If fares were dependent on distance and travel time, then suburban residents regardless of demographic characteristics would experience a fare increase. Raising fares in this way would not be a popular decision and, moreover, it would certainly not encourage transit ridership among suburban residents. However, the best way to encourage transit ridership would not likely be through lower fares for advantaged groups either. Perhaps redirecting subsidies to particular socioeconomic groups could help redistribute income through the transit system, just like some welfare programs do (Medicaid, Medicare, Food Stamps).

In order to increase transit ridership -and in this way improve the transit service, measures to discourage the excessive use of the automobile in congested urban areas may be necessary. Distance- and travel time-based fares could only be implemented after transit ridership is increased. Perhaps increasing parking and congestion pricing measures and similar strategies of travel demand management (TDM) are convenient ways to encourage a more efficient use of transportation resources and in this way promote transit ridership. Further research is needed to analyze the equitable and efficient use of roadways comparing transit vis-à-vis the automobile. An innovative approach in terms of

\footnotetext{
${ }^{6}$ Available at http://www.fhwa.dot.gov/environment/ej2.htm

${ }^{7}$ As reported by Pucher $(1981,1992,1998,2003)$, based on statistics of national household travel surveys.
} 
space requirements (persons per space of highway) has been pointed out by Vukan Vuchic (Vuchic et al, 1994) that may prove an appealing line of research for future transportation studies. An analysis in terms of subsidies received and space of highway required per person for users of both modes (transit and automobile) could provide a better understanding and hints to strive for a more efficient and equitable use of current transportation resources. 


\section{LITERATURE REVIEW}

The expression "time is money" applies to a number of activities people do, including travel. This is especially true since the need to reach a destination is what matters and not the journey itself, unless of course exercise or recreational travel is the case. That is in general, transportation is a necessary means to an end or, in economic terms, a derived demand. It allows people to carry out the diverse range of activities that make up daily life. If two different trips both five miles long charge one dollar, they are indisputably equitable in terms of fpm. Regardless of any other trip characteristic, they are equitable in such terms. However if one of these trips had a better quality service in terms of speed, and there is a need to account for this for equity purposes, additional variables have to be used for such assessment. These trips could be in different buses (regular/express service) or even in the same bus but in different route segments.

The one transportation equity issue that has received the most attention in the academic literature is the perceived spatial mismatch between the residential location of disadvantaged urban households and the location of low-skill jobs (Sanchez 2003, p.17). This study is no exception. Because underprivileged users are generally clustered in large urban areas where transit speeds are slower - resulting in more time-consuming trips per mile, an analysis that takes into account not only fare and distance but also travel time spent would help understand equity among users of different demographic groups, under these conditions.

This literature review is organized into seven sections. The first section describes general research approaches toward transit pricing analysis. The second section provides a brief review of efficiency analyses that have taken passenger's travel time costs into account. The following section explains the drawbacks of economic efficiency analysis and the need to perform additional equity analyses to compensate for shortcomings. Next, a review of transit equity analyses published up until now is provided. In the following section, a description of equity analyses using similar equity measurement tools in other areas is given. Finally, the last two sections provide a short summary of this review and a section for concluding remarks.

\section{A. Different Approaches to Transit Pricing Analysis}

Researchers have approached the problem of transit pricing in different ways, and this has an influence on conclusions. They may assume that all modes are priced efficiently or that there are no substitute modes at all; in either case, this is a first-best approach to the problem. If the study attempts to account for mispricing in other substitute modes, then it is a second-best approach. A challenging task, if not impossible, would be to account for all social costs involved in the transportation problem; instead researchers provide ideas as to what the optimal price should be under specific circumstances. Methodology plays a critical role in the assessment.

With either a first-best or second-best approach, researchers have been concerned with economic efficiency and with distributional matters in transit pricing. Some 
researchers account for efficiency and equity trade-offs altogether ${ }^{8}$. Economic efficiency relates to how well an economy allocates scarce resources to meet the needs and wants of consumers. One way to measure efficiency is with 'Pareto Optimality' or 'Pareto Efficiency'. That is, given a set of alternative allocations and a set of individuals, a movement from one alternative allocation to another that can make at least one individual better off, without making any other individual worse off is called a Pareto improvement. An allocation of resources is Pareto efficient or Pareto optimal when no further Pareto improvements can be made.

Trade-offs between economic efficiency and equity are a fact of life. Efficiency means that all goods or services are allocated to someone (there is none left over). When a market equilibrium is efficient, there is no way to reallocate the good or service without hurting someone else. Equity on the other hand, concerns the distribution of resources and is inevitably linked with concepts of fairness and social justice. A market may have achieved maximum efficiency, however we may be concerned that the "benefits" from market activity do not satisfy one or more equity principles (i.e. benefit received, ability to pay, distribution, etc.). Consequently, there are two fundamental approaches to the transportation problem: equity and efficiency.

\section{B. Efficiency Studies That Include Travel Time Costs in the Analyses}

Efficiency is a relative term. It is never absolute; it is always relative to some criterion. This can be seen when one asks if farms are more efficient in the United States or China. The farming techniques in China are more efficient than those in the United States when measured in terms of output per unit of machinery. However, if measured in terms of output per man-hour the farms in the United States are far more efficient. The statement 'farms in one country are more efficient than farms in another' is inconclusive unless the criterion on which efficiency is measured is given. The criterion for economic efficiency is value ${ }^{9}$. A change that increases value is an efficient change and any change that decreases value is an inefficient change. A situation that is economically efficient according to some criteria may be inefficient when judged on different criteria.

Fare pricing studies have used different criteria to measure efficiency ${ }^{10}$. Efficiency is usually assessed by comparing relative differences in the costs incurred and revenues received in serving trips accounting for more or less elements, per some kind of parameter. Common parameters have been per-trip, per-mile, and with regard to operating costs (depending on time-of-day and level of service). The costs and revenues considered may be as broad as to include subsidies and income taxes paid by users that indirectly fund the transit system (Hodge, 1995; 1998). Analyses may not only include

\footnotetext{
${ }^{8}$ Efficiency analyses: Vickrey, 1980; Kerin, 1992; Taylor, 2000; Moore, 2002. Equity analyses: Ugolik, 1979; Hendrickson, 1980; Pucher, 1981; Garret \& Taylor, 1999; Sanchez, 2003. Equity and efficiency trade-offs: Cervero 1980, 1981a, 1981b; Kerin, 1987; Litman, 1996b; Mayeres, 2003.

${ }^{9}$ Value is a useful term in Economics though not strictly absolute either, as will be explained in the next sub-section. It may depend on circumstances, personal preferences, time, location, and so on.

${ }^{10}$ The terms optimal and efficient have been used interchangeably in the literature.
} 
the transit agency's costs but also the passenger's costs, for instance travel time. Here are some statements of early research on efficient transit pricing indicating the need to include passenger's travel time costs in efficiency analysis:

\begin{abstract}
"Transport demand can be dealt with as if the price of a trip equals whatever fare is charged plus the money value the traveler attaches to the time his trip requires." Page 591 Mohring, 1972

"Pricing a public transportation facility is setting the cost to be paid by the users (to include payments in time, money, and effort). The cost item that is easiest to manipulate directly is the users' money cost, and changing it can change all other costs and benefits." Page 623, Wohl, 1973

"The right approach is to escape the implicit notion that the only costs which are relevant to optimization are those of the bus operator. The time-costs of the passengers must be included too, and fares must be equated with marginal social costs." Page 280, Turvey \& Mohring, 1975; republished in 1994 and 1997

“... some (trip-makers) will receive fast, reliable, frequent service, while others will be served only by slow, unreliable and infrequent service. The underlying notion behind service based fare is that people should be charged based on the level of service they receive from the transit agency." Page 230, Daskin 1983

"A shortcoming in many applications of these methodologies is that time prices of passengers are not considered... Since research indicates that transit passengers do place value on their time... the exclusion of transit time prices from transit performance evaluations may bias the conclusions of these evaluations." Page 462, Talley 1991
\end{abstract}

More recent studies do not abound on the significance of the passenger's time costs and basically refer to the work of Mohring and other pioneers in the field for further details. The most recent research reflects the importance of time costs in the optimization of the generalized cost of travel as shown in the following studies. Swedish transportation economist, K. Jansson, observed two effects of service frequency on passenger's behavior. The first one reflects a dual behavior: for low frequencies people prefer to plan their trips according to the timetable, and for high frequencies they prefer to go spontaneously to the bus stop. The second effect relates to the fact that the disutility of waiting at stops is higher than that of waiting at home or at work, and that the passengers' waiting cost vary by type of service. Typically the cost of time waiting for a high frequency service is higher than waiting for a low frequency service (Jansson, 1993).

Jansson estimated the optimal price as the operator's marginal cost plus the marginal external effects on passengers including: time values, riding time and frequency delay. The generalized cost of travel $G$ for passengers at time $t$ was given as the summation of the monetary cost p plus the cost of travel time plus the cost of waiting time, denoted by the following equation:

$$
G[p, t, F]=p+\phi[X / F \sigma]\left(b X / F+\gamma r^{\gamma}\right)+\phi^{\tau}[1 / F-t](1 / F-t) *
$$

* Arguments of functions are delimited by [ ], polynoms are delimited by (). See Jansson 1993 for details.

Where:

$\phi=$ time values (vector of marginal rates of substitution between price and time)

$X=$ number of passengers per hour

$\sigma=$ number of seats 
$b=$ fixed boarding time per passenger

$\gamma=$ round-trip distance in $\mathrm{km}$

$r^{\gamma}=$ remaining run time per kilometer (passenger independent), assumed constant

$\tau=$ frequency delay, defined as $1 / F-t \geq 0$

$F=$ number of departures per arbitrarily chosen period of time (frequency)

In the study, Jansson only considered first-best pricing rules, one type of charge (pertrip), and one homogeneous passenger group.

A more recent study investigated the effect of value of time (VOT) distributions on price and quality competition among differentiated bus services in Hong Kong in a simple corridor (Yang et al, 2001). Yang considered three travel modes: car, minibus and bus, and a continuous distribution of VOT (a second-best approach with heterogeneous groups of users). Users were assumed to minimize the generalized trip cost and divide themselves among each mode. Yang used the following generalized cost function, consisting of the monetary cost and travel time weighted by VOT to characterize users' choices:

$$
\begin{aligned}
& G_{c}(\tau)=f_{c}+T_{c} \tau, \\
& G_{m}(\tau)=f_{m}+\left[T_{m}+W\left(F_{m}\right)\right] \tau, \\
& G_{n}(\tau)=f_{n}+\left[T_{n}+W\left(F_{n}\right)\right] \tau,
\end{aligned}
$$

where $G_{c}(\tau), G_{m}(\tau), G_{n}(\tau)$ are the generalized cost of an individual user with a VOT equal to $\tau$ using private car, minibus or normal bus, respectively. Variable $f$ is the monetary cost, $T$ the travel time, and $W$ the waiting time of a passenger.

In developing a theoretical three-stage model to identify empirical concepts and mechanisms for optimal transportation policies in Norway, P.A. Pedersen considered both positive and negative market externalities, such as additional routes that would decrease the waiting time for a bus, and delays and crowding due to an increasing number of travelers. Fares were assumed flexible in the short run, routes supplied were flexible in the medium term, and capital equipment was flexible only in the long run. He concluded that the generalized cost that an additional passenger causes on others (delay, crowding) should be included in calculating the optimum fare for all three stages (Pedersen, 2003).

In one of the most recent efficiency studies including passenger's travel time costs, Norwegian researcher F. Jorgensen developed a theoretical model to illustrate the effect of 'traveling distance' and the 'transport agency's weight on profit' on fare levels, quality of transport supply, and the generalized travel costs. Here, the generalized cost is also measured as the sum of pecuniary costs and time costs for the traveler (Jorgensen, 2004). 


\section{The Need to Analyze Travel Time from an Equity Perspective}

The economic notion of value used to measure efficiency is - however - a measure of how an individual or group would trade one thing for another. The notion of a numerical value per se does not exist, and there is no meaning to "economic value" outside the context in which tradeoffs occur. The numbers that economists use to assess value come from the choices that individuals make in such contexts. If a person does not own a car, he/she might choose to use a transit service or walk. If transit fares are not affordable, he/she will have to walk and if the destination is not within walking distance or it is not possible to walk (no pedestrian facilities, disability, etc), he/she will have to stay home. The last two are not in fact choices but represent an economic captivity. Absent a meaningful choice, there is no meaningful notion of economic value (Cangelosi et al, 2001). This study, however, is incapable to account for those not able to use transit service; it assumes that everyone has access and that everyone can afford to ride a bus. In that sense, inequity is underestimated in this study.

The common approach to the cost of passenger's travel time in efficiency studies is to consider the time value each passenger attaches to his/her own time. In this view, the generalized cost includes the fare plus the money value the traveler attaches to the time spent waiting for and riding on the bus. The value of time varies depending on users' income; consequently a disadvantaged user is bound to spend more time to pay less (or walk, go at a different time, or do not go at all), while an advantaged user prefers to pay more to spend less travel time ${ }^{11}$. If not convenient enough, he/she might choose to drive.

The distribution of income therefore, affects the measure of travel costs because the limitation on the ability to pay imparts a limit on the measurement. This is a point of concern due to the fact that underprivileged sectors of the population account for $63 \%$ of the nation's transit riders (Pucher, 2003). Typically, this aspect of income distribution is addressed by using a measure that represents the average for the population (across all income groups), but when a burden befalls a low-income group disproportionately, the measure of cost will reflect the distribution of income. (Cangelosi et al, 2001)

Transit is a key service that allows underprivileged groups to meet basic needs. The main reason to subsidize the service is to provide an affordable mode of transportation. The approach in this study is that if there are travel time savings, they are to be charged to the user at a rate proportional to his/her own value of time - if value of time were to be considered at all. Users spending time on the bus do not help the transit agency offset costs because users' travel time does not produce revenue to the agency.

\footnotetext{
${ }^{11}$ An interesting study in the topic is provided by Mohring (1987). The study infers the values that travelers attach to travel time from their choices among services that differ in time and money costs. Mohring applies maximum-likelihood estimation techniques to ridership survey data from Singapore. However, as opposed to the U.S., Singapore's automobile and gasoline excises and annual registration fees are among the highest in the world, which encourage the use of public transit greatly.
} 
A weakness to the criterion of economic efficiency is that value relates to the extent to which people benefit from a good or service. This good or service may have different roles for different consumers. To measure the economic value, economists observe human preferences - and, when possible, the behavior resulting from those preferences. Preference is what drives our decisions to select one alternative over another. For example, someone who chooses one mode of transportation from a set of available options has a preference for that mode. The extent of this preference is revealed in the amount of time and money that person is willing to give up in return for the preferred option. The "consumer" makes a decision to give up something - either time or money - for the opportunity to enjoy the preferred experience. However, the extent to which underprivileged users (specifically transit captives) "choose" to take or not to take the bus is not captured in this value.

Privileged groups may prefer transit if they choose to give up:

- money because driving were more time-consuming (e.g. availability of uncongested transitways vs. congested roadways), or

- time because driving were more expensive (due to gas prices, registration fees, parking, tolls, etc.), or

- a combination of both possibilities.

Underprivileged groups, on the other hand, may prefer transit if they choose to give up:

- money because walking were more time-consuming (assuming the possibility to walk, so that there is in fact a choice between time or money), or

- time because owning a vehicle or taking other mode of transportation (e.g. taxi) were not affordable (not much of a choice actually for a low-income commuter).

In short, since privileged groups have options, it is assumed here that they choose transit either because it is cheaper or less time-consuming. However, in the case of transit captives the disjunctive between time and money is not clear. Serious questions can arise if the value of time is used to justify differences in travel time among groups of users.

To measure value, economists determine the maximum amount an individual is willing to forego in other goods and services such as time or money, in order to obtain a preferred good or service. This maximum amount is formally expressed in a concept called willingness to pay. However, willingness-to-pay is limited by the ability-to-pay and may be quite different from price (what one must pay).

According to a report by the U.S. General Accounting Office ${ }^{12}$, "environmental costs are often borne disproportionately by low-income segments of society." Frequently, facilities that harm the environment are established in low-income areas where political clout is weakest. Analogously, this lack of political influence has similar effects in

\footnotetext{
${ }^{12}$ United States General Accounting Office (1995). Hazardous and Nonhazardous Waste, Demographic. of People Living Near Waste Facilities. Washington, DC: General Accounting Office.
} 
transportation. Sanchez (2003) acknowledged: "How transportation policies are decided and who is able to influence those decisions have played an important role in creating and sustaining the inequities of current transportation policies" -emphasis added ${ }^{13}$. Problems arise when the differential impacts sustained by subpopulations directly correspond with gross differences in income. In these cases, costs averaged over the entire population may not reflect the effect on wealth (i.e., the opportunity costs) within the individual subpopulations. If the communities are studied separately, economists can clarify the differences in impacts reflected in each community's willingness to pay.

However, this approach would not be enough either. The interpretation of these findings would also be deceiving. Based on these findings, economists might falsely conclude that disadvantaged groups are less willing to pay simply because they would have to sacrifice more meaningful goods and services (such as food or health care) to do so than would more advantaged groups. Underprivileged users may be willing to pay for bus service, or even pay for a better bus service, but they are just not able to. In these cases, economists must attempt to differentiate willingness-to-pay from ability-to-pay. The key question is whether the effect of a given problem is felt most strongly by a lowincome subpopulation. If so, the average willingness to pay obtained by an economic study could be biased downward precisely because the group most severely affected by the costs has low incomes and therefore low willingness to pay. Cangelosi (2001) wisely observed:

"Social justice intersects directly with economics. Justice matters arise in the distribution of ... benefits across society... (This) concern poses challenges for economists who historically have focused on economic efficiency and have had a relative lack of interest in distributional, or equity, considerations. This bias is changing as economists focus more attention on distributional concerns..."

Equity analyses help decisionmakers to counterbalance the inherent weakness of efficiency analyses. In the literature, there are a number of efficiency studies that include passenger's travel time cost; however little attention has been paid to equity analysis including this cost in particular. As mentioned above, using the value of time for equity analysis purposes is controversial. For these reasons no time values are considered in this analysis, instead time costs remain in time units and are compared thereafter without conversion to monetary terms. The analysis provides an objective point of reference for transit agencies and decisionmakers in terms of travel time costs from an equity perspective that, in addition to efficiency studies, can lead to the development of more efficient and, at the same time, more equitable transportation policies.

\section{Transit Equity Analysis - What Has Been Studied So Far}

While passenger's travel time costs have been taken into account in efficiency analyses of transit pricing, there appears to be no transit studies that have addressed this

\footnotetext{
${ }^{13}$ See also Weeks, J. (2002). Public Involvement by Minorities and Low-Income Populations. Removing the Mystery. TR News 220 May-Jun 2002. p. 25.
} 
cost from an equity perspective. Up to now, equity and equity/efficiency trade-off studies have analyzed transit pricing mainly according to trip distance, time of day, bus occupancy levels, per-passenger subsidy and geographic equity of subsidies ${ }^{14}$. Studies consistently have found that longer, peak-hour, and low ridership trips are more expensive to provide, and these are precisely the most subsidized trips in the least subsidized transit mode: the bus (Pucher 2003, Sanchez 2003). From a broader view, considering taxes (i.e. the source of subsidies), findings suggest that, on one hand:

$\Rightarrow$ Among transit users, higher income transit users benefit more from the subsidy of transit than do low income transit users.

On the other hand however:

$\Rightarrow$ Among the general population, transit subsidies generally result in a transfer of benefits from higher-income people to low-income people, though low-income non-transit-users are significant losers (Iseki \& Taylor, 2001).

Still, this last assertion neglects the fact that the use of the automobile is highly subsidized as well (Vuchic 2000). A simple issue such as the use of relative versus absolute tax burdens produces contrary results (Hodge, 1995). Methodology therefore, plays a critical role in equity assessment.

The scope and perspective of the analysis differs from prior studies in the analysis of costs that a regular bus rider faces in terms of money and travel time spent and a further analysis and comparison of these costs among different demographic groups of riders ${ }^{15}$. Specifically, the scope spans from the moment the user gets on the bus until he/she steps down on her final bus stop, be it final destination or point of transfer. No time/effort walking to/from the bus stop or waiting at the bus stop are considered, as only bus trips to bus trips are compared, added up by user.

In order to review the extensive literature on transit equity, Iseki and Taylor (2001) provide a valuable synthesis of the approaches taken in 15 studies. Even though their emphasis is on measuring and evaluating transit subsidy equity, the review is helpful for the purposes of this review. Here though, the emphasis is made on measuring and evaluating equity of passenger costs among different demographic groups. Based on similarity of approach, Iseki and Taylor organize the 15 studies into six groups (See Table No. 3.1).

\footnotetext{
${ }^{14}$ Mayeres \& Proost (2003) provide a framework to define "acceptability" in equity/efficiency trade-offs by examining the effects of replacing current transport pricing by marginal social cost pricing used in Belgium.

${ }^{15}$ Statistical differences will be determined by using the $t$-test procedure and equity performance by measuring inequality among demographic groups using the Gini, Theil, and Atkinson coefficients. Details are explained in the section of Methodology.
} 


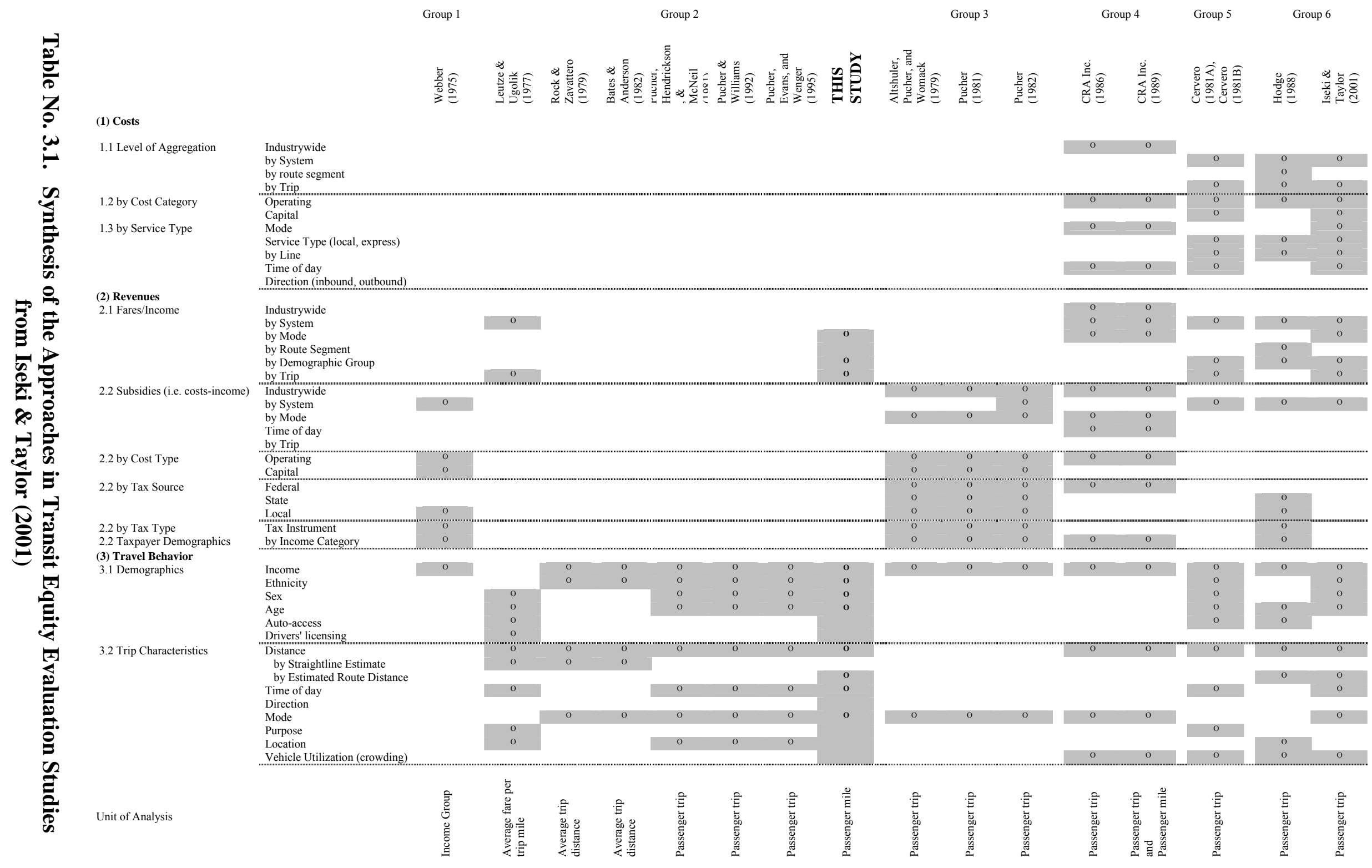


Table No. 3.2. Costs and Benefits from the Passenger Point of View

Group 2

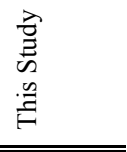

\section{(1) Passenger Costs}

1.1 Fare (cents)

1.2 Travel Time (min)

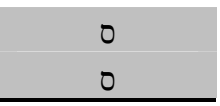

(2) Service Received

2.1 Miles traveled

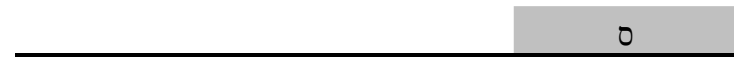

(3) Travel Behavior

3.1 Demographics

Income

Ethnicity

Gender

Age Group

3.2 Trip Characteristics

Distance by estimated route

Fare per mile

Travel time per mile (1/speed)

Time of Day
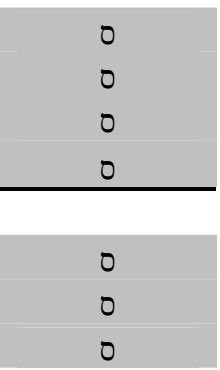

Unit of Analysis

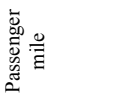


Group 1. Webber's analysis of tax incidence and ridership by income level

Webber (1976) draws on Hoachlander's (1976) analysis of the incidence of property and sales taxes used to pay for most of the BART system and the incomes of BART district residents. Webber argues that BART taxes disproportionately burden lowincome households, while BART service is disproportionately utilized by higher-income households. He does not measure how fares or travel time vary from among demographic groups.

\section{Group 2. Distributional effects using demographic and basic service consumption data}

The second group of studies, in which this study would be classified, uses demographic data on transit users from either transit system rider surveys or the Nationwide Personal Transportation Survey (NPTS) in combination with travel distance data, fare data, or descriptive findings regarding transit costs to draw conclusions regarding transit service equity. In this group, Iseki \& Taylor include: Leutze \& Ugolik (1978); Rock \& Zavattero (1979); Bates \& Anderson (1982); Pucher, Hendrickson, \& McNeil (1981); Pucher \& Williams (1992); Pucher, Evans, \& Wenger (1998).

The two studies by Rock \& Zavattero (1979) and Bates \& Anderson (1982) calculated average trip distance by income and ethnic group, and examined the equity of flat fare policies. Both studies found that flat fare policies are regressive with respect to income, but neutral with respect to ethnicity. Three studies conducted by Pucher and various colleagues [Pucher, Hendrickson, \& McNeil (1981); Pucher \& Williams (1992); Pucher, Evans, \& Wenger (1998)] analyzed the NPTS travel behavior data in detail and combined these with descriptive conclusions regarding the variability of transit costs to draw conclusions regarding transit service equity. These studies consistently found that, on average, the poor, non-whites, women, bus patrons, off-peak travelers, and shortdistance travelers received lower per-ride subsidies than their counterparts. Two more studies not included by Iseki \& Taylor can also be classified in this group: Hendrickson and Pucher (1980) and Pucher (2003).

Leutze \& Ugolik (1978) combined disaggregated fare information with individual travel behavior data, including travel distance, for the Albany, New York transit system using passenger fare paid per mile as a unit of analysis ${ }^{16}$. Studies in the second group do not analyze data on transit system costs and revenues as the rest of the groups did; instead they provide a view from the passenger's side as Leutze \& Ugolik clearly point it out (fare is observed as a passenger cost instead of agency revenue). With the exception of them, the rest of the studies in this group do not analyze any passenger cost. The analysis here though, makes use of disaggregated data from two different MPOs which include fare, passengers' travel time, trip distance, and demographic information per passenger.

\footnotetext{
${ }^{16}$ They estimated travel distance using a straight line between an origin and a destination of individual trips. In this study, in the case of Columbus, trip distance is estimated from TAZ' centroid to centroid following the bus route network using TransCAD 4.8. In the case of Seattle, the distance is provided by the survey, calculated using geocoded addresses through an estimated network using ArcView 3.1.
} 
Clearly, this group does not seek in fact to measure subsidy equity specifically as Iseki \& Taylor's purpose is. The group does not include information on transit subsidies at all; at most they compare their findings with the national subsidy average. The group is actually concerned with equity from the user's point of view and regards subsidies as exogenous to transit users. Because of the approach given to equity assessment from the user's point of view, this analysis is classified in this second group as well, and to show a more clear idea of the approach, Iseki \& Taylor's table is modified from a transit agency perspective to the user's point of view (see Table No. 3.2).

\section{Group 3. Pucher's studies "who benefits from" and "who pays for" transit service}

Drawing on the tax incidence literature in public finance that examines who pays taxes and who benefits from the expenditure, the third group of transit subsidy distribution studies attempts to link transit tax payments with transit patronage benefits. Iseki \& Taylor include in this group: Altshuler, Pucher, \& Womack (1979); and Pucher (1981, 1982). They do not include Pucher (1983) but would also be classified in this group. By combining 1970 and 1977-78 NPTS data and federal, state, and local transit tax incidence data, these studies found that the distribution of costs (taxes paid) and benefits (transit service consumed) is progressive with respect to income.

Assuming that all trips on each mode are subsidized equally (which is clearly not the case), Pucher and colleagues combine modal patterns of transit use by income groups with the distribution of operating and capital subsidies among modes, and found that the lowest-income groups actually receive lower than average transit operating and capital subsidies per household. However, taking into account the tax burden for transit subsidies by each income class, they found that net income per household is mostly progressive, mainly because the overall tax system is progressive.

Some shortcomings in these studies are pointed out by Iseki \& Taylor. First, while the travel behavior data in these three studies were disaggregated to the individual trip level, the estimates of transit subsidies are based on aggregated data which significantly diminished the precision of the subsidy. Second, the analyses did not account for cost variation in service provision within modes. Third, while these studies concluded that the distribution of transit costs and benefits is progressive with respect to income, one might reasonably compare the distribution of service benefits with the distribution of income among transit users, rather than the entire urban population, and come up with opposite results. And finally, the public subsidy of transit has shifted significantly from the federal government to states and localities (Price Waterhouse LLP, 1997). Since the collection of federal taxes tends to be more progressive with respect to income than the collection of state and local taxes, the income progressivity of transit subsidies observed by these three studies may have diminished over time ${ }^{17}$.

\footnotetext{
${ }^{17}$ Pucher (1982) found that the state and local transit taxes in most of the nine urban areas studied were regressive with respect to income.
} 
Group 4. CRA cost allocation models to estimate fare, subsidies, and levels of crowding

Charles River Associates Incorporated (CRA, 1986; 1989) developed a cost allocation model ${ }^{18}$ to compute the average cost per passenger trip by transit mode (bus, subway, commuter rail, and light rail), by time of day, and by trip distance. Then, they computed the average federal operating subsidy per trip for different income groups, accounting for the average fare paid for each mode, federal operating subsidies, and the number of trips made in each mode by income group. The CRA cost allocation model included a passenger-mile factor to account for the smaller fraction of costs allocated to each passenger trip in the peak period due to the level of crowding and associated reduction in service. These studies concluded that the average federal operating subsidy per trip increased with income. Average federal operating subsidy per trip in 1983 was $\$ 0.122$ for households with incomes with less than $\$ 10,000, \$ 0.173$ for households with incomes between $\$ 20,000-29,999$, and $\$ 0.202$ for households with incomes above $\$ 50,000$. Although these studies attempted to account for a wide variety of factors, their point of view was specifically from the transit agency, therefore they did not account for passenger costs other than fare (which is both, an agency revenue and a passenger cost), nor did they account for demographic factors other than income level.

Group 5. Cervero's models to estimate costs, fare, travel behavior, and crowding

Iseki \& Taylor include Cervero (1981A, 1981B) in this group. Cervero (1980) is not included but would also be classified here. These studies used cost allocation models to more accurately account for the cost variation in transit service provision than in any previous study. He developed detailed cost allocation models for three California transit operators -- the Southern California Rapid Transit District, the Alameda-Contra Coast Transit Authority, and the San Diego Transit Corporation -- which accounted for the cost variation by time of day, by trip distance, and by the level of crowding and included both operating and capital depreciation expenses to compute cost per passenger mile (CPM). Revenue per passenger mile (RPM) was also estimated for individual trips to obtain the ratio of RPM to CPM for more than 10,000 travel survey cases. Finally, this ratio (RPM/CPM) was aggregated by trip characteristics and by socio-demographic characteristics of transit users.

Cervero found that the distributional effects of transit pricing appeared to be only modestly regressive in terms of socio-demographic characteristics - lower income, transit-dependent, and minority users tended to return a higher share of their costs than the average passenger, and he found that there was significant variation in RPM/CPM by travel distance and by time of day. Cervero also found that the difference in subsidy could generally be attributed more to trip characteristics, especially as a function of trip distance, than to the socio-demographic characteristics of transit users.

\footnotetext{
${ }^{18}$ The cost allocation model included three variables -- vehicle hour, passenger mile, and passenger trip -and accounted for labor utilization as well.
} 
Group 6. Analysis using cost allocation models, level of crowding, and tax incidence data

Hodge $(1988,1995)$-only the first one is included in Iseki \& Taylor's review, examined the geographic distribution of transit subsidies in King County, WA, taking into account the following factors: (1) variation in cost by the level of ridership for route segments, (2) allocation of fare paid by riders to lines, and (3) residential location of transit users as well as their socio-economic characteristics. Hodge developed a twovariable cost allocation model to estimate the cost to provide service for each bus route segment, and divided these costs by the number of passengers on-board in each segment to obtain the cost per passenger for each bus route segment. By doing so, he took into account the variation in transit operating subsidy by the level of crowding that significantly varies by location ${ }^{19}$ as well as by line. Using the difference between the cost and the fare for each route segment ${ }^{20}$, the subsidy per segment was computed, and the total subsidy per passenger was measured by tracing the rider's route and adding up the subsidy consumed over every segment traveled.

Hodge's innovative research also examined the geographic distribution of user cross-subsidies and net subsidies by accounting for the collection and distribution of tax revenues by income level, and the income level composition of households in census tracts. The geographic distribution of subsidies showed that residents in outlying areas cross-subsidized transit users in the inner-city. While Hodge took into account taxes to finance transit service and added a geographic component in the analysis, its cost allocation model included only two variables, and did not take into account the cost variation by time of day, by mode, or direction.

The study of Iseki \& Taylor (2001) itself is classified into this group. They used a set of multi-factor cost allocation models and combined them with service consumption and travel survey data from the Los Angeles County Metropolitan Transportation Authority (LA MTA) to estimate the variation in subsidies by various demographic measures. They accounted for cost variation by time of day and by mode, but not direction. In fact, directional peaking was not accounted for in any of the six groups of studies and can prove to be a substantial cost that needs to be accounted for in allocation models. The study did not analyze tax incidence data specifically but relied on findings from previous research which, according to them, are remarkably consistent.

Hodge and Iseki \& Taylor concluded that among the general population, transit riders are the biggest winners, especially high income riders; and non-riders are the

\footnotetext{
${ }^{19}$ First, the level of travel demand varies due to the geographic distribution of residential and employment locations of transit users. Second, since trip origins and destinations are not evenly distributed in space, more people are on board while a bus approaches a stop where many people have their destinations. (Hodge 1988). For example, assuming that people live in the suburbs, work downtown, and commute by bus, more and more riders get on a bus as a bus travels from the suburbs to downtown in the morning peak. On the other hand, in the afternoon peak, a bus leaves with many riders from downtown, and drops off passengers as it approaches to the suburbs.

${ }^{20}$ The allocated fare for a bus route segment was the sum of the fare paid by each passenger to each segment in proportion to the relative cost per passenger for each segment.
} 
biggest losers, especially low-income non-riders. Among transit users, the distribution of transit subsidies is income regressive due to systematic variation in travel patterns by income.

\section{Group 7. Studies not included in the groups of Iseki \& Taylor's Review}

An interesting study using a different technique, not mentioned by Iseki \& Taylor, is Ircha \& Gallagher (1985) which would be categorized in a group of its own. The study follows a different approach to analyze equity; it makes use of statistical information obtained from the 1981 census of two cities: Saint John and Moncton in New Brunswick, Canada. Ircha \& Gallagher studied urban transit systems using a linear regression analysis of five equity-measuring variables and seven transit service indicators to demonstrate inequities in service provision, particularly for those "transit captives". They analyzed the correlation between the equity-measuring variables and the transit service indicators to identify specific trends in transit service provision for each city. These equity-measuring variables were socioeconomic status, population density, and percentage of elderly, youth, and low income families. The transit service variables were the number of bus routes, number of buses per week, per weekday, buses on Saturday, buses on Sunday, peak hour headways, and distance to the city center. They found that a flat fare system is neither efficient nor equitable. It is inefficient because it fails to focus on the routes that are the most expensive to serve; it is inequitable because flat fares transfer the pricing benefits from lower-income patrons to the higher-income, longerdistance, peak-period riders. While Ircha \& Gallagher show trends in terms of the quality of transit services from an equity perspective, the correlation coefficients $\left(r^{2}\right)$ were not statistically significant. They focused on time of day and trip length; however the distance was calculated as a straight line distance from census tract centroids to the city center. No attention was given to passenger's costs other than fare nor did they analyze equity in demographic groups based on ethnicity and gender.

In a different order of ideas but looking into the same transit equity problem, Sanchez $(2002,2003)$ examines the effects on minorities and low income-income communities of the - already unquestionable for him - existence of unfair transit service and transportation policies. He found that transit supply is a significant factor on wage inequality across large metropolitan statistical areas (MSAs) in the United States. Transportation policies not only have inequitable effects on the ability of low-income individuals and minorities to access places, Sanchez concludes, but also have serious indirect effects such as encouraging and reinforcing residential segregation; restricting access to employment and other economic opportunities, housing, and education; and causing health disparities.

\section{E. Studies Using Equity Measurement Tools}

In this study, the methodology is based on $t$-statistics to determine significant differences in two equity parameters ( $f p m$ and tpm) among different demographic groups. Measurement tools to determine the inequality in these parameters provides further assistance in determining the equity performance of the bus transit service. The 
performance is calculated for two metropolitan areas which later are compared. The inequality measurement tools are explained in the Methodology section.

These tools are the Gini, Theil and Atkinson indices. They have been widely used in the field of Economics. However, studies in other fields have also taken advantage of the usefulness of these tools, for example Castillo-Salgado (2001) in Health Sciences and Damgaard (2000) in Ecology. Castillo-Salgado applies these tools to determine and measure health inequalities that help identify inequities in health care using health information aggregated by geographical units. The fundamental difference between inequities and inequalities, Castillo-Salgado explains, resides in the fact that inequities represent inequalities that are considered and qualified as unjust and avoidable. ${ }^{21}$

Damgaard on the other hand, makes use of the Gini coefficient and the Lorenz Curve to describe inequality in plant size or fecundity. He proposed a second and complementary statistic, the Lorenz asymmetry coefficient, which helps determine which classes contribute most to the population's total inequality. ${ }^{22}$

There are studies in the transportation field that have also used the measures of inequality, specifically the Gini coefficient and the Lorenz curve: Levinson (2002), Levinson et al (2002), and Sanchez (2002) are some examples. Levinson applies statistic tools to analyze travel time, delay and speed inequalities to determine the effectiveness of ramp metering comparing with and without ramp meters. The distribution of the total delay is represented by the Lorenz curve and the statistical analysis is performed using the Gini coefficient as a measure of inequality. Sanchez used ordinary least squares regression (OLS) and relied on the Gini coefficient as a measure of wage inequality in a study of 158 large US metropolitan statistical areas (MSAs) to determine whether higher levels of public transport accessibility were related to the wage levels of individual workers. All these studies show the value of these useful tools in different fields.

\section{F. Summary of Review}

The literature review has discussed different approaches taken so far to analyze bus transit service from equity and efficiency perspectives, and has mentioned some approaches that consider tradeoffs between these two -sometimes conflicting-goals. Travel time is a passenger cost that has been included in a number of research papers since the early work of Mohring and others in efficient transit pricing. However to this point, this trip attribute has been given attention mostly in efficiency studies. Value, which is the usual efficiency yardstick, is not an absolute term and does not always reflect the goals of society. Therefore equity, in addition to efficiency analyses, is necessary to establish a reasonable trade-off between these two objectives: efficient and equitable public transportation for all. Given that travel time is a useful measure that aligns with user experience, some researchers call for "broadening evaluation beyond

\footnotetext{
${ }^{21}$ If two users of different income pay differently, there is inequality in payments but it is equitable (fair) if both users pay according to their 'ability to pay'.

${ }^{22}$ In this case, the concept of inequity (unfairness) makes no sense.
} 
efficiency and into equity and for taking the subjective point of view of the traveler rather than the objective point of view of the omniscient planner/engineer/economist/manager" (Levinson, 2003).

A review of twenty two studies in transit equity, including 15 from Iseki \& Taylor and those added here, was examined in this section. Building on the literature review (and using Iseki \& Taylor's useful table), the twenty two studies were classified into seven groups based on similarity of approach in Table No. 3.1. This table however, has an outer look to the transit user and therefore Table No. 3.2 is presented to visualize the costs faced from the passenger's perspective. The tools used in this study to measure equity performance are the $t$-test, the Gini coefficient, and the Theil and Atkinson indices, which are further explained in the Methodology section. These are useful instruments in the analysis of equity and have been used in fields other than Economics. A quick review of studies using them in fields such as Biology, Health Science and Transportation was presented here to show the utility of these tools.

\section{G. Concluding Remarks}

In the United States, as in many other developed countries, public transportation is subsidized for many reasons. The underpriced use of the automobile and the uneven distribution of the population (spatial mismatch) are two main reasons for transit subsidies that differentiate the United States from its "peer countries" (Vuchic, 2000).

Taxes are collected from the population and corporations at large, and those with higher earnings pay more taxes than those less able to pay. Decisionmakers make their best decision as to where that money should go. All public sectors receive money collected from taxes to provide a public service, from national defense to the postal service. Public services are available to all, regardless of income. In this way, all citizens are entitled to protection in case of war or natural disasters regardless of how much tax they pay. The mission of some executive departments at the federal level is replicated next to illustrate this:

- US Department of Housing and Urban Development: To help create a decent home and suitable living environment for all Americans.

- US Department of Education: To provide access to equal educational opportunity for every individual.

- US Department of Health and Human Services: To protect the health of all Americans and provide essential human services.

- US Department of Transportation: Serve the United States by ensuring a fast, safe, efficient, accessible and convenient transportation system that meets our vital national interests and enhances the quality of life of the American people, today and into the future.

A 1994 Presidential Executive Order directed every Federal agency to make environmental justice part of its mission by identifying and addressing the effects of all programs, policies, and activities on "minority populations and low-income populations." 
The US Department of Transportation has three fundamental environmental justice principles:

- To avoid, minimize, or mitigate disproportionately high and adverse human health and environmental effects, including social and economic effects, on minority populations and low-income populations.

- To prevent the denial of, reduction in, or significant delay in the receipt of benefits by minority and low-income populations.

- To ensure the full and fair participation by all potentially affected communities in the transportation decision-making process.

Title VI of the Civil Rights Act of 1964 and environmental justice principles apply to all transportation decisions as well:

\begin{abstract}
"Concern for environmental justice should be integrated into every transportation decision from the first thought about a transportation plan to post-construction operations and maintenance. The U.S. DOT Order applies to all policies, programs, and other activities that are undertaken, funded, or approved by the Federal Highway Administration (FHWA), the Federal Transit Administration (FTA), or other U.S. DOT components. Federal agencies, State DOTs, Metropolitan Planning Organizations (MPOs), and transit providers advance Title VI and environmental justice by involving the public in transportation decisions. Effective public involvement programs enable transportation professionals to develop systems, services, and solutions that meet the needs of the public, including minority and low-income communities." U.S. DOT, Environmental Justice, available at http://www.fhwa.dot.gov/environment/ej2.htm, accessed December 2005.
\end{abstract}

Transit agencies receive subsidies from authorities to lower the full price of providing the service in the public interest. Money for subsidies is collected from taxes at the federal, state, and local levels (contributions vary) to provide equitable service to users no matter who pays more taxes, and regardless of the source of subsidy. These subsidies allow transit agencies to operate properly as an integrated transportation system, similar to other public services. Most importantly, the fundamental reason for the subsidy is to provide for those in need.

This study is done with the transit user in mind. The analysis aims to analyze the costs faced by passengers in using the bus service and the performance of equity among users of different socioeconomic background. That is, the study is concerned with how much they pay (fare) and how much time they spend commuting (travel time) compared to how much they receive in return (miles traveled). Monetary costs and travel time expenses per mile (user costs), aggregated per user and per household ${ }^{23}$, are compared among different demographic groups of users to determine equity performance in passenger costs. Because the study is from the user point of view, no attention is given to transit operating costs, taxes paid by users, subsidies received by the transit agency (or the sources of these subsidies), the non-optimal pricing of automobile use and parking, and so on. Passenger travel time costs have been taken into account through transit

\footnotetext{
${ }^{23}$ For the city of Columbus, a per-household analysis is included in the Appendix.
} 
efficiency analysis; however no analysis has focused on the issue from an equity perspective. This is the main contribution of this research.

In analyzing passenger costs (both fare and travel time) and comparing them among different demographic groups of riders, the findings show which groups are paying less per mile, which ones enjoy a better quality of service in terms of speed, and if users of similar quality service pay similar fares. The study also looks into the possibility of having the transit system as a way to redistribute income among different demographic groups of users, given that some of them have alternatives to travel. Since trip distance and time are the main components of transit costs (time being the major contributor with $75 \%$ of operating $\operatorname{costs}^{24}$ ), it is important to take travel time into account as a passenger cost in an equity analysis.

${ }^{24}$ Hodge (1988). 


\section{METHODOLOGY}

In the past years, researchers have followed different ways to assess transit equity. Here, a new approach is performed: a cost analysis of user expenses with a close and simultaneous look at time and money spent by bus riders. The focus is made on how much users spend in terms of fare and travel time, and how much they receive in return (miles traveled). These equity indicators, fpm and tpm, are compared among users of different demographic groups (income, ethnicity, gender, and age) and significant differences are determined using the $t$-test analysis. The equity performance of these indicators is determined by calculating the inequality using the Gini coefficient and Theil and Atkinson indices.

This analysis can provide evidence to determine whether faster trips (of better quality service) are charged differently. Whenever faster trips are charged at lower rates per mile, then the study indicates a bias in transportation policies that needs to be addressed to meet environmental justice goals.

\section{A. Research Objectives}

The key questions of this research as defined in the Problem Definition section are stated here once more to delineate the research objectives:

- Which groups pay lower fares per mile for transit service?

- Which groups receive a better quality service in terms of speed?

- Are faster trips charged at least equal rates of fare per mile?

In order to answer these questions, the specific research objectives are:

1. Determine the fpm spent by different demographic groups of bus riders

2. Determine the tpm spent by different demographic groups of bus riders

3. Compare resources spent, fpm and tpm, and find significant differences among different demographic groups of users by using the $t$-test analysis

4. Measure equity performance among groups using inequality measurement tools (Gini coefficient, Theil and Atkinson indices)

5. Compare inequality within and between groups, and then between case studies

6. Consider the possibility to establish a transit pricing system that redistributes income among different socioeconomic groups of users

In general, the research objectives are to compare passenger costs spent by bus transit users. Rates of fpm and tpm are the equity indicators of resources spent by bus riders which are calculated by analyzing data from household travel surveys (HTS) performed by two MPOs. Significant differences among user costs are determined and equity performance is measured to determine a way in which the transit system could redistribute income. 


\section{B. Guiding Principles}

The focus of this study is on the distributional impacts of the benefits received from the transit service and the research question concerns the inequality of passenger costs among socio-economic groups. Altshuler described three ways in which social equity has been typically addressed in transportation policy:

1) Fee for service. It derives from private markets, in which the quality of goods and services varies in proportion to the price, fare, and fee paid.

2) Equality in service distribution. Each individual is entitled to an equal share of public expenditures or public services regardless of need or financial contribution.

3) Distribution according to need. Each individual is entitled to receive a share of public expenditure or service in accordance with individual need.

Depending on their way of thinking, political conservatives are most likely to favor the first principle; moderate thinkers are likely to favor the second one; and liberal activists would favor the third principle (Altshuler et al, 1979; Rosenbloom \& Altshuler, 1979). Distributional equity measures are useful in analyzing equity from each of these three perspectives; therefore the second principle is the guiding light in this analysis.

\section{Case Studies}

Due to the fact that bus transit equity varies from place to place, and even differs among transit agencies in the same metropolitan area, it is appropriate to perform this equity analysis by examining metropolitan areas where transportation policies are comparable. This provides a better understanding of transit equity at the metropolitan level, contrary to the work of researchers in Group 2 of the literature review, which used aggregate data from the Nationwide Personal Transportation Survey (NPTS) ${ }^{25}$. For this reason, the study is conducted using different case studies separately to analyze transit equity in each metropolitan area, and then compared against each other.

\section{Choosing Case Studies}

In this research, only bus trips, both regular and express service, are explored. The cities chosen for the study should have a high-quality bus transit system but no heavy rail system (HRT). The rationale behind this decision is that the HRT is capable of attracting large numbers of users from the bus system, and thus have a significant influence on the analysis. Transit users of privileged groups are more likely to use HRT than any other transit service (Pucher 2003). On the other hand, the existence of a light rail transit system (LRT) does not represent a significant impact on bus ridership due to a similar level of service and ridership numbers.

\footnotetext{
${ }^{25}$ Examples include: Pucher, Hendrickson, \& McNeil, 1981; Pucher \& Williams, 1992; Pucher, Evans, \& Wenger, 1998, in Group 2 of the literature review.
} 
The data required to carry out this type of study can be obtained from household travel surveys (HTS) performed by MPOs. These organizations hire independent professional research firms to conduct the surveys, which are available to the public upon request... when available. Due to many and diverse reasons, not all MPOs have useful, complete, or updated HTS. Some MPOs are in fact in the process of conducting their first travel survey. Sixteen planning organizations were requested to provide HTS ${ }^{26}$; however six of them did not respond to the call and three did not have surveys available at the time. Five of them were not useful because the MPO lacked the necessary GIS information or were incomplete for the purpose of this analysis because they missed important information, such as the fare paid by bus riders. The surveys need to have the following minimum information available:

- Trip mode, because the research focus is on bus transit only

- Trip distance, or information regarding the traffic analysis zone (TAZ) of origin and of destination, to calculate the distance traveled with GIS software

- Trip duration, or time at the beginning and at the end of the trip for its calculation

- Fare paid, and information concerning type of payment: cash, pass, transfers, etc.

- Rider demographics (income level, age, gender, ethnicity, student and disability status, and so on)

If the fare paid is not provided explicitly but instead the cost of a pass then some assumptions had to be made to calculate the cost per trip, depending on how many trips per pass on average could have been taken by the user (e.g. 40 trips/monthly pass). The cities and HTS meeting the criteria are: Columbus, $\mathrm{OH}$ and Seattle, WA. Nationally, these two cities rank as follows:

\begin{tabular}{lcccc} 
Metropolitan Area & $\begin{array}{c}\text { 2002 Population } \\
\text { (City) }\end{array}$ & $\begin{array}{c}\text { Rank } \\
\text { by city }\end{array}$ & $\begin{array}{c}\text { 2001 Population } \\
\text { (Metro Area) }\end{array}$ & $\begin{array}{c}\text { Rank by } \\
\text { Metro Area }\end{array}$ \\
\hline Columbus, OH & 725,228 & 15 & $1,612,694$ & 31 \\
Seattle, WA & 570,426 & 24 & $3,043,878$ & 15
\end{tabular}

The Mid-Ohio Regional Planning Commission (MORPC) from Columbus and the Puget Sound Regional Council (PSRC) from Seattle, both performed the survey in 1999. These MPOs have used the data from the surveys for transportation planning purposes in recent years and will continue to use for a period of 10 to 20 years.

\section{Survey Procedures}

Survey research firms interviewed a number of randomly chosen households in both metropolitan areas to represent the local residents (one out of 100 in the case of Seattle). Even though the survey procedures varied somewhat between the two firms, both followed these steps: 1) advance calls, 2) advance mailing, 3) recruitment interview,

\footnotetext{
${ }^{26}$ Indianapolis IN, Kansas KS, Louisville KY, Minneapolis MN, Las Vegas NV, Columbus OH, Cincinnati OH, Oklahoma OK, Providence RI, Nashville TN, Memphis TN, Houston TX, San Antonio TX, Austin TX, Salt Lake City UT, and Seattle WA.
} 
4) respondent material mailing, 5) reminder call, 6) retrieval interview, 7) data editing and processing, and 8) geocoding. The firms identified non-response bias and found that, in the case of Seattle, households with the following characteristics are less likely to participate in travel studies:

- Households with 4 or more persons

- Households with no workers or more than 2 workers

- Households with no vehicles

- Households earning less than $\$ 20,000$

- Households earning between $\$ 60,000$ and $\$ 75,000$

In both case studies, the sampling design controlled for non-response bias in similar ways, by household size and household vehicles. Another issue to have in mind is that both HTS involved different research firms, different jurisdictions, and different transit agencies. Seattle involved 4 counties and 5 transit agencies; while Columbus involved 7 counties and 1 transit agency. Due to these multidimensional characteristics, the surveys are far from standard.

The lack of uniformity and a growing desire in the transportation planning field to achieve a minimum level of standardization has originated an ongoing research project called: "The Case for Standardizing Household Travel Surveys" (NCHRP 2002). The project has been completed and the revised draft final reports have been submitted; publication decision is pending. In the future, this standardization will help to carry out similar transit equity studies in other metropolitan areas.

Once the required information from the surveys is obtained to perform the analysis, transit users are classified into demographic groups: by income, ethnicity, gender, and age. For the first group, household income is divided by the household size equivalents according to the "Organisation for Economic Co-operation and Development" OECD-modified scale, i.e. 1 for the household head, 0.5 for each additional adult, and 0.3 for each child under 15 .

\section{Measuring Equity}

The term equity is related to the idea of fairness; it implies fair access to livelihood, education, and resources. Equality, on the other hand, refers to the state of being equal. For instance, there is no equality on taxes paid by different people, however there is equity according to the "ability to pay" principle. The terms are different, but they focus on similar and interrelated ideas of "difference", thus they are often referred to indistinctively.

\section{Types of Equity}

Litman (2002) classifies equity into three general categories, depending on the distribution of costs and benefits: 
1) Horizontal equity is concerned with whether or not each individual or group is treated equally, assuming that their needs and abilities are comparable. It implies that costs should be borne by users unless a subsidy is specifically justified (it is related to Altshuler's fee for service and equality in service distribution principles) $)^{27}$.

2) Vertical equity with regard to income and social class considers the allocation of costs between different socioeconomic classes, assuming that public policies should favor economically disadvantaged groups (it is related to distribution according to need principle).

3) Vertical equity with regard to mobility need and ability considers whether a transportation system provides adequate service to people who have special transportation needs (also related to distribution according to need principle and mandated by the Americans with Disabilities Act).

However, there is an ongoing debate about how to measure vertical equity. A different way to classify equity can be made depending on the outcome. Litman himself and Levinson (2003) make a distinction between:

1) Equity of opportunity: Everyone has the same opportunities in life to achieve an end (e.g. the right to pursue happiness), regardless of where they were born or who their parents are.

2) Equity of outcome: Everyone achieves the same end (e.g. the right to life and liberty). It seeks to reduce or eliminate differences between individuals or households in a society. Advocates of "equity of outcome" most often want to eliminate a very specific kind of difference between people, not all differences in general.

There is general agreement that everybody deserves "equity of opportunity", meaning that society ensures that disadvantaged people have equal access to education and employment opportunities. However, there is less agreement concerning "equity of outcome", meaning that society ensures that disadvantaged people actually succeed in these activities. Given that the purpose of this study is to compare resources actually spent by different demographic groups, equity of outcome, i.e. the resources actually spent by users is considered here to evaluate equity performance in fpm and tpm.

Now, different outcome measures can give different results in terms of equity. For instance, equity can be measured for the following:

- Income- each income group has the same outcome

- Ethnicity- each ethnic group has the same outcome

- Gender- males and females have the same outcome

- Age- each age group has the same outcome

- Perfect equity- the hypothetical result where each and everyone gets the same outcome considering all possible points of view

\footnotetext{
${ }^{27}$ The main purpose of transit subsidies is to help disadvantaged groups to afford transit services in similar ways than advantaged groups. However, these subsidies do not aim disadvantaged groups directly and anyone can benefit from them.
} 
Since transit subsidies aim to address transportation issues of underprivileged groups, the purpose of this study is to measure outcome within income, ethnic, gender, and age groups. Therefore, conditions are considered equitable when the indicators fpm and tpm are spent similarly regardless of income, ethnicity, gender, or age (i.e. there is no significant difference in the mean of these indicators between groups).

\section{Finding Significant Differences Using t-Test}

The study makes use of individual trip data (trip distance, travel time, and fare) aggregated by user and by household, and the passenger's demographic characteristics (income, ethnicity, gender, and age), to obtain average fpm and tpm spent per demographic group. Travel time stands for the average time in minutes for a one-way any-purpose unlinked bus trip, without considering walking time to and waiting time at bus stops. In order to determine significant differences among groups, the individual and household rates of fpm and tpm are considered, using an independent-sample $t$-test analysis using the software STATA 9.2. A brief description of this analysis is given next.

A) Statement of the problem: The purpose of the analysis is to determine whether there is a significant difference among users of different demographic groups (by income, ethnicity, gender, and age) with respect to fpm and tpm.

B) Nature of the variable: This analysis involves two variables. The predictor variable is the demographic group, which is measured on a nominal scale. In the case of income group, it assumes three values: high, middle, and low income (compared one against each other); for ethnicity: white vs. non-white; for gender: males vs. females; and for age: youth, working class, and seniors (compared one against each other). The criterion variable is fpm or tpm (depending on the equity indicator under study), which is measured on an interval scale.

C) Statistical test: Independent-samples $t$ test.

D) Null hypothesis $\mathrm{H}_{0}$ : Difference $=\mathrm{R}_{1}-\mathrm{R}_{2}=0$. In the population, there is no difference between users of different demographic groups with respect to fpm or tpm rates.

E) Alternative hypotheses $\mathrm{H}_{\mathrm{A} 1}$ : Difference $<0, \mathrm{H}_{\mathrm{A} 2}$ : Difference $\neq 0, \mathrm{H}_{\mathrm{A} 3}$ : Difference $>0$. In the population, there is a difference between users of different demographic groups with respect to fpm and tpm (be it less than, different than, or greater than zero, respectively).

Individual and household rates of fpm and tpm are used as well to determine equity performance among demographic groups by using inequality indices as explained next.

\section{Tools to Measure Equity Performance}

Equity measures are often expressed as ratios, and the ratios are compared. In this case, fpm and tpm are compared among groups to measure equity performance. This performance is measured using the Gini coefficient and the Theil and Atkinson indices, which have been used in economic studies to analyze basically income inequality. The Lorenz Curve is a cumulative frequency curve that compares the distribution of a specific 
variable with the uniform distribution that represents equality (see Figure No. 4.1). This equality distribution is represented by a diagonal line, and the greater the deviation of the Lorenz Curve from this line, the greater the inequality.

\section{Cumulative Percentage of Income (or Equity Indicator: fpm/tpm)}

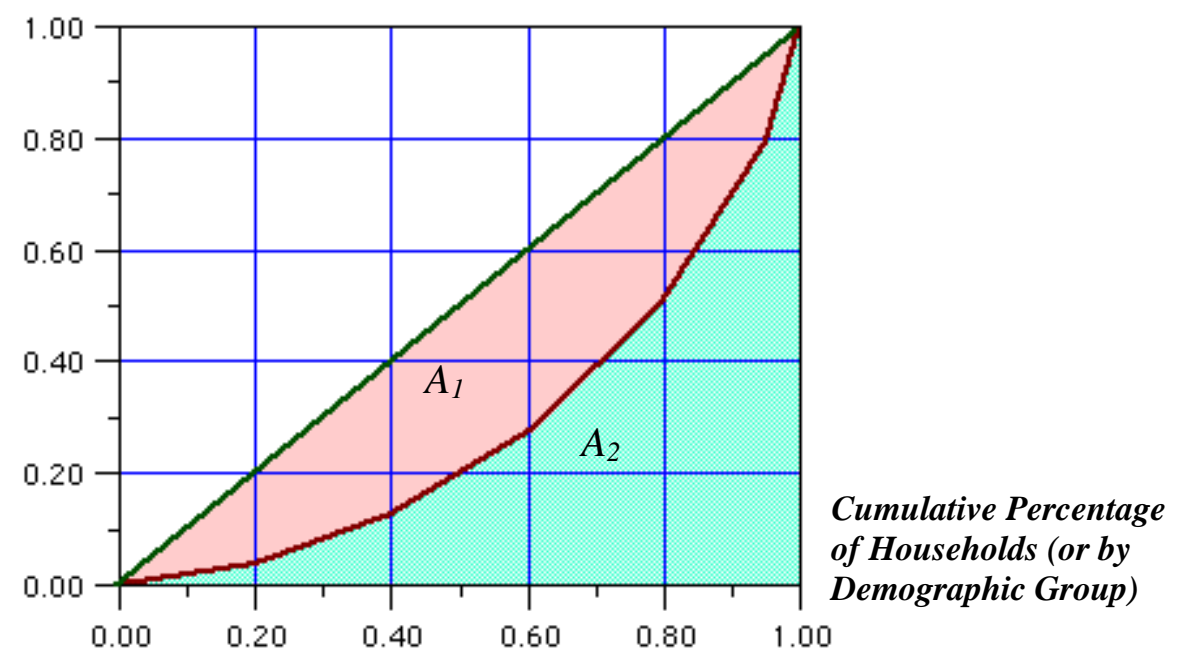

Figure No. 4.1. Lorenz Curve

In applying this index to transit equity indicators, the cumulative percentage of the population is shown on the $\mathrm{X}$ axis (by demographic group); and the cumulative percentage of the equity indicator is shown on the $\mathrm{Y}$ axis ( $f p m$ or tpm). The greater the distance from the diagonal line, the greater the inequality. The curve can be below or above the diagonal depending on the variable being used. When the variable is beneficial to the population, for example income, the curve is found below the diagonal line. In contrast, when the variable is prejudicial or a cost to the population, for example fpm or tpm, it is found above the line. As a reference, the income inequality for the United States in 1994 (according to the Census Bureau) was 0.456, with a steady and accelerating tendency over the last 25 -year period.

The figure illustrates the Lorenz Curve, the line separating $A_{1}$ and $A_{2}$ for a hypothetical case income distribution. The Lorenz Curve relates the percentage of households receiving a percentage of income. While the bottom $100 \%$ of the population receives $100 \%$ of the total income by definition, the bottom $50 \%$ receives $20 \%$ of the total income. A Gini Coefficient ranges from 0 to $1 ; 0$ indicates perfect equality (everyone receives the same) and 1 indicates perfect inequality (one person receives all).

The Gini Coefficient $(\mathrm{G})$ is defined as:

$$
G=\frac{A_{1}}{A_{1}+A_{2}}
$$

Where:

$\mathrm{A}_{1}$ - $\quad$ area between Lorenz Curve and 45-degree line;

$\mathrm{A}_{2}$ - $\quad$ the rest of triangle defined by Lorenz Curve, $X$-axis, and vertical line projecting from $100 \%$ of the population in question. 
While the Gini coefficient is an accepted measure for estimating inequality, some argue that, although it quantifies the level of inequality, it fails to indicate the structure of inequality. In other words, two Lorenz curves can have the same Gini coefficient and therefore it does not express how income, for example, concentrates by group. This difference can be quantified however, by calculating the Gini for each subgroup independently, along with the decomposition of inequality in within and between groups as performed here (calculated by Theil and Atkinson indices).

Alternative tools to the Gini coefficient - used in Economics for income distribution analyses- include the Theil and Atkinson indices which are also calculated here for a more complete interpretation of the inequality among demographic groups. The Theil index is calculated by the formula:

$$
T=\frac{1}{N} \sum_{i=1}^{N}\left(\frac{x_{i}}{\bar{x}} \cdot \ln \frac{x_{i}}{\bar{x}}\right)
$$

Where $x_{i}$ is the income of the $i$ th person, $\bar{x}$ is the mean income, and $N$ is the number of people. The first term inside the sum can be considered the individual's share of aggregate income, and the second term is that person's income relative to the mean. If everyone has the same income (i.e., the mean), then the index $=0$. If one person has all the income, then the index $=\ln N$.

The Atkinson index, on the other hand, can be turned into a normative measure once a coefficient $e$ is chosen to weight incomes. The formulas are:

$$
A=1-\frac{1}{\bar{X}}\left(\frac{1}{N} \sum_{i=1}^{N} x_{i}^{1-e}\right)^{1 /(1-e)} \forall e>0, e \neq 1
$$

and

$$
A=1-\frac{1}{\bar{x}}\left(\prod_{i=1}^{N} x_{i}\right)^{1 / N} \text { for } e=1
$$

where $x_{i}$ is individual income $(i=1,2, \ldots, N)$ and $\bar{x}$ is the mean income. An entropy measure from Atkinson can be computed from the Theil index (example without using $e$ ). Atkinson index $=1-e^{- \text {Theil index }}$

\section{E. Summary of Methodology}

To recapitulate proceedings: significant differences of resources (time and money) spent by users of different demographic groups are calculated using the $t$-test analysis. In order to perform the analysis, the household equivalent income and the individual equivalent income are considered. The equivalent income is computed 
considering the household income reported in the survey and the household size (equivalent number of adults). Afterward, a measurement of equity performance for each city at the individual and household level is carried out using the Gini coefficient, Theil and Atkinson inequality indices using STATA 9.2. The demographic groups that contribute most to the existing total inequality are determined with the analysis of within and between inequalities. Equity performance of both cities, Columbus and Seattle, are compared afterwards. 


\section{RESEARCH FINDINGS}

\section{A. The Case of Columbus}

The results for the city of Columbus are shown in this section. The analysis includes average characteristics, statistical differences, and measures of inequality by demographic group (income, ethnicity, gender, and age). The 1999 Mid-Ohio Area HTS includes 65,555 records that correspond to 13,524 persons, of which 2,260 did not travel during the $24 \mathrm{hrs}$ of study of this survey (the dates varied). The mode split of the 52,046 trips registered is shown in Table No. 5.1.

Table No. 5.1. Travel Mode Split in Columbus

\begin{tabular}{|lrr|}
\hline Walk & $\mathbf{5 . 2 7 \%}$ \\
\hline Private & $\mathbf{8 9 . 5 3 \%}$ & \\
Auto/Drive & & 64.91 \\
Auto/Passenger & 22.42 \\
Carpool / Driver \& Passenger & 1.93 \\
Vanpool / Driver \& Passenger & & 0.27 \\
\hline Commercial / Driver \& Passenger & $\mathbf{0 . 3 4 \%}$ & \\
\hline Transit/Paratransit & $\mathbf{4 . 1 0 \%}$ & \\
Bus & & 0.85 \\
School Bus & & 3.13 \\
Taxi & & 0.12 \\
\hline Bicycle/Motorcycle & $\mathbf{0 . 5 4 \%}$ & \\
Bicycle & & 0.5 \\
Motorcycle & & 0.04 \\
\hline Other & $\mathbf{0 . 2 2 \%}$ & \\
\hline
\end{tabular}

There were 410 bus trips made by 221 persons who had complete data regarding trip distance, travel time and fare, as well as the required demographic information. The analysis shown here was made at the individual scale ${ }^{28}$ (i.e. single trips grouped by user) and considers the equivalent income, calculated dividing the lower and upper income limits of each category by the household adult equivalents. These two values are then averaged to obtain the equivalent income per person.

\section{Average Travel Characteristics in Columbus}

Figures No. 5.1 and No. 5.2 compare bus riders to the city population. Income groups are classified in: low, middle and high ( $1 / 3$ each); Ethnic, Gender, and Age groups are according to actual percentages in the city and bus users population.

\footnotetext{
${ }^{28}$ The analysis was also made at the trip and household scale. Results are shown in the appendix.
} 


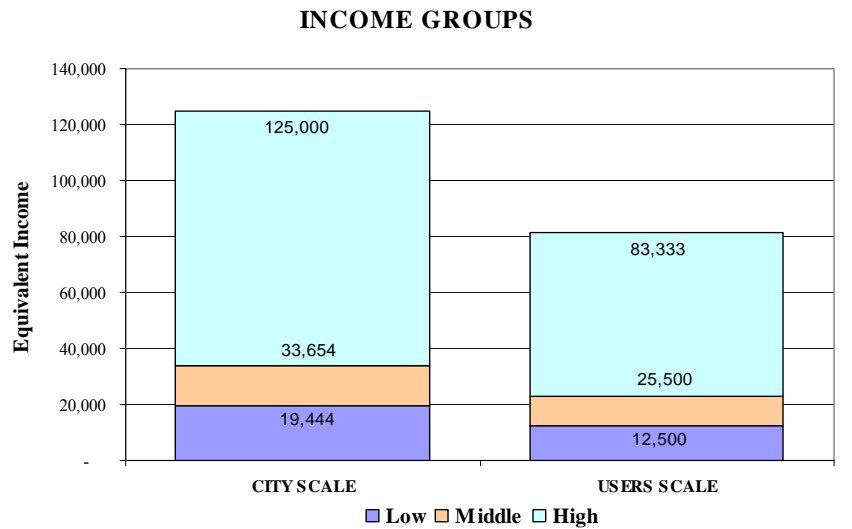

Figure. No. 5.1. Comparative of Income Groups in Columbus
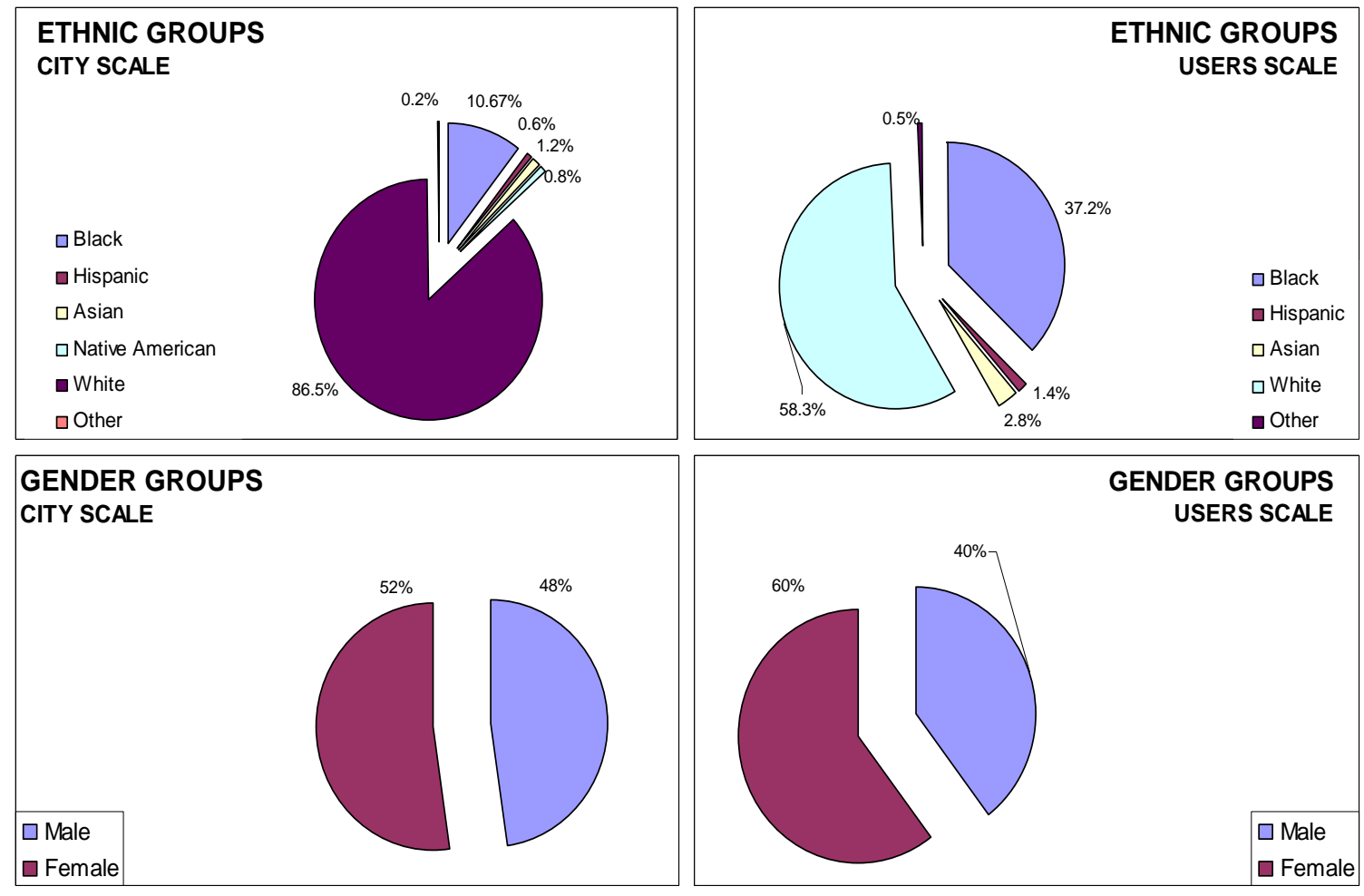

\section{AGE GROUPS}

CITY SCALE
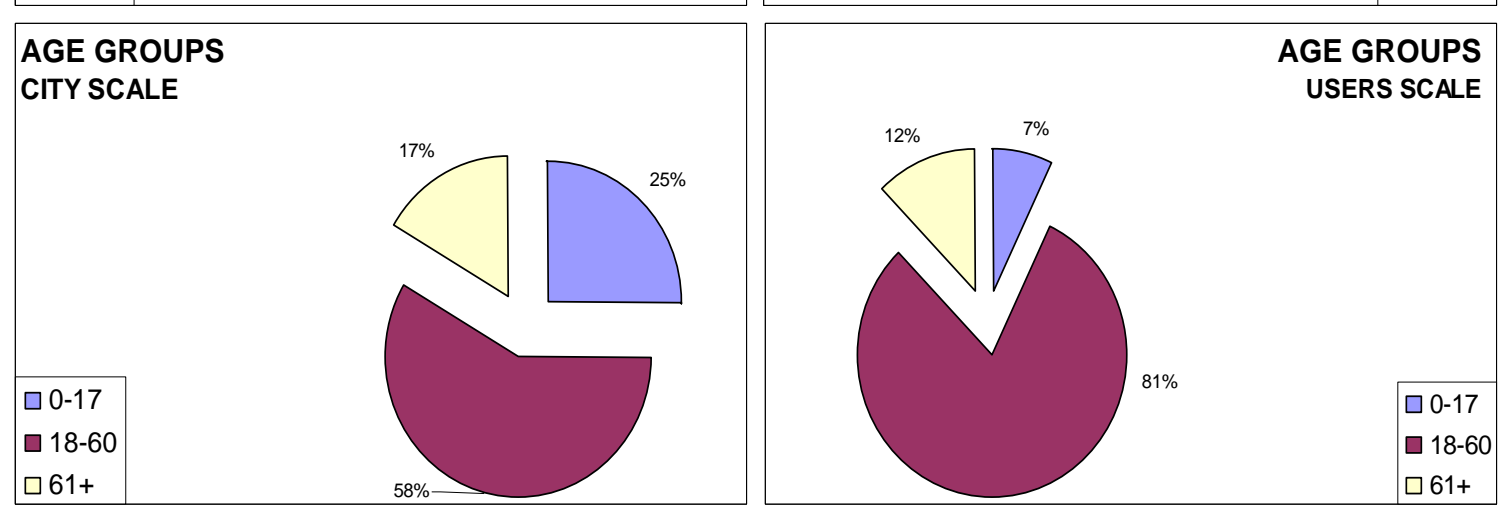

Figure. No. 5.2. Comparative of Ethnic, Gender, and Age Groups in Columbus 
Due to the narrow ethnic diversity in Columbus, the analysis was made comparing whites versus non-whites. Population shares and average trip characteristics of bus users (with complete information) are indicated in the next table. The legal age to apply for a driver license in the city of Columbus is 18 years old, therefore age groups were classified as: 17 and under (youth), 18-60 (working class), and 61+ (seniors). Most of the non-working students are in the first age category while most of the non-working retired seniors are in the third age category.

Table No. 5.2 shows average trip characteristics aggregated by individual and shown by demographic group. The share of each group is indicated as a percentage of the bus user population.

Table No. 5.2. Average Characteristics by Demographic Group of Bus Riders

\begin{tabular}{|c|c|c|c|c|c|c|}
\hline $\begin{array}{l}\text { COLUMBUS } \\
\text { Group }\end{array}$ & $\begin{array}{c}\text { Pop } \\
\text { Share }\end{array}$ & $\begin{array}{c}\text { Distance } \\
\text { (miles) }\end{array}$ & $\begin{array}{c}\text { Time } \\
\text { (minutes) }\end{array}$ & $\begin{array}{l}\text { Speed } \\
(\mathrm{mph})\end{array}$ & $\begin{array}{c}f p m \\
\text { (cents/mile) }\end{array}$ & $\underset{(\mathrm{min} / \mathrm{mile})}{\boldsymbol{t p m}}$ \\
\hline \multicolumn{7}{|l|}{ INCOME GROUPS } \\
\hline Lower & 33.0 & 7.83 & 60.85 & 9.55 & 33.38 & 10.83 \\
\hline Middle & 33.5 & 8.62 & 60.55 & 9.56 & 35.86 & 9.65 \\
\hline Higher & 33.5 & 11.06 & 62.00 & 11.48 & 24.65 & 8.46 \\
\hline \multicolumn{7}{|l|}{ ETHNIC GROUPS } \\
\hline Whites & 57.5 & 9.22 & 57.31 & 10.22 & 32.09 & 9.32 \\
\hline Non-whites & 42.5 & 9.04 & 66.16 & 10.18 & 30.53 & 10.20 \\
\hline \multicolumn{7}{|l|}{ GENDER GROUPS } \\
\hline Males & 39.8 & 8.91 & 63.20 & 8.54 & 33.29 & 10.66 \\
\hline Females & 60.2 & 9.36 & 59.77 & 11.30 & 29.97 & 8.96 \\
\hline \multicolumn{7}{|l|}{ AGE GROUPS } \\
\hline Youth: 0-17 years & 8.60 & 5.89 & 49.44 & 9.51 & 25.70 & 11.10 \\
\hline Working: $18-60$ years & 80.54 & 9.65 & 62.70 & 9.91 & 31.37 & 9.55 \\
\hline Seniors: $61+$ years & 10.86 & 8.05 & 57.74 & 12.50 & 34.08 & 9.39 \\
\hline
\end{tabular}

* Number of observations varied slightly depending on the availability of demographic information. Differences greater than $15 \%$ are shown in bold.

These average numbers show that for lower rates of fpm, higher income groups also spend lower rates of tpm. That is, not only do privileged groups appear to pay less per mile, but they also appear to receive a better quality service in terms of speed, this is on average, everything else equal, and in the case of Columbus.

The table shows in bolds differences greater than $15 \%$ in absolute average time spent traveling between ethnic groups, non-whites travel for longer periods of time. There is also a high difference in average speed between gender groups: women travel relatively faster. This can be explained if most of women travel during non-peak hours. Also, there is a high difference in the average distance traveled by different age groups, younger groups appear to travel shorter distances at slower speeds, probably because students tend to live close to education centers.

The difference in average trip characteristics though, does not indicate a statistical evidence of significant differences among them. It is possible that the difference in 
average is due to outlying values that take the average from the real population mean. Outlier values were however, taken out of the analysis, i.e. unreasonable values greater than logical maximum values for distance $(<50 \mathrm{mi})$, travel time $(<120 \mathrm{~min})$ and fare paid $(<3 \mathrm{dls})$. The real difference is revealed with statistical evidence using the $t$-student analysis next.

\section{Statistical Differences by t-Statistics Analysis in Columbus}

Table No. 5.3 indicates statistical differences found among demographic groups using the $t$-test analysis. Income groups, categories: low (L), middle (M), and high $(\mathrm{H})$, were tested one against each other. Ethnic groups were tested: white (W) vs. non-white (NW); and gender groups: males (M) vs. females (F). Age groups, categories: youth -17 or less (Y), working class - ages 18 to $60(\mathrm{~W})$, and seniors $-61+(\mathrm{S})$, were also tested one against each other.

Table No. 5.3. Statistical Differences by Demographic Group in Columbus

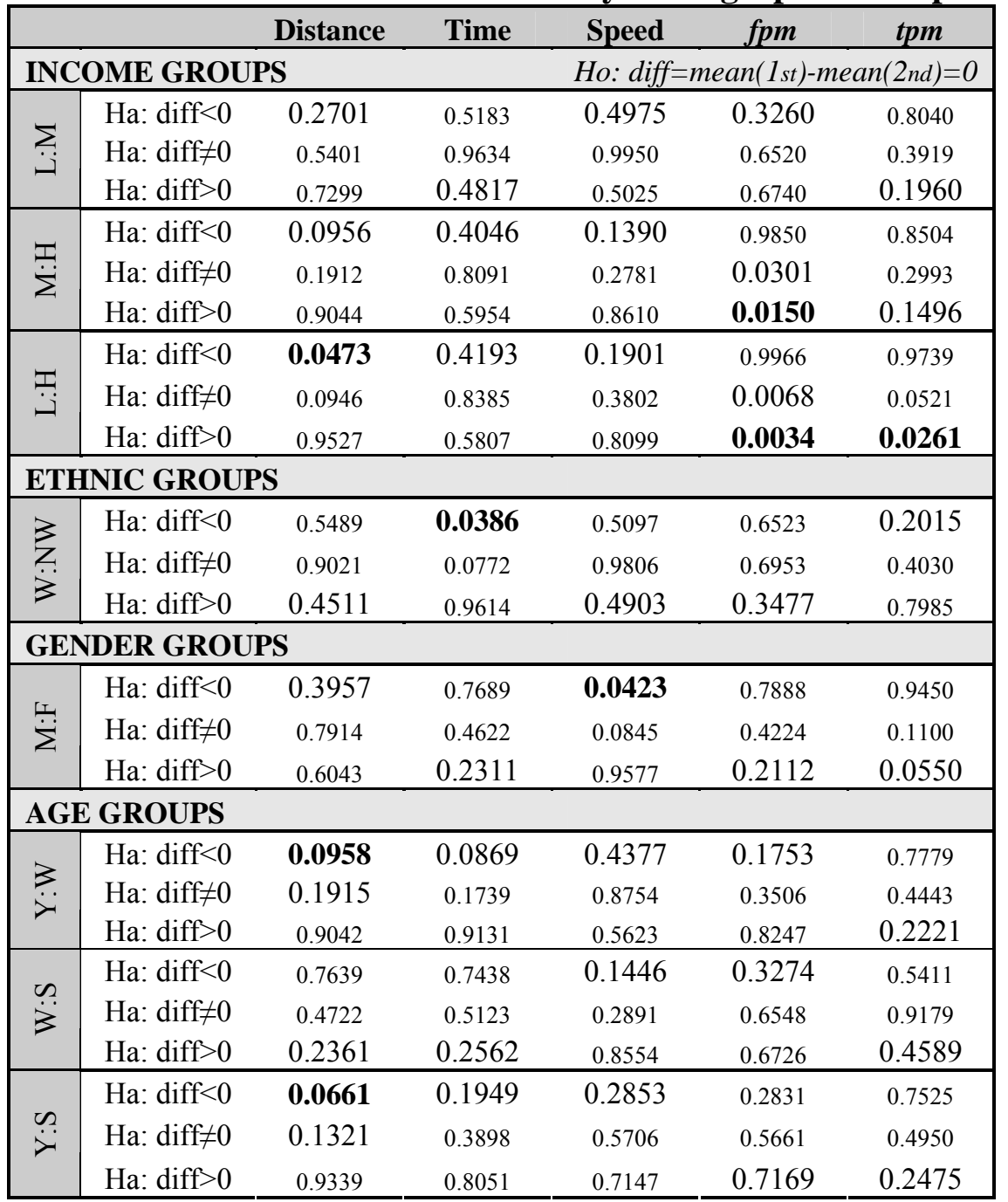

* Smaller values are shown in a larger font size and significant differences $(<0.05)$ are in bold. The analysis at the household scale is shown in the appendix. 


\section{INCOME GROUPS}

A significant difference in distance traveled was found between income groups $\mathrm{L}$ and $\mathrm{H}$, i.e. L travels shorter distances than $\mathrm{H}(0.0473)$. In other words, there is little chance that Ho was true, and therefore a higher possibility that the alternative $\mathrm{Ha}(\operatorname{diff}<0)$ is in fact true. If $\operatorname{diff}<0$, that means that (2) or the average distance traveled by $\mathrm{H}$, is greater. No significant difference was found with regard to distance between L and $\mathrm{M}$ and between $\mathrm{M}$ and $\mathrm{H}$.

Despite the significant difference in distance traveled between $\mathrm{L}$ and $\mathrm{H}$, there was no significant difference in travel time or speed, this may not seem very reasonable at first sight. If $\mathrm{H}$ travels longer distances, either they travel longer periods of time or they travel faster. The smaller $p$-values for speed compared to travel time (0.1901 vs. 0.4193) suggest the idea that it is more likely that $\mathrm{H}$ travels faster than $\mathrm{L}$, though not statistically significant. The fact that the p-value for tpm, comparing income groups $\mathrm{L}$ vs. $\mathrm{H}$, is statistically significant (0.0261) is evidence that L spends more tpm than $\mathrm{H}$, and therefore supports the idea that L travels slower. Statistical evidence was found with regard to tpm between income groups $\mathrm{L}$ and $\mathrm{H}$, and only a moderate tendency indicating that $\mathrm{H}$ travels faster than $\mathrm{M}$, and $\mathrm{M}$ travels faster than $\mathrm{L}$.

Now regarding $\mathrm{fpm}$, significant differences were found comparing income groups $\mathrm{L}$ vs. $\mathrm{H}$ and $\mathrm{M}$ vs. $\mathrm{H}$, evidencing that $\mathrm{H}$ pay lower fpm compared to $\mathrm{L}$ and $\mathrm{M}$. There was no statistical difference between income groups $\mathrm{L}$ and $\mathrm{M}$ at the $5 \%$ level for any variable.

Accordingly to what the averages indicated in Table No. 5.2, the $t$-test results of Table No. 5.3 confirms the fact that $\mathrm{H}$ pay less per mile and on top of that, compared to $\mathrm{M}$ and $\mathrm{L}, \mathrm{H}$ also receives a better quality service in terms of speed compared to $\mathrm{L}$ at the $5 \%$ confidence level. In short, it was found the following results which resemble very closely the average values from Table No. 5.2. Statistical differences at 5\% C.L. are in italic-bolds and the subscript represents the reference, e.g. in Distance, $\boldsymbol{H}_{\boldsymbol{L}}>\boldsymbol{L}_{\boldsymbol{H}}$ means that there is a difference in distance traveled between $\mathrm{H}$ and $\mathrm{L}$ at the $5 \% \mathrm{C}$.L ( $\mathrm{H}$ travels longer distances than $\mathrm{L}$ ). There is no significant difference in $\mathrm{M}$ compared to $\mathrm{H}$ or $\mathrm{L}$ ( $\mathrm{M}$ has a wide distribution of distance traveled).

$\begin{array}{llllll}\text { Distance: } & \boldsymbol{H}_{\boldsymbol{L}} & > & \mathrm{M} & > & \boldsymbol{L}_{\boldsymbol{H}} \\ \text { Time: } & \mathrm{H} & > & \mathrm{L} & > & \mathrm{M} \\ \text { Speed: } & \mathrm{H} & > & \mathrm{M} & > & \mathrm{L} \\ \text { tpm: } & \boldsymbol{L}_{\boldsymbol{H}} & > & \mathrm{M} & > & \boldsymbol{H}_{\boldsymbol{L}} \\ \text { fpm: } & \boldsymbol{M}_{\boldsymbol{H}} & > & \boldsymbol{L}_{\boldsymbol{H}} & > & \boldsymbol{H}_{L, M}\end{array}$

Note: Grouping of L and M groups together may yield more significant results when compared to $\mathrm{H}$ (two groups rather than 3 ). 


\section{ETHNIC GROUPS}

In regard to the analysis by ethnic groups, a significant difference was found in travel time $(0.0386)$ between $\mathrm{W}$ and $\mathrm{NW}$, as implied by the difference in averages shown in the previous table. That is, NW travel longer periods of time compared to W. If NW travel longer periods of time, either they travel longer distances or they travel slower; however no significant difference was found in neither of these two variables. The smaller values for distance, speed and tpm though, suggests a slight to moderate tendency that NW travel slower. No statistical evidence at the 5\% level was found indicating that ethnic groups pay fpm differently, but a slight tendency suggesting that $\mathrm{W}$ pays more. Results are shown in the following table (in bolds statistical differences at 5\% C.L.):

$\begin{array}{llll}\text { Distance: } & \mathrm{W} & > & \mathrm{NW} \\ \text { Time: } & \boldsymbol{N W}_{W}> & \mathbf{W}_{N W} \\ \text { Speed: } & \mathrm{W} & > & \mathrm{NW} \\ \text { tpm: } & \mathrm{NW}> & \mathrm{W} \\ \text { fpm: } & \mathrm{W} & > & \mathrm{NW}\end{array}$

\section{GENDER GROUPS}

Regarding gender groups, a significant difference was found indicating that females travel in fact at higher speeds (0.0423), possibly at non-peak hours. No statistical evidence is found indicating any difference between genders with respect to distance, travel time or fpm. The smaller p-values though, suggest the idea that females travel relatively longer distances, for shorter periods of time (thus spending less tpm), and pay less per mile. Results are summarized in the table (in bolds are differences at 5\% C.L.):

$\begin{array}{llll}\text { Distance: } & \mathrm{F} & > & \mathrm{M} \\ \text { Time: } & \mathrm{M} & > & \mathrm{F} \\ \text { Speed: } & \boldsymbol{F}_{\boldsymbol{M}} & > & \boldsymbol{M}_{\boldsymbol{F}} \\ \text { tpm: } & \mathrm{M} & > & \mathrm{F} \\ \text { fpm: } & \mathrm{M} & > & \mathrm{F}\end{array}$

\section{AGE GROUPS}

The analysis by age groups provided statistical evidence that $\mathrm{Y}$ travels shorter distances compared to the $\mathrm{W}(0.0958)$ and $\mathrm{S}(0.0661)$. No significant difference was found in any other variable between age groups. However, if $Y$ travels shorter distances, either they travel shorter periods of time or they travel at slower speeds, or both. The smaller $p$-values for time, speed and tpm suggest that $Y$ travels both, slower and for shorter periods of time, probably short trips during peak hours. A slight tendency in fpm indicates that $\mathrm{Y}$ pays more than $\mathrm{S}$ and $\mathrm{S}$ pays more than $\mathrm{W}$. In short, the analysis suggests the worst case for Y: travels shorter distances, for shorter periods of time, at slower speeds and paying more $\mathrm{fpm}$. On the other hand, $\mathrm{W}$ travels longer distances, for longer periods of time, at faster speeds and paying less fpm. $\mathrm{S}$ is found in an intermediate 
condition between $\mathrm{Y}$ and $\mathrm{W}$. In short, results are summarized as follows (statistical differences at 5\% C.L. are shown in bolds and italics):

$\begin{array}{llllll}\text { Distance: } & \boldsymbol{W}_{\boldsymbol{Y}} & > & \boldsymbol{S}_{\boldsymbol{Y}} & > & \boldsymbol{Y}_{W, \boldsymbol{S}} \\ \text { Time: } & \mathrm{W} & > & \mathrm{S} & > & \mathrm{Y} \\ \text { Speed: } & \mathrm{S} & > & \mathrm{W} & > & \mathrm{Y} \\ \text { tpm: } & \mathrm{Y} & > & \mathrm{W} & > & \mathrm{S} \\ \text { fpm: } & \mathrm{Y} & > & \mathrm{S} & > & \mathrm{W}\end{array}$

A statistical difference $(<0.05)$ in speed does not necessarily is followed by a statistical difference in tpm. Even though tpm is the inverse of speed, the 'bell-shaped' distributions of these two variables are not necessarily symmetrical. The $t$-test is testing opposite sides of their distributions. In general, a pattern is observed, e.g. if a low p-value is found in speed for $\mathrm{H}$ compared to $\mathrm{L}$, it is very likely that a low $\mathrm{p}$-value will be observed in L compared to $\mathrm{H}$. If this pattern is not observed, it is very likely that there is no significant difference between these two demographic groups.

\section{Inequality Measurements in Columbus}

Table No. 5.4 - Inequality Measurements by Demographic Group in Columbus, provides the Gini coefficient, and Theil and Atkinson inequality indices by column. The analysis for each demographic group (by income, ethnicity, gender and age) consists of 4 index measurements: 1) income inequality at the city level, 2) income inequality at the users level, 3) consumption inequality in fpm and 4) consumption inequality in tpm. Consumption inequalities in fpm and tpm are compared in this section to income inequality, at the city and bus users' level.

At the top of each box, the overall inequality indices are shown in bolds, for example: for income groups, with respect to the equivalent income at the city level (first box), the overall Gini coefficient is 0.338 , the Theil index [or GE(1)] is 0.188 , and the Atkinson index [or A(1)] is 0.200 . Besides the overall Gini coefficient, Gini values per category are also shown, for example for the income group, the Gini values for $\mathrm{L}=0.242$, for $\mathrm{M}=0.082$, and for $\mathrm{H}=0.161$. This is shown for each box, and for each demographic group.

The Theil and Atkinson indices, contrary to Gini, are additively decomposable. That is, the inequality within group plus the inequality between groups is equal to the overall index (within + between $=$ overall). For example, for demographic groups by income, for the cluster of 'income inequality at city level', the overall Theil index $[\mathrm{GE}(1)]=0.036$ (within) +0.152 (between $)=0.188$. The first page of the table provides the inequality measures for income and ethnic groups, while the second page provides measurements for gender and age groups. The indices in the tables are shown per user only $^{29}$.

\footnotetext{
${ }^{29}$ Per household Theil and Atkinson decomposition indices are shown in the appendix.
} 
The Gini coefficient is most sensitive to income differences about the middle (more precisely, the mode), while the Theil and Atkinson indices depend on the parameter (a) or (e) that is used. The table provides different generalized entropy indices or GE(a), where the more negative (a) is, the more sensitive it is to differences at the bottom of the distribution. The Theil index is given by the value of GE(1). On the other hand, the Atkinson index is provided by $\mathrm{A}(\mathrm{e})$, in which the more positive e is $(\mathrm{e}>0$, the inequality aversion parameter), the more sensitive $\mathrm{A}(\mathrm{e})$ is to income differences at the bottom of the distribution. The indices corresponding to inequality within and between groups are ordered from most sensitive to bottom classes, down to most sensitive to top classes.

\section{GINI COEFFICIENT}

Table No. 5.4 indicates that bus users' income inequality is greater than the city's income inequality, as measured by the overall Gini coefficients ( 0.385 vs. 0.338$)$. This means that there is more inequality among bus users' income compared to the city's income inequality. Now, assuming that income and consumption inequality indices are comparable for the city of Columbus, inequality in fpm (0.386) is similar to that of income inequality of bus users. That is, the bus transit system is not doing better or worse compared to the existing inequality in the city. Regarding tpm, it is found to be less unequal (0.356) compared to bus users' income inequality. Since these are overall values, these should be equal for all four demographic groups, however slight variations are observed since some records were not considered if they lacked information regarding ethnicity, gender or age. The Gini values for each category of each demographic group are compared to income inequality next at both scales: city and users' scales. ${ }^{30}$

Income inequality is lowest for the middle income group at the city and users scale (0.082 and 0.122); however consumption inequality is highest for both, fpm and tpm, compared to the other two income groups $(0.433$ and 0.360$)$. This indicates a considerable disparity within this group regarding resources spent using the bus system compared to the other two groups. In fact, more inequality is observed in fpm and tpm compared to income (city and users) relative to its own group (e.g. for low income: $f p m=0.359$ and $t p m=0.358$, compared to income-city $=0.242$ and income-users $=0.246$ ).

The analysis by ethnic groups reveals that income inequality is greater for nonwhite groups at the city and users' scale $(0.382$ and 0.381$)$; this is also true for consumption inequality for both parameters: fpm (0.388) and tpm (0.376). The inequality in fpm however, is very similar for both, whites and non-whites. Regarding tpm, it is found to be more unequal for non-whites (0.376 vs. 0.339).

The analysis by gender groups shows that income inequality is slightly greater for females at the city scale $(0.342)$ but equal at the users' scale $(0.383)$. This is not surprising since interviewees report household income (most likely integrated by males and females). Regarding consumption inequality, it is found more fpm inequality for

\footnotetext{
${ }^{30}$ The analysis was performed at the household scale too, which is shown in the appendix.
} 
males than for females ( 0.412 vs. 0.366$)$; the opposite happens for tpm inequality $(0.360$ vs. 0.346). This means that there is less disparity in what females pay (i.e. it is more even) but more disparity in the time they spent per mile compared to males.

The analysis by age groups indicates less inequality among the youth group (17 and under) for income inequality (city and users' scale) and for consumption inequality in fpm compared to the other two age groups $(0.309,0.333$, and 0.349 respectively), meaning that income and consumption are more even within the group (there is less disparity). Inequality in the consumption parameter of tpm is, however highest compared to the other 2 groups, meaning that there is a lot of disparity within this group with respect of tpm (or speed). The one value that draws particular attention is the high inequality found in fpm within the group of seniors (0.523), meaning that members of this group are paying very differently from one another. This is the highest inequality value found among categories of all groups. One possibility is that some senior users take advantage of the special fares and passes for the service and others are not.

\section{THEIL AND ATKINSON INDICES}

The Theil and Atkinson indices also show more income inequality among bus users compared to the city income inequality (Theil: 0.243 vs. 0.188 , and Atkinson: 0.249 vs. 0.200). The values for fpm and tpm (consumption parameters) are also greater than the income inequality index at the city scale. Compared to the users' scale though, only the fpm, given by the Theil index, is greater.

\begin{tabular}{|r|c|c|c|c|}
\hline & $f p m$ & $t p m$ & City & Users \\
\hline Theil: & 0.271 & 0.228 & 0.188 & 0.243 \\
\hline Atkinson: & 0.223 & 0.202 & 0.200 & 0.249 \\
\hline
\end{tabular}

The Theil and Atkinson indices also show that, when the analysis is made by income groups, most of the inequality is found between the groups rather than within the groups at the city scale and at the users' scale. In any other case, most -if not all- of the inequality is found within the group. In most of the cases, the Theil inequality index is greater at bottom classes and decreases towards top classes. In some cases the index is higher in extreme classes (bottom and top), although it is usually greater at bottom classes. The Atkinson index is greater, in all but one case, at bottom classes indicating greater inequality here. 
Table No.5.4. Inequality Measurements by Demographic Group in Columbus

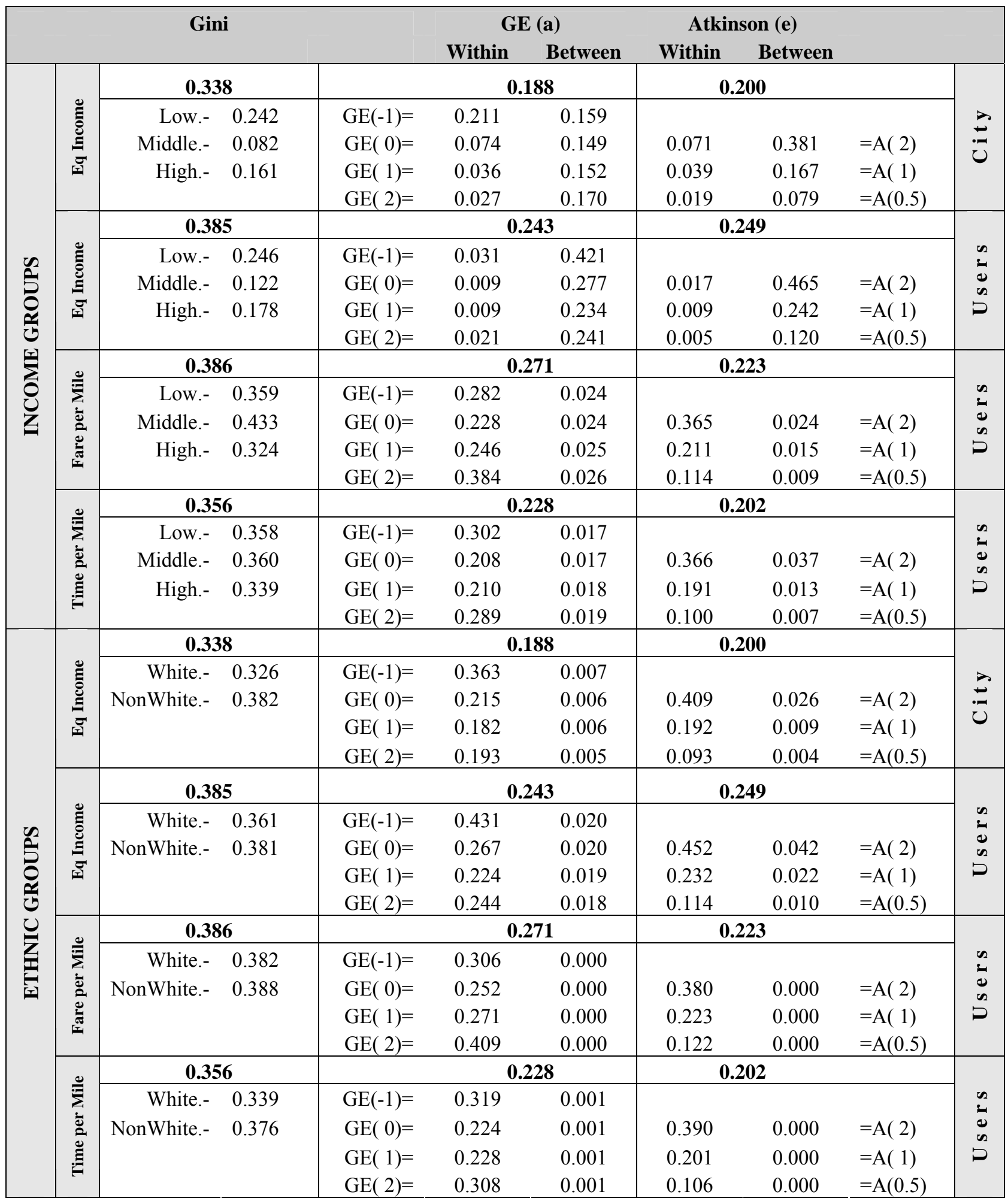

* Overall values of Gini, Theil and Atkinson are in bold, below them are shown the-per category, within and between values for each demographic group. Number of observations varied slightly depending on the availability of demographic information. 
Table No. 5.4. Inequality Measurements by Demographic Group in Columbus (Cont.)

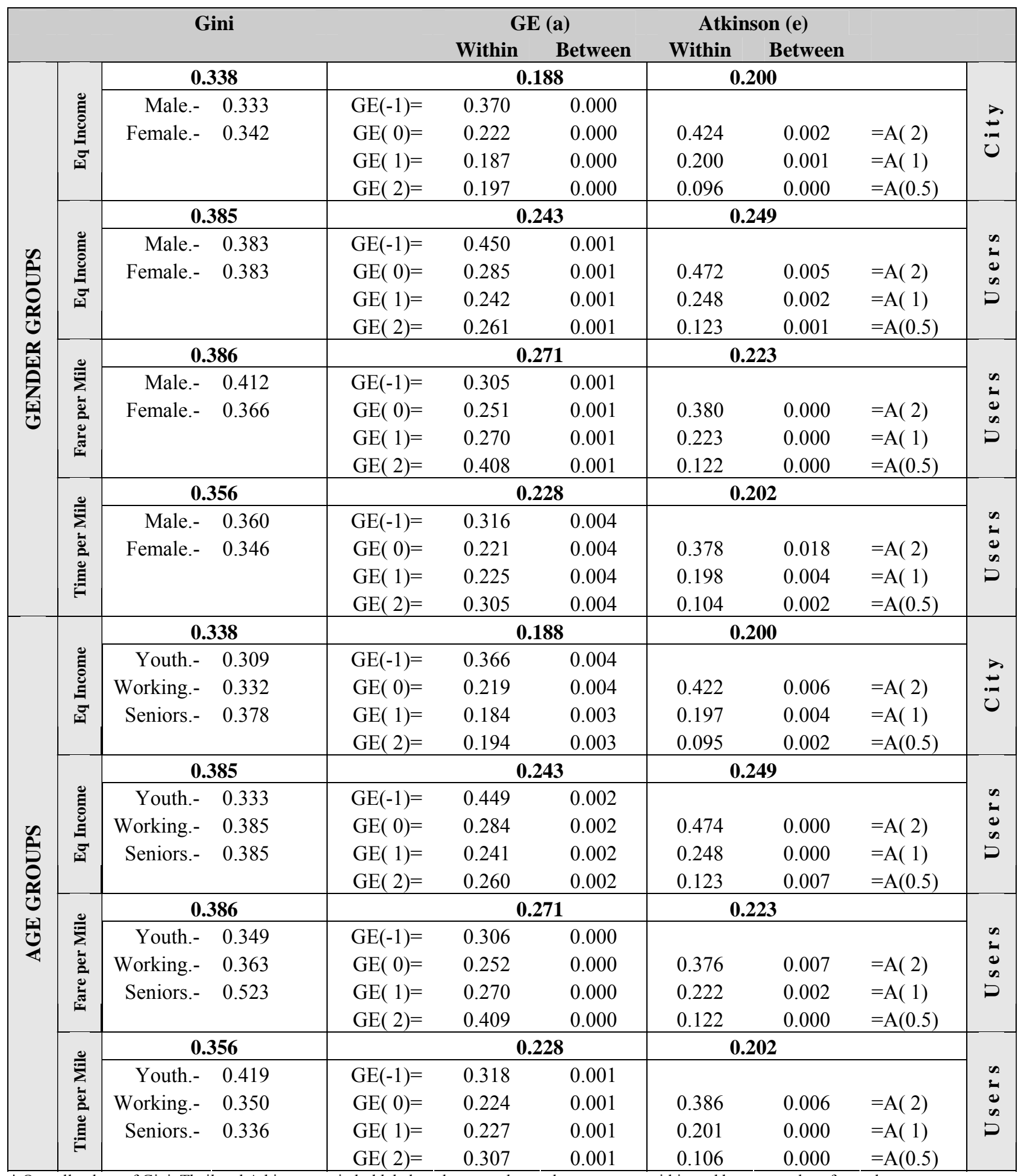

* Overall values of Gini, Theil and Atkinson are in bold, below them are shown the per-group, within and between values for each demographic group. Number of observations varied slightly depending on the availability of demographic information. 


\section{B. The Case of Seattle}

The data collected in the HTS of Seattle, WA is shown in this section. The analysis is similar to the one presented for the city of Columbus, $\mathrm{OH}$. It includes average characteristics, statistical differences, and measures of inequality by demographic group (income, ethnicity, gender, and age). This section also provides an analysis of the demographics of pass holders. The HTS performed in 1999 by the Puget Sound Regional Council, which is Seattle area's MPO, includes 130,339 records of 5,988 households (52 households did not reported any activity). These records correspond to 101,770 trips made by 12,768 persons in the 48 -hour period of the survey (dates varied). The mode split of these trips is shown in Table No. 5.5.

Table No. 5.5. Travel Mode Split in Seattle

\begin{tabular}{|c|c|}
\hline Walk & $6.08 \%$ \\
\hline Private & $86.62 \%$ \\
\hline Auto/Drive & 62.81 \\
\hline Auto/Passenger & 22.40 \\
\hline Carpool / Driver \& Passenger & 1.14 \\
\hline Vanpool / Driver \& Passenger & 0.27 \\
\hline Transit/Paratransit & $6.06 \%$ \\
\hline Bus & 2.60 \\
\hline Ferry/Pass Boat & 0.65 \\
\hline School Bus & 2.77 \\
\hline Taxi/Paid Limo & 0.04 \\
\hline Bicycle/Motorcycle & $1.02 \%$ \\
\hline Bicycle & 0.93 \\
\hline Motorcycle & 0.09 \\
\hline Other & $0.22 \%$ \\
\hline
\end{tabular}

There were 1,267 bus trips made by 430 persons who had complete data regarding trip distance, travel time and fare, as well as the required demographic information. The analysis was made at the individual scale (i.e. trips grouped by user) and considers the equivalent income, which is calculated dividing the lower and upper income limits of each category by the household adult equivalents. These two values are then averaged to obtain the equivalent income per person-similar to the analysis made for Columbus.

\section{Demographics of Pass Holders in Seattle}

Even though the data from the 1999 HTS from Seattle was extensive, there was a large percentage of bus users that did not reported the fare, the cost of the pass or some other crucial information for this analysis. A large proportion of these incomplete records were pass holders. Contrary to the city of Columbus, where there was only one transit agency and few pass options, the bus transit service in the city of Seattle was offered by six transit agencies throughout four counties, which offered a number of day passes, 
ticket books with $11,20 \ldots$ passes, monthly passes and even yearly passes. This made impossible to figure out the cost of many trips and use all of them in the database. There were records for 732 bus users, however only 430 of them were possible to use for the purpose of this analysis. The demographics of the 732-user sample however, were preserved in the 430-user sub-sample. This promises (but not guarantees) that, the fact of not taking into account those records, could have affected significantly the conclusions of this analysis. This is shown in the following tables.

Distance and Travel Time. The original database had $74 \%$ of pass holders and $26 \%$ of non-pass-holders. The sub-sample that was finally used in the analysis was comprised of $67 \%$ pass-holders and $33 \%$ of non-pass-holders. This is the largest difference between the two databases and the difference may seem significant, however the distance and travel time of pass- and non-pass holders did not differ much between sample and sub-sample. The average distance traveled by bus was the same in both cases (33.20 miles) for pass holders, and very similar for non-pass holders (23.20 vs. 22.25). The average travel time was also very similar between the sample and sub-sample (157 vs. 155 and 129 vs. 128$)$.

Income Groups. The split of pass-holders between income groups (considering the income limits indicated at the top of the column), was 30, 33 and 37 percent for income groups 1, 2 and 3, compared to a 30,31 and 39 percent split in the sub-sample. For non-pass holders, the split was 42, 36, and 22 percent compared to 39, 39, and 21 percent. The sum of pas-holders and non-pass holders was of course one third each (by construction). The income limits for each income category are very similar.

Ethnic Groups. The split of pass/non-pass holders in the original database was $85 / 15$ percent. This was practically the same split in the sub-sample. For the total numbers (pass plus non-pass holders), percentages remain just about the same as well.

Gender Groups. The split for pass/non-pass holders was almost even in the original dataset. This did not vary much in the sub-sample that was used. Apparently fewer male pass-holders remembered how much they paid for their passes compared to females.

Age Groups. The split in the original database for pass-holders was 4, 87, and 9 percent, which remain practically unchanged: 5,85 , and 11 percent. The same happened for non-pass holders: 12,83 and 5 percent compared to 13, 82, and 6 percent in the subsample.

Given that the demographics and trip characteristics between sample and subsample were preserved, it is not expected that the final results obtained from the analysis might differ significantly from the original database provided by the HTS of Seattle. This information, between data from the survey and the sub-sample taken for this study, is summarized in Table 5.6. Conclusions, however, are as good as the available data and the unavoidable assumptions that have to be made for the analysis. 
Table No. 5.6. Demographics of Pass-Holders, Survey Data vs. Sample Taken From Survey Data

\begin{tabular}{|c|c|c|c|c|}
\hline \multicolumn{3}{|l|}{ SURVEY } & \multirow{2}{*}{$\begin{array}{l}\text { Average } \\
\text { Distance }\end{array}$} & \multirow{2}{*}{$\begin{array}{c}\text { Average } \\
\text { Time }\end{array}$} \\
\hline PASS & Freq. & Percent & & \\
\hline & & & 27.37 & 135.71 \\
\hline Yes & 412 & $74 \%$ & 33.20 & 157.22 \\
\hline No & 146 & $26 \%$ & 23.20 & 129.84 \\
\hline SubTotal & 558 & $100 \%$ & & \\
\hline $\mathrm{ND} / \mathrm{RF}=$ & $5^{*}$ & & & \\
\hline $\operatorname{missing}=$ & $169^{*}$ & & & \\
\hline Total & 732 & & & \\
\hline
\end{tabular}

\begin{tabular}{|l|r|r|r|r|}
\hline \multirow{2}{*}{ INCOME } & \multicolumn{3}{|c|}{ SURVEY } \\
\cline { 2 - 5 } & \multicolumn{1}{|c|}{$\mathrm{L}$} & \multicolumn{1}{c|}{ M } & \multicolumn{1}{c|}{ H } & \\
\hline PASS & & & & Total \\
\hline Yes & 125 & 135 & 152 & 412 \\
\hline & $\mathbf{3 0 \%}$ & $\mathbf{3 3 \%}$ & $\mathbf{3 7 \%}$ & $\mathbf{1 0 0 \%}$ \\
\hline No & 61 & 53 & 32 & 146 \\
\hline & $\mathbf{4 2 \%}$ & $\mathbf{3 6 \%}$ & $\mathbf{2 2 \%}$ & $\mathbf{1 0 0 \%}$ \\
\hline Total & 188 & 191 & 184 & 558 \\
\hline & & & & 174 \\
\hline & $34 \%$ & $34 \%$ & $33 \%$ & 732 \\
\hline
\end{tabular}

\begin{tabular}{|l|r|r|r|c|}
\hline \multicolumn{2}{|l|}{ SAMPLE } & $\begin{array}{c}\text { Average } \\
\text { Distance }\end{array}$ & $\begin{array}{c}\text { Average } \\
\text { Time }\end{array}$ \\
\hline \multicolumn{1}{|c|}{ PASS } & Freq. & Percent & 26.44 & 132.53 \\
\hline Yes & 222 & $67 \%$ & 33.20 & 155.53 \\
\hline No & 109 & $33 \%$ & 22.25 & 128.01 \\
\hline SubTotal & 331 & $100 \%$ & & \\
\hline ND/RF $=$ & $3^{*}$ & & & \\
\hline missing $=$ & $96^{*}$ & & & \\
\hline Total & 430 & & & \\
\hline
\end{tabular}

* ND/RF - Not declared or missing data

\begin{tabular}{|l|r|r|r|r|}
\hline \multirow{2}{*}{ INCOME } & \multicolumn{4}{|c|}{ SAMPLE } \\
\cline { 2 - 5 } & \multicolumn{1}{|c|}{$\mathrm{L}$} & \multicolumn{1}{|c|}{$\mathrm{M}$} & $\mathrm{H}$ & \\
\hline PASS & & & & Total \\
\hline Yes & 67 & 69 & 86 & 222 \\
\hline & $\mathbf{3 0 \%}$ & $\mathbf{3 1 \%}$ & $\mathbf{3 9 \%}$ & $\mathbf{1 0 0 \%}$ \\
\hline No & 43 & 43 & 23 & 109 \\
\hline & $\mathbf{3 9 \%}$ & $\mathbf{3 9 \%}$ & $\mathbf{2 2 \%}$ & $\mathbf{1 0 0 \%}$ \\
\hline Total & 110 & 112 & 109 & 331 \\
\hline & & & & 99 \\
\hline & $33 \%$ & $34 \%$ & $33 \%$ & 430 \\
\hline
\end{tabular}

\begin{tabular}{|l|r|r|r|}
\hline \multirow{2}{*}{ ETHNIC } & \multicolumn{3}{|c|}{ SURVEY } \\
\cline { 2 - 4 } & W & NW & \\
\hline PASS & \multicolumn{3}{|c|}{ Total } \\
\hline Yes & 349 & 63 & 412 \\
\hline & $\mathbf{8 5 \%}$ & $\mathbf{1 5 \%}$ & $\mathbf{1 0 0 \%}$ \\
\hline No & 125 & 21 & 146 \\
\hline & $\mathbf{8 6 \%}$ & $\mathbf{1 4 \%}$ & $\mathbf{1 0 0 \%}$ \\
\hline Total & 479 & 84 & 558 \\
\hline & & & 174 \\
\hline & $86 \%$ & $15 \%$ & 732 \\
\hline
\end{tabular}

\begin{tabular}{|l|r|r|r|}
\hline \multirow{2}{*}{ GENDER } & \multicolumn{3}{|r|}{ SURVEY } \\
\cline { 2 - 4 } & M & \multicolumn{1}{|c|}{ F } \\
\hline PASS & \multicolumn{3}{|c|}{ Total } \\
\hline Yes & 207 & 205 & 412 \\
\hline & $\mathbf{5 0 \%}$ & $\mathbf{5 0 \%}$ & $\mathbf{1 0 0 \%}$ \\
\hline No & $\mathbf{7 2}$ & 74 & 146 \\
\hline & $\mathbf{4 9 \%}$ & $\mathbf{5 1 \%}$ & $\mathbf{1 0 0 \%}$ \\
\hline Total & $\mathbf{2 8 1}$ & $\mathbf{2 8 2}$ & 558 \\
\hline & & & 174 \\
\hline & $50 \%$ & $51 \%$ & 732 \\
\hline
\end{tabular}

\begin{tabular}{|l|r|r|r|r|}
\hline \multirow{2}{*}{ AGE } & \multicolumn{4}{|c|}{ SURVEY } \\
\cline { 2 - 5 } & Y & W & \multicolumn{2}{|c|}{ S } \\
\hline PASS & \multicolumn{4}{|c|}{ Total } \\
\hline Yes & 15 & 358 & 39 & 412 \\
\hline & $\mathbf{4 \%}$ & $\mathbf{8 7 \%}$ & $\mathbf{9 \%}$ & $\mathbf{1 0 0 \%}$ \\
\hline No & 17 & 121 & 8 & 146 \\
\hline & $\mathbf{1 2 \%}$ & $\mathbf{8 3 \%}$ & $\mathbf{5 \%}$ & $\mathbf{1 0 0 \%}$ \\
\hline Total & 34 & 481 & 48 & 558 \\
\hline & & & & 174 \\
\hline & $6 \%$ & $86 \%$ & $9 \%$ & 732 \\
\hline
\end{tabular}

\begin{tabular}{|l|r|r|r|}
\hline \multirow{2}{*}{ ETHNIC } & \multicolumn{3}{|c|}{ SAMPLE } \\
\cline { 2 - 4 } & W & NW & \\
\hline PASS & \multicolumn{3}{|c|}{ Total } \\
\hline Yes & 191 & 31 & 222 \\
\hline & $\mathbf{8 6 \%}$ & $\mathbf{1 4 \%}$ & $\mathbf{1 0 0 \%}$ \\
\hline No & 92 & 17 & 109 \\
\hline & $\mathbf{8 4 \%}$ & $\mathbf{1 6 \%}$ & $\mathbf{1 0 0 \%}$ \\
\hline Total & 283 & 48 & 331 \\
\hline & & & 99 \\
\hline & $85 \%$ & $15 \%$ & 430 \\
\hline
\end{tabular}

\begin{tabular}{|l|r|r|r|}
\hline \multirow{2}{*}{ GENDER } & \multicolumn{3}{|c|}{ SAMPLE } \\
\cline { 2 - 4 } & $\mathrm{M}$ & \multicolumn{1}{|c|}{$\mathrm{F}$} & \\
\hline PASS & \multicolumn{3}{|c|}{ Total } \\
\hline Yes & 103 & 119 & 222 \\
\hline & $\mathbf{4 6 \%}$ & $\mathbf{5 4 \%}$ & $\mathbf{1 0 0 \%}$ \\
\hline No & 53 & 56 & 109 \\
\hline & $\mathbf{4 9 \%}$ & $\mathbf{5 1 \%}$ & $\mathbf{1 0 0 \%}$ \\
\hline Total & 156 & 175 & 331 \\
\hline & & & 99 \\
\hline & $47 \%$ & $53 \%$ & 430 \\
\hline
\end{tabular}

\begin{tabular}{|l|r|r|r|r|}
\hline \multirow{2}{*}{ AGE } & \multicolumn{4}{|c|}{ SAMPLE } \\
\cline { 2 - 5 } & Y & W & \multicolumn{1}{|c|}{ S } & \\
\hline PASS & \multicolumn{4}{|c|}{ Total } \\
\hline Yes & 10 & 188 & 24 & 222 \\
\hline & $\mathbf{5 \%}$ & $\mathbf{8 5 \%}$ & $\mathbf{1 0 \%}$ & $\mathbf{1 0 0 \%}$ \\
\hline No & 14 & 89 & 6 & 109 \\
\hline & $\mathbf{1 2 \%}$ & $\mathbf{8 2 \%}$ & $\mathbf{6 \%}$ & $\mathbf{1 0 0 \%}$ \\
\hline Total & 24 & 277 & 30 & 331 \\
\hline & & & & 99 \\
\hline & $7 \%$ & $84 \%$ & $9 \%$ & 430 \\
\hline
\end{tabular}




\section{Average Travel Characteristics in Seattle}

Figures No. 5.3 and No. 5.4 compare bus riders to the rest of the city population. Income groups are classified in low, middle, and high (1/3 each); Ethnic, Gender, and Age groups are according to actual percentages in the city and bus users population.

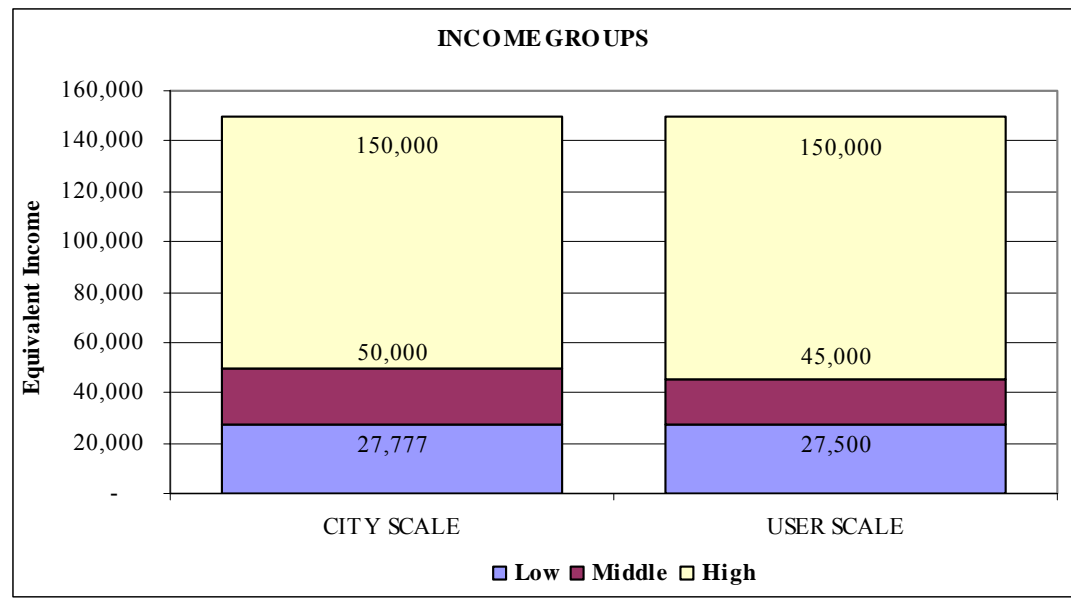

Figure. No. 5.3. Comparative of Income Groups in Seattle 

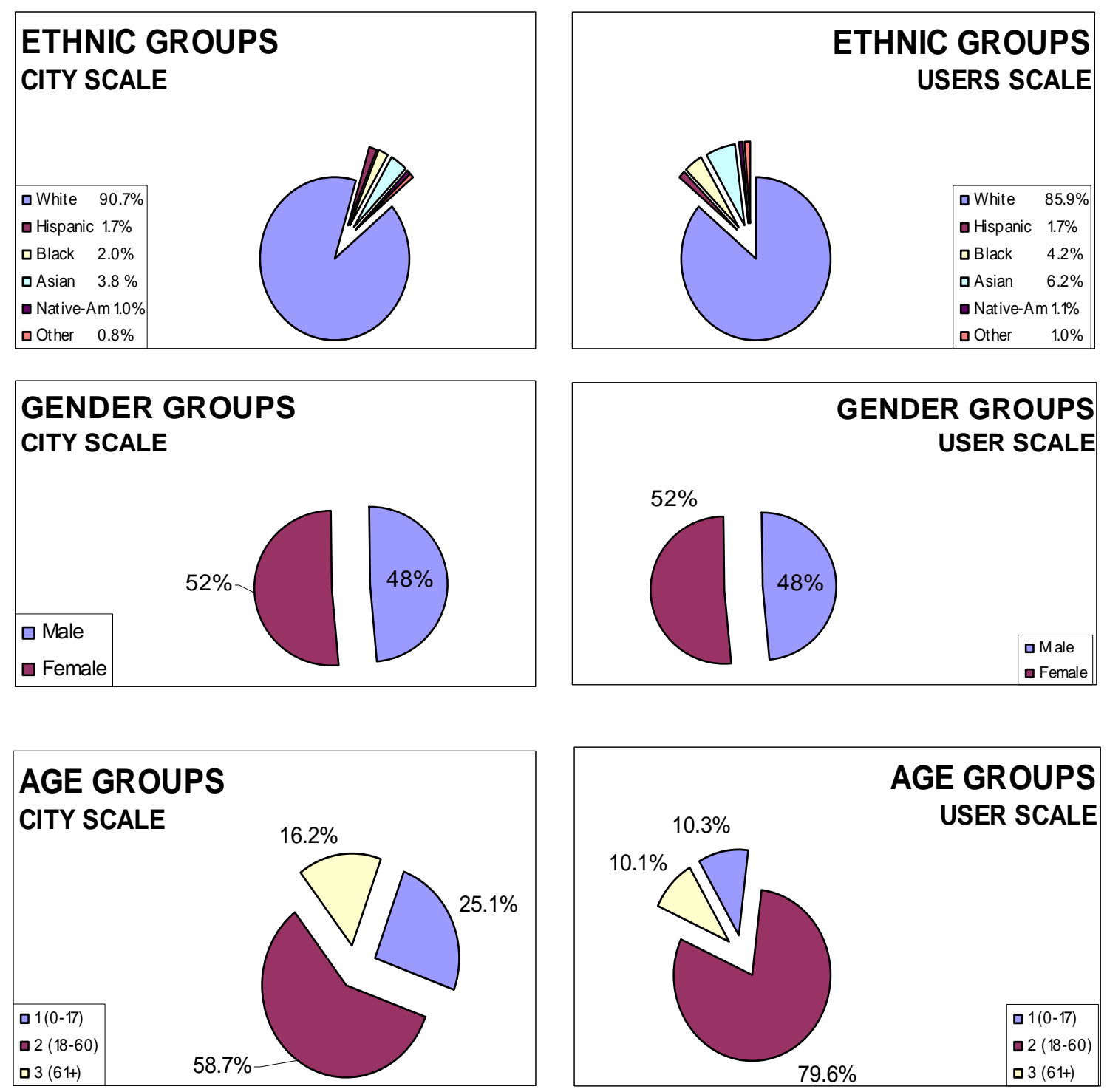

Figure. No. 5.4. Comparative of Ethnic, Gender and Age Groups in Seattle

Due to the narrow ethnic diversity in Seattle (even narrower than Columbus), the analysis was made comparing whites versus non-whites. Population shares and average trip characteristics of bus users (with complete information) are indicated in the next table. The legal age to apply for a driver license in the city of Seattle is 18 years old, therefore age groups were classified as 17 and under (youth), 18 to 60 (working class), and $61+$ (seniors). The first age group of bus riders includes most of the non-working youth while the third one includes most of the non-working retired seniors.

Table No. 5.7 shows average trip characteristics by demographic group. The population share of each group is indicated as a percentage of the bus user population. 
Table No. 5.7. Average Characteristics by Demographic Group of Bus Riders

\begin{tabular}{|c|c|c|c|c|c|c|}
\hline $\begin{array}{l}\text { SEATTLE } \\
\text { Group }\end{array}$ & $\begin{array}{c}\text { Pop } \\
\text { Share }\end{array}$ & $\begin{array}{l}\text { Distance } \\
\text { (miles)* }\end{array}$ & $\begin{array}{c}\text { Time } \\
\text { (minutes)* }\end{array}$ & $\begin{array}{l}\text { Speed } \\
(\mathrm{mph}) \\
\end{array}$ & $\begin{array}{c}f p m \\
\text { (cents/mile) }\end{array}$ & $\begin{array}{c}\text { tpm } \\
(\mathrm{min} / \mathrm{mile})\end{array}$ \\
\hline \multicolumn{7}{|l|}{ INCOME GROUPS } \\
\hline Lower & 33.3 & 12.35 & 71.77 & 9.93 & 24.94 & 9.55 \\
\hline Middle & 33.3 & 13.60 & 65.48 & 11.52 & 28.00 & 8.22 \\
\hline Higher & 33.3 & 13.65 & 61.53 & 12.19 & 26.50 & 8.05 \\
\hline \multicolumn{7}{|l|}{ ETHNIC GROUPS } \\
\hline Whites & 85.5 & 12.79 & 63.38 & 11.27 & 26.79 & 8.56 \\
\hline Non-whites & 14.5 & 14.07 & 79.50 & 10.94 & 25.12 & 8.35 \\
\hline \multicolumn{7}{|l|}{ GENDER GROUPS } \\
\hline Males & 44.9 & 14.38 & 67.99 & 12.10 & 24.57 & 8.02 \\
\hline Females & 55.1 & 11.84 & 63.87 & 10.50 & 28.16 & 8.95 \\
\hline \multicolumn{7}{|l|}{ AGE GROUPS } \\
\hline Youth: 0-17 years & 9.0 & 4.77 & 37.01 & 9.43 & 33.34 & 11.78 \\
\hline Working:17-60years & 79.7 & 14.51 & 70.41 & 11.69 & 27.16 & 7.92 \\
\hline Seniors: $61+$ years & 11.3 & 8.70 & 55.52 & 9.33 & 16.82 & 10.22 \\
\hline
\end{tabular}

* Distance and time refer to total amounts traveled per person in one day. Differences greater than $15 \%$ are shown in bold.

The table shows that lower income groups travel shorter distances for longer periods of time on average. This is confirmed given the slower speeds (or greater tpm) than the other two income groups. Regarding fare spent on bus service, they appear to pay lower amounts in absolute terms compared to the other two groups. In a per-mile basis, bus users in Seattle appear to also pay lower fares per mile on average. That is, lower income groups appear to receive a lower quality service in terms of speed, but they also appear to pay a lower fpm on average.

The table shows in bolds differences greater than $15 \%$ for each demographic group. In the case of ethnic groups, whites appear to travel shorter distances for shorter periods of time, however -on average- no significant difference is observed in terms of tpm or fpm. This implies that different ethnic groups receive similar quality of service in terms of speed. Regarding gender groups, males appear to travel longer distances for slightly higher periods of time. However, no significant difference is observed in terms of speed (tpm). Males appear though, to pay lower rates of fpm than women, on average.

With respect to age groups, younger groups appear to travel shorter distances and travel for shorter periods of time than the other two groups. This may be explained probably because students tend to live closer to education centers. The average of Y also appears to be slower than W's and their rates of fpm appear to be higher compared W and $\mathrm{S}$. That is, not only do they pay higher fpm but they also receive a lower quality service in terms of speed compared to the other two groups.

The average trip characteristics does not indicate any evidence of statistical difference among demographic groups. It is possible that the difference in average is due to outlying values that take away the average from the real population mean. Extreme 
outlying values however, were taken out of the analysis, i.e. unreasonable values greater than logical maximum values for distance $(<55 \mathrm{mi})$, travel time $(<150 \mathrm{~min})$ and fare paid $(<4$ dlls). The real difference is revealed with statistical evidence using the $t$-student analysis next.

\section{Statistical Differences by t-Statistics Analysis in Seattle}

Table No. 5.8 indicates statistical differences found among demographic groups using the $t$-test analysis. Income groups, categories: low $(\mathrm{L})$, middle $(\mathrm{M})$, and high $(\mathrm{H})$, were tested one against each other. Ethnic groups were tested: white (W) vs. non-white (NW); and gender groups: males (M) vs. females (F). Age groups, categories: youth -17 or less $(\mathrm{Y})$, working class - ages 18 to $60(\mathrm{~W})$, and seniors $-60+(\mathrm{S})$, were also tested one against each other.

As explained in the section of Columbus, an important note in the statistical differences found should be mentioned here. A statistical difference $(<0.05)$ in speed does not necessarily is followed by a statistical difference in tpm. Even though tpm is the inverse of speed, the 'bell-shaped' distributions of these two variables are not necessarily symmetrical. The $t$-test is testing opposite sides of their distributions. In general, a pattern is observed, e.g. if a low p-value is found in speed for $\mathrm{H}$ compared to $\mathrm{L}$, it is very likely that a low p-value will be observed in L compared to $\mathrm{H}$. If this pattern is not observed, it is very likely that there is no significant difference between these two demographic groups. 
Table No. 5.8. Statistical Differences by Demographic Group in Seattle

\begin{tabular}{|c|c|c|c|c|c|c|}
\hline & & Distance & Time & Speed & fpm & tpm \\
\hline \multicolumn{4}{|c|}{ INCOME GROUPS } & \multicolumn{3}{|c|}{ Ho: diff $=$ mean $(1 s t)-$ mean $(2 n d)=0$} \\
\hline \multirow{3}{*}{ 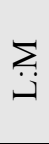 } & Ha: $\operatorname{diff}<0$ & 0.1748 & 0.9203 & 0.0162 & 0.2320 & 0.9495 \\
\hline & Ha: $\operatorname{diff} \neq 0$ & 0.3497 & 0.1594 & 0.0324 & 0.4641 & 0.1010 \\
\hline & Ha: $\operatorname{diff}>0$ & 0.8552 & 0.0797 & 0.9838 & 0.7680 & 0.0505 \\
\hline \multirow{3}{*}{$\stackrel{\square}{\dot{\Sigma}}$} & Ha: $\operatorname{diff}<0$ & 0.4815 & 0.6339 & 0.3377 & 0.5150 & 0.5817 \\
\hline & Ha: $\operatorname{diff} \neq 0$ & 0.9631 & 0.7322 & 0.6753 & 0.9699 & 0.8366 \\
\hline & Ha: $\operatorname{diff}>0$ & 0.5185 & 0.3661 & 0.6623 & 0.4850 & 0.4183 \\
\hline \multirow{3}{*}{ } & Ha: $\operatorname{diff}<0$ & 0.1590 & 0.9553 & 0.0035 & 0.2531 & 0.9409 \\
\hline & Ha: $\operatorname{diff} \neq 0$ & 0.3180 & 0.0894 & 0.0071 & 0.5062 & 0.1182 \\
\hline & Ha: $\operatorname{diff}>0$ & 0.8410 & 0.0447 & 0.9965 & 0.7469 & 0.0591 \\
\hline \multicolumn{7}{|c|}{ ETHNIC GROUPS } \\
\hline \multirow{3}{*}{$\underset{3}{3}$} & Ha: $\operatorname{diff}<0$ & 0.2520 & 0.0051 & 0.6239 & 0.6787 & 0.5834 \\
\hline & Ha: $\operatorname{diff} \neq 0$ & 0.5040 & 0.0103 & 0.7521 & 0.6427 & 0.8332 \\
\hline & Ha: $\operatorname{diff}>0$ & 0.7480 & 0.9949 & 0.3761 & 0.3213 & 0.4166 \\
\hline \multicolumn{7}{|c|}{ GENDER GROUPS } \\
\hline \multirow{3}{*}{$\stackrel{\Gamma}{\dot{\Sigma}}$} & Ha: $\operatorname{diff}<0$ & 0.9699 & 0.8226 & 0.9868 & 0.0786 & 0.0924 \\
\hline & Ha: $\operatorname{diff} \neq 0$ & 0.0601 & 0.3549 & 0.0264 & 0.1573 & 0.1848 \\
\hline & Ha: $\operatorname{diff}>0$ & 0.0301 & 0.1774 & 0.0132 & 0.9214 & 0.9076 \\
\hline \multicolumn{7}{|c|}{ AGE GROUPS } \\
\hline \multirow{3}{*}{$\underset{\ddot{\nu}}{\ddot{z}}$} & Ha: $\operatorname{diff}<0$ & 0.0000 & 0.0000 & 0.0399 & 0.9179 & 0.9994 \\
\hline & Ha: $\operatorname{diff} \neq 0$ & 0.0001 & 0.0000 & 0.0798 & 0.1643 & 0.0012 \\
\hline & Ha: $\operatorname{diff}>0$ & 1.0000 & 1.0000 & 0.9601 & 0.0821 & 0.0006 \\
\hline \multirow{3}{*}{$\stackrel{\mathscr{n}}{\ddot{3}}$} & Ha: $\operatorname{diff}<0$ & 0.9961 & 0.9816 & 0.9827 & 0.9956 & 0.0063 \\
\hline & Ha: $\operatorname{diff} \neq 0$ & 0.0079 & 0.0368 & 0.0345 & 0.0088 & 0.0126 \\
\hline & Ha: $\operatorname{diff}>0$ & 0.0039 & 0.0184 & 0.0173 & 0.0044 & 0.9937 \\
\hline \multirow{3}{*}{$\stackrel{\mathscr{\varphi}}{\ddot{\nu}}$} & Ha: $\operatorname{diff}<0$ & 0.0030 & 0.0019 & 0.5261 & 0.9980 & 0.7387 \\
\hline & Ha: $\operatorname{diff} \neq 0$ & 0.0059 & 0.0039 & 0.9478 & 0.0039 & 0.5226 \\
\hline & Ha: $\operatorname{diff}>0$ & 0.9970 & 0.9981 & 0.4739 & 0.0020 & 0.2613 \\
\hline
\end{tabular}

* Smaller values are shown in a larger font size and significant differences $(<0.05)$ are in bold.

\section{INCOME GROUPS}

No significant difference in distance traveled was found between income groups. Only a slight tendency for shorter distances traveled by L compared to $\mathrm{M}$ and $\mathrm{H}$, but not significant at the $5 \%$ level. There is however a significant difference in travel time; $\mathrm{L}$ appears to travel for longer periods of time compared to $\mathrm{M}$ and $\mathrm{H}$. The difference is significant at the 5\% level when $\mathrm{L}$ and $\mathrm{H}$ are compared. This finding, in addition to the numbers close to the $5 \%$ level of tpm and the statistical difference shown in speed $(<5 \%)$ are evidence that $\mathrm{L}$ travels at slower speeds compared to $\mathrm{M}$ and $\mathrm{H}$. On the other hand, a slight tendency indicates that $\mathrm{L}$ pays lower rates of fpm compared to $\mathrm{M}$ and $\mathrm{H}$. In other words, $\mathrm{L}$ receives a lower quality service in terms of speed, but it also pays lower rates of $\mathrm{fpm}$, which in a way is in accordance with the service received. 
Accordingly to what the averages indicated in Table No. 5.7, the $t$-test results of Table No. 5.8 show slight tendencies indicating that $L$ travels shorter distances for longer periods of time compared to $\mathrm{M}$ and $\mathrm{H}$. Even though $\mathrm{L}$ receives a lower quality service in terms of speed compared to $\mathrm{M}$ and $\mathrm{H}$ at the $5 \%$ confidence level, a tendency is observed showing that L pays lower fpm, though not statistically significant. In short, it was found the following results which resemble very closely the average values from Table No. 5.7. Statistical differences at 5\% C.L. are in italic-bolds and the subscript represents the reference, e.g. in Speed, $\boldsymbol{H}_{\boldsymbol{L}}>\boldsymbol{L}_{\boldsymbol{H}}$ means that there is a difference in travel speed between $\mathrm{H}$ and $\mathrm{L}$ at the $5 \% \mathrm{C} . \mathrm{L}$ ( $\mathrm{H}$ travels faster than $\mathrm{L}$ ). There is no significant difference between $\mathrm{M}$ and $\mathrm{H}$ though ( $\mathrm{M}$ and $\mathrm{H}$ may travel at similar speeds):

$\begin{array}{llllll}\text { Distance: } & \mathrm{H} & > & \mathrm{M} & > & \mathrm{L} \\ \text { Time: } & \boldsymbol{L}_{\boldsymbol{H}} & > & \boldsymbol{H}_{\boldsymbol{L}} & > & \mathrm{M} \\ \text { Speed: } & \boldsymbol{H}_{L} & > & \boldsymbol{M}_{\boldsymbol{L}} & > & \boldsymbol{L}_{M, \boldsymbol{H}} \\ \text { tpm: } & \boldsymbol{L}_{\boldsymbol{H}, \boldsymbol{M}}> & \boldsymbol{M}_{\boldsymbol{L}} & > & \boldsymbol{H}_{\boldsymbol{L}} \\ \text { fpm: } & \mathrm{M} & > & \mathrm{L} & > & \mathrm{H}\end{array}$

\section{ETHNIC GROUPS}

In regard to the analysis by ethnic groups, no significant difference was found on distance traveled but a significant difference was found in travel time. NW spend periods of time significantly longer than $\mathrm{W}$ at the $5 \%$ level, while there is a slight tendency indicating that they also travel longer distances (though not statistically significant). The apparently contradictory numbers of tpm and speed, and given the high values (meaning "is not likely that-") for Ha: diff $\neq 0$, suggest that speeds are most likely similar. This is also observed in the average values given in Table No. 5.7. On the other hand, no significant difference is observed in $\mathrm{fpm}$. This suggests that for relatively similar quality of service (in terms of speed), these two groups pay relatively similar rates of fpm. Results are shown here (in bolds and italics are shown the statistical differences at 5\% C.L.):

$\begin{array}{llll}\text { Distance: } & \mathrm{W} & > & \mathrm{NW} \\ \text { Time: } & \mathrm{NW}_{W}> & \mathbf{W}_{N W} \\ \text { Speed: } & \mathrm{W} & > & \mathrm{NW} \\ \text { tpm: } & \mathrm{NW}> & \mathrm{W} \\ \text { fpm: } & \mathrm{W} & > & \mathrm{NW}\end{array}$

\section{GENDER GROUPS}

Regarding gender groups, a significant difference was found indicating that $\mathrm{M}$ travels longer distances than F; this is significant at the 5\% level. A slight tendency also indicates that $\mathrm{M}$ travels for longer periods of time, though not statistically significant. It is also found that $\mathrm{M}$ travels faster; this is statistically significant in terms of speed and suggested by tpm. The average values of tpm in Table No. 5.7 and the tendency suggested in Table No. 5.8, suggest that $\mathrm{M}$ receives a better quality of service in terms of speed for which apparently pays lower rates of fpm. However, the p-value is $0.0786(>0.05)$, 
therefore not statistically significant at the 5\% level. Results are summarized in the table (in bolds and italics are differences at 5\% C.L.):

$\begin{array}{llll}\text { Distance: } & \boldsymbol{M}_{\boldsymbol{F}}> & \boldsymbol{F}_{\boldsymbol{M}} \\ \text { Time: } & \mathrm{M} & > & \mathrm{F} \\ \text { Speed: } & \boldsymbol{M}_{\boldsymbol{F}} & > & \boldsymbol{F}_{\boldsymbol{M}} \\ \text { tpm: } & \mathrm{F} & > & \mathrm{M} \\ \text { fpm: } & \mathrm{F} & > & \mathrm{M}\end{array}$

\section{AGE GROUPS}

The analysis by age groups provides statistical evidence that $\mathrm{Y}$ travels shorter distances and travels for shorter periods of time compared to $\mathrm{W}$ and $\mathrm{S}$. On the other hand, there is statistical evidence indicating that $S$ travels shorter distances and travels for shorter periods of time compared to $\mathrm{W}$. The values for speed and tpm provide evidence that $\mathrm{W}$ travels faster than $\mathrm{Y}$ and $\mathrm{S}$. No significant difference was found between $\mathrm{Y}$ and $\mathrm{S}$, suggesting that their speeds are most likely similar. In regard to fpm, $\mathrm{S}$ is found to pay lower rates of fpm compared to $\mathrm{W}$ and $\mathrm{Y}$, and a slight tendency indicating that $\mathrm{Y}$ pays probably higher rates of fpm compared to $\mathrm{W}$, though not statistically significant. From these three groups, $\mathrm{Y}$ is found to be the most disadvantaged, given that travels slower and pays higher rates of fpm. In short, results are summarized as follows (statistical differences at 5\% C.L. are shown in bolds and italics):

$\begin{array}{llll}\text { Distance: } & W_{Y, S}> & S_{Y, W}> & Y_{W, S} \\ \text { Time: } & W_{Y, S}> & S_{Y, W}> & Y_{W, S} \\ \text { Speed: } & W_{Y, S}> & S_{W}> & \boldsymbol{Y}_{W} \\ \text { tpm: } & \boldsymbol{Y}_{W}> & \boldsymbol{S}_{W}> & W_{Y, S} \\ \text { fpm: } & \boldsymbol{Y}_{W}> & W_{S}> & S_{Y, W}\end{array}$

\section{Inequality Measurements in Seattle}

Table No. 5.9 - Inequality Measurements by Demographic Group in Seattle, provides the Gini coefficient, the General Entropy (GE) and Atkinson inequality indices by column (the last two show indices for different parameters). The analysis for each demographic group (by income, ethnicity, gender and age) consists of 4 clusters containing index measurements for: 1) income inequality at the city level, 2) income inequality at the bus users level, 3) consumption inequality in fpm, and 4) consumption inequality in tpm. In this section, consumption inequalities in fpm and tpm are compared to income inequality at the city and bus users' level.

At the top of each cluster, the overall inequality indices are shown in bolds. For example, in the analysis by income groups the income inequality at the city level (first box), shows that the overall Gini coefficient is 0.304 , the Theil index [given by GE(1)] is 0.149 , and the Atkinson index [considering $\mathrm{A}(1)$ ] is 0.159 . Besides the overall Gini coefficient, Gini values are also give for each category, for example for the first demographic group (by income groups), and in the cluster for income inequality at the 
city level, the Gini values are $\mathrm{L}=0.185$, for $\mathrm{M}=0.081$, and for $\mathrm{H}=0.127$. This is indicated for every category for each one of the four clusters, and for each one of the four demographic groups.

Contrary to Gini, the Theil and Atkinson indices are additively decomposable, that is inequality within group plus inequality between groups equals the overall index (within + between $=$ overall). For example, for the demographic group by income, for the cluster 'income inequality at the city level', the overall Theil index $[\mathrm{GE}(1)]=0.028$ (within) +0.121 (between) $=0.149$. The first page of the table provides the inequality measures for income and ethnic groups, and the second page provides measurements for gender and age groups. The indices in the tables are shown per user only (i.e. travel information aggregated by bus user).

The Gini coefficient is most sensitive to income differences about the middle (more precisely, the mode), while the Theil and Atkinson indices depend on the parameter (a) or (e) that is used. The table provides different generalized entropy indices or GE(a), where the more negative (a) is, the more sensitive it is to differences at the bottom of the distribution. On the other hand, the Atkinson index is provided by A(e), in which the more positive $\mathrm{e}$ is ( $\mathrm{e}>0$, the inequality aversion parameter), the more sensitive $\mathrm{A}(\mathrm{e})$ is to income differences at the bottom of the distribution. The indices corresponding to inequality within and between groups are ordered from most sensitive to differences at the bottom of the distribution, down to most sensitive to differences at the top of the distribution.

\section{GINI COEFFICIENT}

In Table No. 5.9, the overall Gini coefficients indicate that bus users' income inequality (0.322) is greater than the city's income inequality $(0.304)$. This means that there is more income inequality among bus users compared to the income inequality at the city scale. Now, assuming that income and consumption inequality are comparable for the city of Seattle, the inequality in fpm paid by users (0.481) is much higher than the income inequality of bus users and even more compared at the city level. That is, the bus transit system does not appear to help reduce the existing inequality at the users' level and at the city level. The inequality in tpm is found to be less unequal $(0.386)$ than in $f p m$ compared to city and users' income inequalities. Since these are overall values, these should be equal for all four demographic groups, however slight variations are observed since some records were not considered if they lacked information regarding ethnicity, gender or age. The Gini values for each category of each demographic group are compared to income inequality next, at both levels of analysis: city and users.

Income inequality among the middle income group is the lowest at the city and users scale (0.081 and 0.065). On the other hand, $M$ appears with lower-than-average values in consumption inequality for both fpm (0.472) and tpm (0.379). L appears with the greatest inequality in fpm (0.497) and $\mathrm{H}$ with the greatest inequality in tpm (0.405). These numbers indicate considerable equality within $\mathrm{M}$ regarding income and resources spent in using the bus system compared to the other two groups, $\mathrm{L}$ and $\mathrm{H}$. 
The analysis by ethnic groups reveals that income inequality is greater for NW than for W at the city and users' scale: 0.328 vs. 0.301 and 0.394 vs. 0.309 . That is, NW appear to have a wide range of income -at both levels- compared to W. However, the opposite happens in consumption inequality for fpm and tpm, where fpm and tpm appear to have lower-than-average values ( 0.470 vs. 0.481 and 0.356 vs. 0.386 , respectively). The inequality in fpm however, does not appear to be significantly different between these two groups.

The analysis by gender groups shows that income inequality is almost equal for $\mathrm{M}$ and $\mathrm{F}$ at the city scale $(0.303,0.304)$ and slightly greater for $\mathrm{F}$ at the users' scale $(0.326)$. This is not surprising since survey interviewees reported household income instead of individual income (where households most likely include one male and one female). The inequality increases at the bus users' scale since probably the percentage of households headed by females also increase. Regarding consumption inequality, it is found more fpm inequality for $\mathrm{F}$ than for $\mathrm{M}(0.490$ vs. 0.466$)$. The opposite happens for tpm inequality $(0.383$ vs. 0.386$)$, though here the inequality is less significant.

The analysis by age groups indicates the highest income inequality in $\mathrm{S}(61+)$ at the city and users' scale ( 0.315 and 0.334 , respectively). They also show the highest consumption inequality in fpm compared to the other two groups $(0.582-\mathrm{S}$ vs. $0.471-\mathrm{W}$ and $0.394-Y$ ), which portrays them as the most disadvantaged group of all three in this sense. Members of this group appear to be paying very differently from one another. Just like in the case of Columbus, this is the highest inequality value found among categories of all groups. One possibility is that some senior users take advantage of special fares and passes for the service and others do not. With regard to consumption inequality in tpm, Y appears with the highest inequality value, 0.416 , compared to the other two groups. It is possible that the time of day of their travel varies much more than for the other two groups, that is peak/off-peak. This has a direct effect in speed and tpm, thus increasing disparity.

\section{THEIL AND ATKINSON INDICES}

As mentioned previously, the Generalized Entropy [GE(a)] and Atkinson [A(e)] indices are additively decomposable (within + between $=$ overall index). In the analysis by income groups, the income inequality at the city and users' level is mostly due to inequality between groups rather than within groups. Given that no individual income was reported in the survey and that the income used for these calculations was the individual equivalent income, it is possible that this procedure had an effect reducing the within-group inequality and increasing the between-group inequality. In contrast, consumption inequality in fpm and tpm comes mostly from within the groups. As in the case of Columbus, between-group inequalities are only higher in the analysis of income inequality by income groups, at both levels of analysis: city and users. In all other cases, most of the inequality is due to inequality within the groups and not between groups. 
The analysis also shows more income inequality at the bus users' scale than at the city scale (Theil: 0.172 vs. 0.149 , and Atkinson: 0.191 vs. 0.159 ). The indices for fpm and tpm both show greater inequality compared to income inequality at the city and users' scale. Depending on the parameters used, higher ratings of inequality are found using parameters more sensitive to differences at the bottom of the distribution.

\begin{tabular}{|r|c|c|c|c|}
\hline & City & Users & fpm & tpm \\
\hline Theil: & 0.149 & 0.172 & 0.403 & 0.271 \\
\hline Atkinson: & 0.159 & 0.191 & 0.346 & 0.223 \\
\hline
\end{tabular}

The analysis for ethnic, gender and age groups show similar conclusions than that for income groups. That is, for GE, higher ratings of inequality within groups are found using parameters more sensitive to differences at the bottom of the distribution, except for tpm where more inequality is found at the top of the distribution. Lower ratings of inequality within groups are found at the middle of the distribution. The Atkinson indices show in all cases higher ratings of inequality using parameters more sensitive to differences at the bottom of the distribution, within and between groups. 
Table No. 5.9. Inequality Measurements by Demographic Group in Seattle

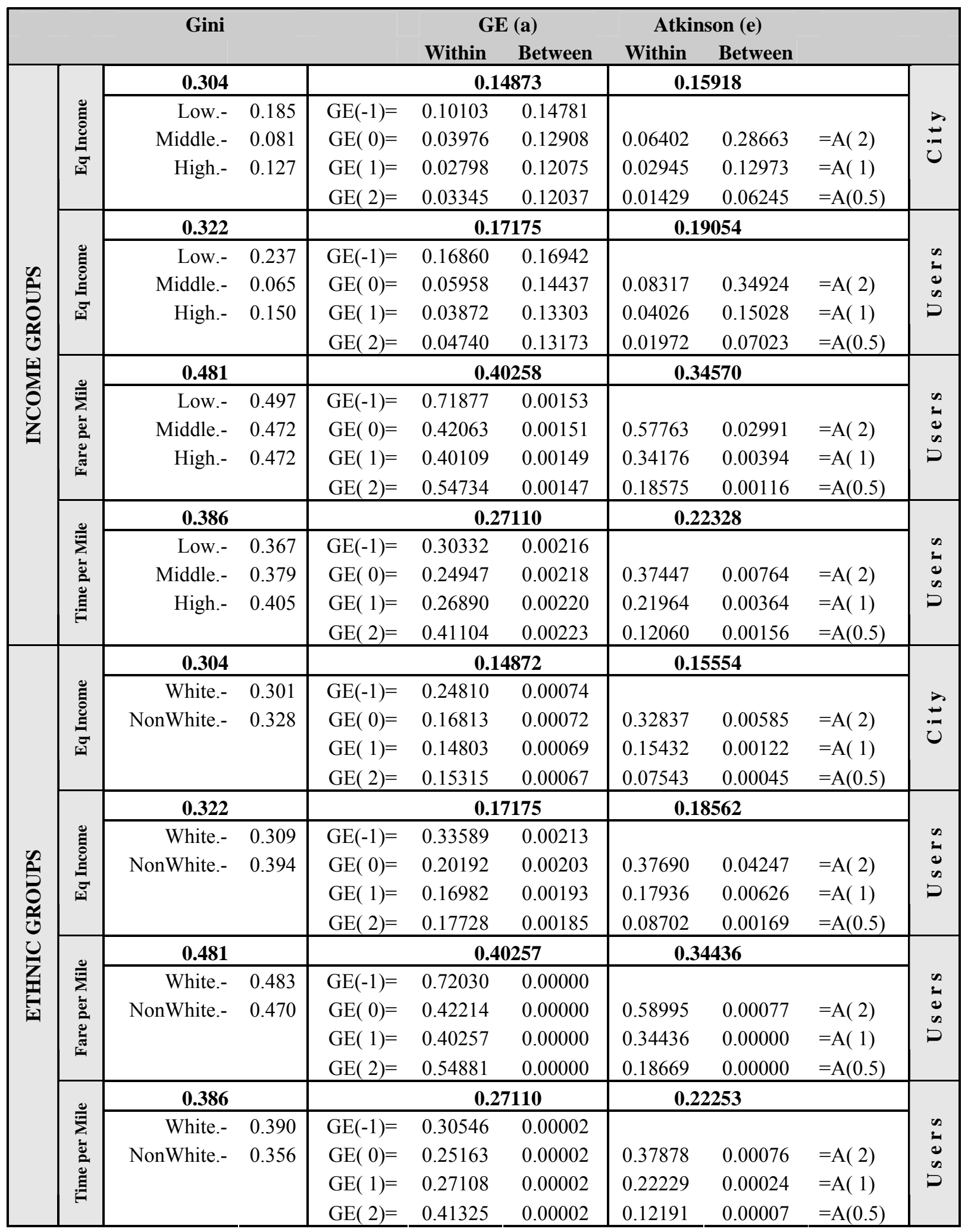


Table No. 5.9. Inequality Measurements by Demographic Group in Seattle (Cont.)

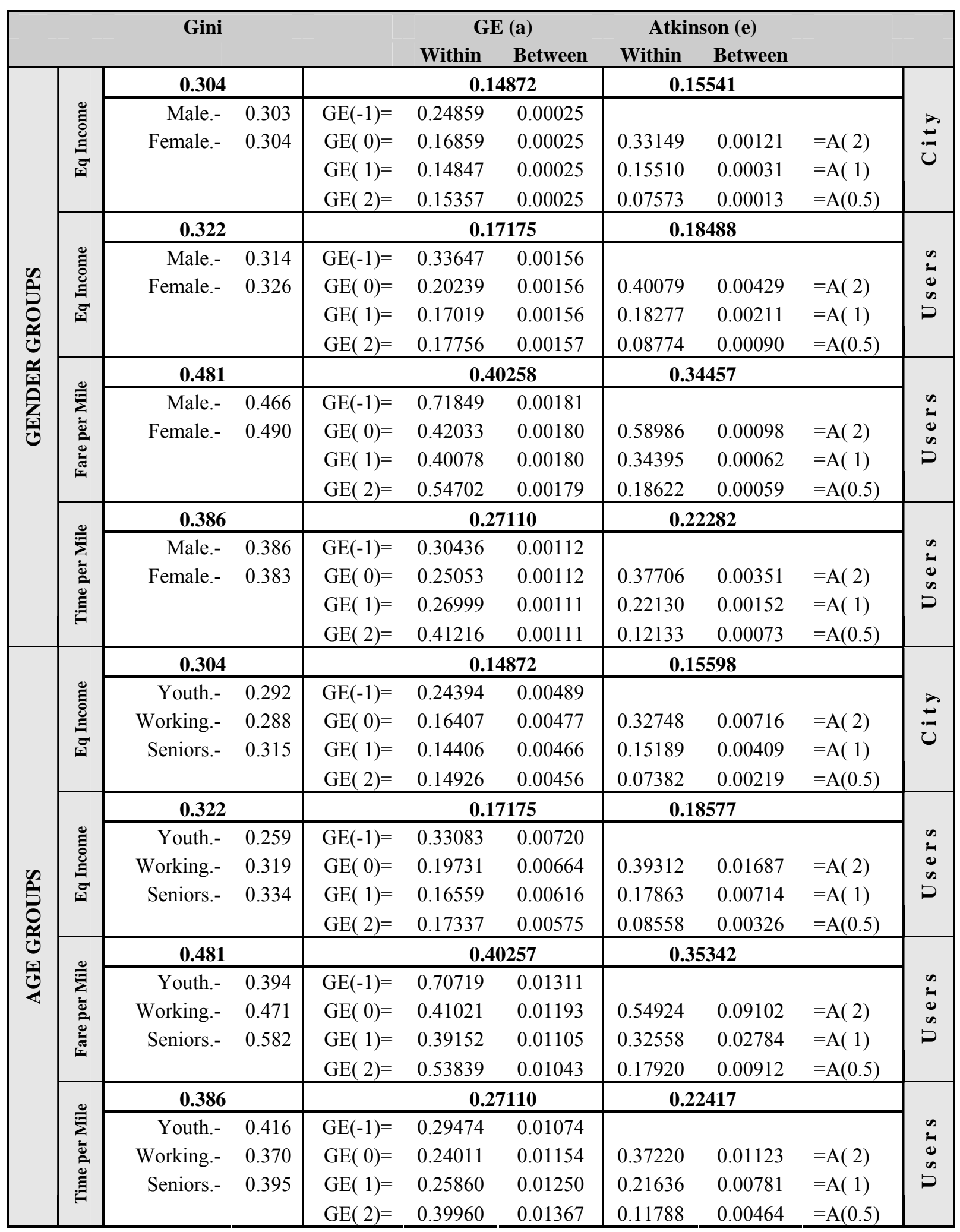




\section{Contrast between Cities: Columbus vs. Seattle}

In this section, the relative differences between income inequality and consumption inequality ( $\mathrm{fpm}$ and tpm) found in the cities of Columbus and Seattle, are compared at the city and users' scales separately. This comparison is called "difference in differences" between cities, and indicates which bus transit system is doing better or worse in reducing the existing inequality in each city.

\section{Comparing Overall Inequality Indices Between Cities}

\section{COLUMBUS VS. SEATTLE}

Fare per mile

* Comparing consumption inequality in fpm to income inequality using the overall Gini index

City Scale

$$
\begin{aligned}
\frac{{ }^{B} \operatorname{Gini}_{(f p m)}-{ }^{C} \operatorname{Gini}_{(I N C)}}{{ }^{C} \operatorname{Gini}_{(I N C)}} & \Leftrightarrow \frac{{ }^{B} \operatorname{Gini}_{(f p m)}-{ }^{C} \operatorname{Gini}_{(I N C)}}{{ }^{C} \operatorname{Gini}_{(I N C)}} \\
\frac{0.386-0.338}{0.338} & \Leftrightarrow \frac{0.481-0.304}{0.304} \\
0.142 & \Leftrightarrow 0.582
\end{aligned}
$$

This indicates that in Columbus the overall inequality found in fpm compared to the city's income inequality, is greater by 14 percent. In Seattle on the other hand, the inequality is even greater, 58 percent.

User Scale

$$
\begin{aligned}
\frac{{ }^{B} \operatorname{Gini}_{(f p m)}-{ }^{B} \operatorname{Gini}_{(I N C)}}{{ }^{B} G i n i_{(I N C)}} & \Leftrightarrow \frac{{ }^{B} G i n i_{(f p m)}-{ }^{B} G i n i_{(I N C)}}{{ }^{B} G i n i_{(I N C)}} \\
\frac{0.386-0.385}{0.385} & \Leftrightarrow \frac{0.481-0.322}{0.322} \\
0.003 & \Leftrightarrow 0.494
\end{aligned}
$$

At the users' scale, the overall fpm inequality appears to be less significant than at the city scale. That is, the transit service appears to mitigate the inequality in both cities. However, the contribution of Columbus' transit agency appears to do a better job, reducing it significantly from 0.142 to 0.003 , a $98 \%$ decrease, compared to a $15 \%$ decrease in Seattle, from 0.582 to 0.494 . 


\section{COLUMBUS Vs. SEATTLE}

Time per mile

* Comparing consumption inequality in tpm to income inequality using the overall Gini index

City Scale

$$
\begin{aligned}
\frac{{ }^{B} \operatorname{Gini}_{(t p m)}-{ }^{C} \operatorname{Gini}_{(I N C)}}{{ }^{C} \operatorname{Gini}_{(I N C)}} & \Leftrightarrow \frac{{ }^{B} \operatorname{Gini}_{(\text {tpm })}-{ }^{C} \operatorname{Gini}_{(I N C)}}{{ }^{C} G i n i_{(I N C)}} \\
\frac{0.356-0.338}{0.338} & \Leftrightarrow \frac{0.386-0.304}{0.304} \\
0.05 & \Leftrightarrow 0.27
\end{aligned}
$$

In regard to tpm, comparing at the city's income inequality, both cities appear to have a much lower inequality than that of fpm. The city of Seattle though, has a considerably higher degree of inequality compared to Columbus, considering overall numbers at the city scale.

Users' Scale

$$
\begin{aligned}
\frac{{ }^{B} \operatorname{Gini}_{(t p m)}-{ }^{B} \operatorname{Gini}_{(I N C)}}{{ }^{B} \operatorname{Gini}_{(I N C)}} & \Leftrightarrow \frac{{ }^{B} \operatorname{Gini}_{(t p m)}-{ }^{B} \operatorname{Gini}_{(I N C)}}{{ }^{B} G i n i_{(I N C)}} \\
\frac{0.356-0.385}{0.385} & \Leftrightarrow \frac{0.386-0.322}{0.322} \\
-0.07 & \Leftrightarrow 0.20
\end{aligned}
$$

Comparing tpm with income inequality at the bus users' scale, Columbus' transit agency appears to actually help diminish the inequality in that respect. The negative number indicates that Columbus transit, instead of increasing the inequality, helps reduce inequality. Seattle, on the other hand appears with a 20 percent higher inequality than that of user's income inequality.

Comparing inequality at the city and users' scales, it is found that Columbus' transit observes a much greater improvement in decreasing inequality than Seattle $(240 \%$ vs. $26 \%$ ). 


\section{Comparing Between-Group Inequality Indices Between Cities}

Now, as explained in the 'Theil and Atkinson Indices' sections, much of the inequality is due to inequality within groups, rather than between groups. A transit agency cannot do much about reducing within-group inequalities, but can help reduce inequalities between groups. If a closer look at the between-group inequality is sought in the analysis, then using the between-group indices provides further information.

Comparing between-group inequalities with parameters sensitive to differences at the bottom of the distribution provides a more detailed analysis at that level. In the next calculations, results are compared using indices given by GE(-1) in both cities.

\section{COLUMBUS VS. SEATTLE}

Fare per mile

* Comparing inequality in fpm to income inequality using between-group inequality indices.

City Scale

$$
\begin{aligned}
\frac{{ }^{B} G E_{(f p m)}-{ }^{C} G E_{(I N C)}}{{ }^{C} G E_{(I N C)}} & \Leftrightarrow \frac{{ }^{B} G E_{(f p m)}-{ }^{C} G E_{(I N C)}}{{ }^{C} G E_{(I N C)}} \\
\frac{0.024-0.159}{0.159} & \Leftrightarrow \frac{0.002-0.148}{0.148} \\
-0.85 & \Leftrightarrow-0.99
\end{aligned}
$$

User Scale

$$
\begin{aligned}
\frac{{ }^{B} G E_{(f p m)}-{ }^{B} G E_{(I N C)}}{{ }^{B} G E_{(I N C)}} & \Leftrightarrow \frac{{ }^{B} G E_{(f p m)}-{ }^{B} G E_{(I N C)}}{{ }^{B} G E_{(I N C)}} \\
\frac{0.024-0.421}{0.421} & \Leftrightarrow \frac{0.002-0.169}{0.169} \\
-0.94 & \Leftrightarrow-0.99
\end{aligned}
$$

The analysis of between-group indices shows that the inequality gap between cities is much less significant from this particular point of view. That is, they are not very different from each other. At first sight, the city of Seattle appears to be doing a better job in decreasing between-group inequalities than Columbus (reducing inequality at a higher percentage). However, Columbus achieves a decrease of inequality by $10.6 \%$ (from 0.85 to -0.94 ). Nevertheless, Seattle does not have much room for improvement since inequality between groups is already low for that city. 
COLUMBUS Vs. SEATTLE

Time per mile

* Comparing inequality in tpm to income inequality using between-group inequality indices.

City Scale

$$
\begin{aligned}
\frac{{ }^{B} G E_{(t p m)}-{ }^{C} G E_{(I N C)}}{{ }^{C} G E_{(I N C)}} & \Leftrightarrow \frac{{ }^{B} G E_{(t p m)}-{ }^{C} G E_{(I N C)}}{{ }^{C} G E_{(I N C)}} \\
\frac{0.017-0.159}{0.159} & \Leftrightarrow \frac{0.002-0.148}{0.148} \\
-0.89 & \Leftrightarrow-0.99
\end{aligned}
$$

Users' Scale

$$
\begin{aligned}
\frac{{ }^{B} G E_{(f p m)}-{ }^{B} G E_{(I N C)}}{{ }^{B} G E_{(I N C)}} & \Leftrightarrow \frac{{ }^{B} G E_{(f p m)}-{ }^{B} G E_{(I N C)}}{{ }^{B} G E_{(I N C)}} \\
\frac{0.017-0.421-}{0.421} & \Leftrightarrow \frac{0.002-0.169}{0.169} \\
-0.96 & \Leftrightarrow-0.99
\end{aligned}
$$

Just like in the analysis for fpm, Seattle shows a relative improvement in performance when looking at between-group differences. Columbus appears to have a better performance at the users' level than at the city level. In that sense, the transit system is helping to balance inequalities among users. A reduction of $7.9 \%$ is attained by the transit agency in Columbus (from -0.89 to -0.96). Seattle again, has not much room for improvement since between-group inequalities are already low.

Even though income inequality at the city and users' level are lower in the city of Seattle than in the city of Columbus, the larger inequalities in fpm and tpm situates Seattle with a higher degree of inequality than Columbus when overall indices are used in the analysis. Since most of the inequality in fpm and tpm in both cities comes from within group and not from between groups, this method allows to compare particular inequalities at more detailed levels by using parameters more sensitive to differences at the top or at the bottom of the distribution. Parameters more sensitive to differences at the bottom were used in this analysis, given that they provide greater values of inequality at the bottom level. Columbus appears to have a better performance in reducing inequality among bus users at the overall scale.

Alternative Method. The following procedure shows an alternative method which controls for both, city and users inequality at the same time. This method is opposed to the previous one in which city and users inequality are calculated and compared separately. This is determined by calculating the difference in consumption inequality (fpm, tpm) and income inequality at the users scale, and then dividing by the difference in income inequality between the users and city as shown next. 


\section{Overall Inequality Indices}

The calculation is as follows using the overall Gini indices. The Gini values from tables 5.4 and 5.9 are summarized here.

Fare per mile
\begin{tabular}{|l|c|c|}
\hline GINI & Columbus & Seattle \\
\hline City Inc Ineq $=$ & 0.338 & 0.304 \\
\hline Bus Inc Ineq $=$ & 0.385 & 0.322 \\
\hline fpm Ineq $=$ & 0.386 & 0.481 \\
\hline
\end{tabular}

$$
\begin{aligned}
\frac{{ }^{B} \operatorname{Gini}_{(\text {fpm })}-{ }^{B} \operatorname{Gini}_{(I N C)}}{{ }^{B} \operatorname{Gini}_{(I N C)}-{ }^{C} \operatorname{Gini}_{(I N C)}} & \Leftrightarrow \frac{{ }^{B} \operatorname{Gini}_{(\text {fpm })}-{ }^{B} \operatorname{Gini}_{(I N C)}}{{ }^{B} \operatorname{Gini}_{(\text {INC) }}-{ }^{C} \operatorname{Gini}_{(I N C)}} \\
\frac{0.386-0.385}{0.385-0.338} & \Leftrightarrow \frac{0.481-0.322}{0.322-0.304} \\
0.021 & <8.833
\end{aligned}
$$

\section{Time per mile}

\begin{tabular}{|l|c|c|}
\hline GINI & Columbus & Seattle \\
\hline City Inc Ineq $=$ & 0.338 & 0.304 \\
\hline Bus Inc Ineq $=$ & 0.385 & 0.322 \\
\hline tpm Ineq $=$ & 0.356 & 0.386 \\
\hline
\end{tabular}

$$
\begin{aligned}
\frac{{ }^{B} \operatorname{Gini}_{(\text {tpm })}-{ }^{B} \operatorname{Gini}_{(I N C)}}{{ }^{B} \operatorname{Gini}_{(I N C)}-{ }^{C} \operatorname{Gini}_{(I N C)}} & \Leftrightarrow \frac{{ }^{B} \operatorname{Gini}_{(t p m)}-{ }^{B} \operatorname{Gini}_{(I N C)}}{{ }^{B} \operatorname{Gini}_{(I N C)}-{ }^{C} \operatorname{Gini}_{(I N C)}} \\
\frac{0.356-0.385}{0.385-0.338} & \Leftrightarrow \frac{0.386-0.322}{0.322-0.304} \\
-0.617 & <3.556
\end{aligned}
$$

\section{Between-Group Inequality Indices}

The calculation is shown next using the between-group inequality indices. The Theil values for GE(-1) from tables 5.4 and 5.9 are summarized here.

Fare per mile

\begin{tabular}{|l|c|c|}
\hline GE Between & Columbus & Seattle \\
\hline City Inc Ineq $=$ & 0.159 & 0.148 \\
\hline Bus Inc Ineq $=$ & 0.421 & 0.169 \\
\hline fpm Ineq $=$ & 0.024 & 0.002 \\
\hline
\end{tabular}

\section{Time per mile}

\begin{tabular}{|l|c|c|}
\hline GE Between & Columbus & Seattle \\
\hline City Inc Ineq $=$ & 0.159 & 0.148 \\
\hline Bus Inc Ineq $=$ & 0.421 & 0.169 \\
\hline tpm Ineq $=$ & 0.017 & 0.002 \\
\hline
\end{tabular}

$$
\begin{aligned}
\frac{{ }^{B} G E_{(f p m)}-{ }^{B} G E_{(I N C)}}{{ }^{B} G E_{(I N C)}-{ }^{C} G E_{(I N C)}} & \Leftrightarrow \frac{{ }^{B} G E_{(f p m)}-{ }^{B} G E_{(I N C)}}{{ }^{B} G E_{(I N C)}-{ }^{C} G E_{(I N C)}} \\
\frac{0.024-0.421}{0.421-0.159} & \Leftrightarrow \frac{0.002-0.169}{0.169-0.148} \\
-1.515 & >-7.952
\end{aligned}
$$

$$
\begin{aligned}
\frac{{ }^{B} G \operatorname{Gini} i_{(p p m)}-{ }^{B} G i n i_{(I N C)}}{{ }^{B} G i n i_{(I N C)}-{ }^{C} G i n i_{(I N C)}} & \Leftrightarrow \frac{{ }^{B} \operatorname{Gini}_{(t p m)}-{ }^{B} G i n i_{(I N C)}}{{ }^{B} G i n i_{(I N C)}-{ }^{C} G i n i_{(I N C)}} \\
\frac{0.017-0.421}{0.421-0.159} & \Leftrightarrow \frac{0.002-0.169}{0.169-0.148} \\
-1.542 & >-7.952
\end{aligned}
$$

This alternative method also shows that, at the between-group inequality, Seattle is doing a better job than Columbus. That is, much of the inequality is due to factors outside of the transit system. Transit in fact is helping decrease the inequality that exists in the city (more negative numbers). 


\section{DISCUSSION OF RESULTS AND CONCLUSIONS}

The conclusions of this analysis provide comparative information between cities, in this case for Columbus and Seattle, which might help policy-makers and decisionmakers, transit agencies, community leaders and MPOs in the improvement of transit policies. The comparison of cities and transportation agencies, the analysis of equity performance of a city across time, and the study of conditions that correlate to successful fare policies, can help researchers understand the impact of policies that seek more equitable conditions among different demographic groups. The results can provide guidelines for transit agencies looking for successful programs to increase transit ridership among specific groups, and may well help community leaders to gain support to enhance the transportation system serving their community.

Information regarding the existing travel amenities, such as HOV lanes, busways, pedestrian facilities, etc. would be very helpful in future analyses to understand the impact of such facilities in the improvement of the transportation system of a city. These amenities can have significant influence on the results of an equity analysis. A study of the multi-modal implications of the transportation system compared between cities can be an interesting extension to this work.

The purpose of this work is to highlight distributional disparities in the transit system performance among different socioeconomic groups. The urban distribution and environment, along with the specific demographic conditions of each city, are quite different from one another. However, by comparing the performance in consumption inequality in the transit system relative to the urban income inequality provides a compatible way to evaluate performance between cities, so that critical conditions can be addressed -as far as possible- through the transit system.

Distributional goals need to be balanced however, with efficiency goals. Since travel time has been considered previously from an efficiency point of view, similar equity analysis like the one presented here can be weighed against for acceptable tradeoffs, according to each community goals. Nevertheless, the possibility to have the transit system as a way to redistribute income among underprivileged groups is rather complex given the alternatives that privileged groups have. Since transit service is regarded as an inferior good, the high elasticity of its demand would drop ridership numbers among those groups that subsidize the less favored. Therefore, subsidy would need to come from external sources.

In conclusion, there are important inequities among demographic groups of transit users, even more than has been previously found in the literature if temporal resources are included in the analysis. Significant differences were found in fare paid per mile and the service received in terms of speed. In the case of Columbus, lower income groups appear to pay more per mile and receive a lower quality service in terms of speed compared to higher income groups (Table No. 5.3). In the case of Seattle, younger groups 
appear to pay more per mile and at the same time spend more travel time compared to the other two groups (Table 5.8).

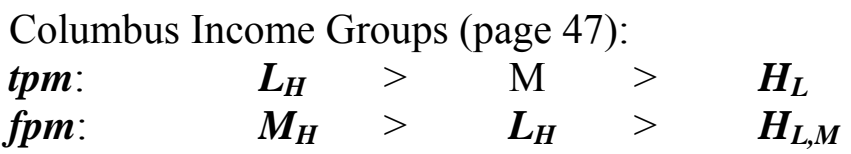

Seattle Age Groups (page 63):

$\begin{array}{llll}\text { tpm: } & Y_{W}>S_{W}> & W_{Y, S} \\ \text { fpm: } & Y_{W}> & W_{S}> & S_{Y, W}\end{array}$

No other significant differences at the 5 percent level of confidence were found, but there tendencies found on the same direction for some groups:

Columbus: male and younger groups appear to have higher rates of fpm and tpm.

Seattle: poor, female and younger groups appear to have higher rates of fpm and tpm.

The 'difference in differences' analysis shows that there is more inequality in the city of Seattle, as shown by the numbers in section C, pages 63-67. However, much of that inequality is due to income inequality at the city scale (i.e. exogenous to transit). When the between-group values are used in the analysis, the lower values of inequality in Seattle (more negative) compared to those found in Columbus, indicate this fact: inequality is mostly due to "other" inequality aside from that found on transit. Seattle appears to be doing a better job when considering the 'between-group' indices. In this way, the methodology followed in this analysis can also help to determine the impact of the urban form: monocentric vs. polycentric, as well as the impact of travel amenities, such as HOV lanes, busways, pedestrian facilities, terminals and multi-modal facilities offered by a city.

Nevertheless, the solution to this problem can hardly be found within the transit system alone. The private car dominates the daily, local travel nationwide. Its share was over $86 \%$ compared to less than $2 \%$ for public transportation in 2001 (Pucher, 2003). Future research on transit subsidies that come from taxes to the automobile use (depending on location and time of day -i.e. where and when the car is used), can perhaps illustrate how well the transit service can be improved (creating more routes, frequency of service, level of service, reliability, exclusive lanes, transit signal priority, etc.) while at the same time discourage the automobile use in high density congested areas at peak hours. If ridership increases thanks to transit improvements and car use decreases due to these disincentives, transit subsidies could probably be decreased gradually. If subsidies were cut radically or diminished before the service is not improved and ridership increased, the accessibility of underprivileged groups would be threatened significantly (see Accessibility and Economic Opportunity, O'Regan and Quigley 1999). Discouraging car use not only by economic disincentives (taxes, fees, tolls), but also by travel time incentives (getting there faster by transit than by the use of a private car), can probably assist in reducing the efficiency loss due to transit subsidies and strive for a better transit service. 


\section{REFERENCES}

- Altshuler, A.; Pucher, J.R.; Womack, J.P. (1979). The Urban Transportation System: Politics and Public Innovation. Cambridge: MIT Press.

- Altshuler, A.A. (1969). Transit subsidies: by whom, for whom? American Institute of Planners Journal, 35, pp. 84-89.

- Cangelosi, A.; Weiher, R.; Taverna, J.; Cicero, P. (2001). Revealing the Economic Value of Protecting the Great Lakes. Northeast-Midwest Institute \& National Oceanic and Atmospheric Administration.

- Castillo-Salgado, C; et al. (2001). Measuring Health Inequalities: Gini Coefficient and Concentration Index. Epidemiological Bulletin, Vol. 22 No. 1, March 2001.

- Cervero, R; Wachs; M; Berlin, R; and Gephart, RJ. (1980): "Efficiency and Equity Implications of Alternative Fare Policies", Urban Mass Transportation Administration, Sep 1980.

- Cervero, Robert (1981A). Efficiency and Equity Impacts of Current Transit Fare Policies. Transportation Research Record No. 799.

- Cervero, Robert (1981B). Flat versus Differentiated Transit Pricing: What's a Fair Fare? Transportation 10. pp 211-235.

- Cervero, Robert (1998). Flat versus Differentiated Transit Pricing: What's a Fair Fare? Transport policy / edited by Kenneth J. Button and Roger Stough pp. 569-90.

- Charles River Associates Incorporated. (1986). Allocation of Federal Transit Operating Subsidies to Riders by Income Group. CRA Report No. 784.15. Washington, D.C.: UMTA, U.S. Department of Transportation.

- Charles River Associates Incorporated. (1989). Transit Deficits: Peak and Off-Peak Comparisons. CRA Report No. 784.30C. Washington, D.C.: UMTA, U.S. Department of Transportation.

- Damgaard, C; Weiner, J. (2000). Describing Inequality in Plant Size or Fecundity. Ecology, No. 81, April 2003

- Daskin, M.S. (1983). A Review of Transit Service and Pricing Options. Journal of Advanced Transportation 17:3.

- Garrett, M.; Taylor, B. (1999). Reconsidering Social Equity in Public. Transit. Berkeley Planning Journal 13: 6-30

- Gomez-Ibanez, J.A.; Meyer, J.R. (1993). Going Private: The International Experience with Transportation Privatization. Washington, DC.: The Brookings Institution.

- Hendrickson, C. Pucher, J. (1980). Distribution of Urban Transportation Costs. Urban Transportation Financing, ASCE 1980.

- Hoachlander, E.G. (1976). Bay Area Rapid Transit: Who Pays and Who Benefits? Berkeley, University of California, Institute of Urban and Regional Development.

- Hodge, D.C. (1988). Fiscal Equity in Urban Mass Transit Systems: A Geographic Analysis. Annals of the Association of American Geographers, 78, 288-306.

- Hodge, D.C. (1995). My fair share. Equity issues in Urban Transportation. Chapter in: Susan Hanson. The Geography of Urban Transportation.

- Ihlanfeldt, K. R., \& Sjoquist, D. L. (1998). The Spatial Mismatch Hypothesis: A Review Of Recent Studies And Their Implications For Welfare Reform. Housing Policy Debate 9(4), 849-892.

- Ihlanfeldt, K.R., Sjoquist, D.L. (1990). Job accessibility and racial differences in youth employment rates, The American Economic Review, 80, pp. 267-276. 
- Ircha, M.C. Gallagher, M.A. (1985). Urban Transit: Equity Aspects. Journal of Urban Planning and Development, Vol. 111, No. 1.

- Iseki, Hiroyuki; Taylor, Brian D. (2001). The Demographics of Public Transit Subsidies: A Case Study of Los Angeles. Presented at the 81st Annual Meeting of the Transportation Research Board. Washington, D.C. Jan. 2002.

- Jansson, JO (1979). Marginal Cost Pricing of Scheduled Transport Services: A development and generalization of Turvey and Mohring's theory of optimal bus fares. Journal of Transport Economics, Vol.13, No.3 Sept 1979.

- Jansson, K. (1993). Optimal Public Transport Price and Service Frequency. J. of Transport Economics and Policy, Vol. 27, Issue. 4.

- Jorgensen, F. (2004). Travel Distance and Optimal Transport Policy. Transportation Research Part B. V38. 415-430.

- Kain, J. F. (1968). Housing segregation, Negro employment, and metropolitan decentralization. Quarterly Journal of Economics 82, 175-197.

- Kelley, Robin D.G. (1996). Freedom Riders (The Sequel). Nation, 2/5/1996, vol. 262 Issue 5.

- Kerin, P.D (1987). Why subsidize state transport authorities? Australian Quarterly, 59 (1), Autumn, pp. 60-72.

- Kerin, P.D. (1992). Efficient Bus Fares. Transport Reviews, Vol. 12, No. 1.

- Leutze, C.B.; Ugolik, W.R. (1978). Who Pays the Highest and the Lowest Per-Mile Transit Fares? Albany, NY. New York State Department of Transportation.

- Levinson, D. (2002). Identifying Winners and Losers in Transportation. Transportation Research Record 1812.

- Levinson, D.; Zhang, L.; Das, S.; Sheikh, A. (2002). Ramp Meters on Trial: Evidence from the Twin Cities Ramp Meters Shut-off. Presented at the 81st Annual Meeting of the Transportation Research Board. Washington, D.C. Jan. 2002.

- Levinson, D. (2003). Perspectives on Efficiency in Transportation. International Journal of Transport Management 1 pp.145-155

- Litman, T. (1996). Using Road Pricing Revenue: Economic Efficiency and Equity Considerations. Transportation Research Record, 1558.

- Litman, T. (2002). Evaluating Transportation Equity. Journal: World Transport Policy \& Practice, Vol. 8, No. 2 (p. 50).

- Mayeres, I; Proost, S. (2003). Reforming Transport Pricing: An Economic Perspective on Equity, Efficiency and Acceptability. Chapter 6 in 'Acceptability of Transport Pricing Strategies', Pub. Elsevier Science. J. Schade and B. Schlag.

- Mohring, H. (1972). Optimization and scale economies in urban bus transportation. American Economic Review, September 1972.

- Mohring, H; Schroeter, J; Wiboonchutikula, P (1987). The Values of Waiting Time, Travel Time, and a Seat on a Bus. Rand Journal of Economics, Vol. 18, No. 1, Spring 1987.

- Moore, G.R. (2002). Transit Ridership Efficiency as a Function of Fares. Journal of Public Transportation Vol. 5, No. 1.

- Musgrave, R.A. and Musgrave, P.B. (1984) Public Finance in Theory and Practice. Fourth Edition, McGraw-Hill.

- National Cooperative Highway Research Program (NCHRP) Research Results Digest (2002). The Case For Standardizing Household Travel Surveys. Transportation Research Board.

- Ong, P.M \& Miller, D. (2005). Spatial and Transportation Mismatch in Los Angeles. Journal of Planning Education and Research. 25:43-56. Association of Collegiate Schools of Planning 
- Pedersen, P.A. (2003). On the Optimal Fare Policies in Urban Transportation. Transportation Research, Part B, 423-435.

- Price Waterhouse LLP. (1997). Funding Strategies for Public Transportation. Project H-07, FY 1995. TCRP Report 31. Washington, D.C.: Transit Cooperative Research Program.

- Pucher, J. (1981). Equity in transit finance: Distribution of transit subsidy benefits and costs among income classes. American Planning Association Journal, 47, 387-407.

- Pucher, J. (1983). Who Benefits from Transit Subsidies? Recent Evidence from Six Metropolitan Areas. Transportation Research A, 17A (1), January, 39-50

- Pucher, J. (1998). Who Benefits from Transit Subsidies? Recent Evidence from Six Metropolitan Areas. Transport policy / edited by Kenneth J. Button and Roger Stough pp.603-614

- Pucher, J; Hendrickson, C; McNeil, S. (1981). Socioeconomic Characteristics of Transit Riders: Some Recent Evidence. Traffic Quarterly, Vol. 35. No. 3. July 1981, pp 461-483.

- Pucher, J; Renee, J. (2003). Socioeconomics of Urban Travel: Evidence from the 2001 NHTS. Transportation Quarterly, Summer 2003, Vol. 57 Issue 3, p49.

- $\quad$ Rock, S. \& Zavattero, S. (1979). Flat Fares, Transit Trip Distance, and Income Redistribution. Proceedings of the Transportation Research Forum, 20(1), 291-296.

- Rosenbloom, S.; Altshuler, A. (1979). Equity Issues in Urban Transportation. In Altshuler, A. (Ed.), Current Issues in Urban Transportation Policy. Lexington, MA: Lexington Books.

- Sanchez, T. (2002). The Impact of Public Transport on US Metropolitan Wage Inequality. Urban Studies, Vol. 39, No. 3, 423-436. March 2002.

- Sanchez, TW, Stolz, R, and Ma, JS. (2003). Moving to Equity: Addressing Inequitable Effects of Transportation Policies on Minorities. The Civil Rights Project at Harvard University. Cambridge, MA

- Scott, A.J. \& Brown, E.R. (1993). South-Central Los Angeles: Anatomy of an Urban Crisis. The Ralph and Goldy Lewis Center for Regional Policy Studies. Working Paper Series; Paper 06; University of California, Los Angeles (http://repositories.cdlib.org/lewis/wps/06/)

- Talley, W.K. (1991). Transit Performance Evaluation and Time Prices: A Single Indicator Methodology. J. of the Transportation Research Forum, Vol. 31, Issue 2.

- Taylor, B.D; Garret, M.; Iseki, H. (2000). Measuring Cost Variability in the Provision of Transit Service. Transportation Research Record No. 1735.

- Transportation Research Board (2001). Critical Issues in Transportation 2002. The National Academies; November-December 2001.

- Transportation Research Board (2006). Critical Issues in Transportation. The National Academies; issued January 2006.

- Turvey, R., Mohring, H. (1975). Optimal Bus Fares. Journal of Transport Economics and Policy, Vol 9, Sep.

- Turvey, R., Mohring, H. (1994). Optimal Bus Fares. The Economics of Transport II

- Turvey, R., Mohring, H. (1997). Optimal Bus Fares. Transport Economics, Selected Readings

- Ugolik, W.R., Leutze, C.B. (1979). Who Pays the Highest and the Lowest Per-Kilometer Transit Fares? (Abridgement). Transportation Research Record No. 719.

- United States General Accounting Office (1995). Hazardous and Nonhazardous Waste, Demographic of People Living Near Waste Facilities. Washington, DC: General Accounting Office.

- Vickrey, WS. (1980). Efficiency through Pricing in Urban Transportation. Urban Transportation Financing, ASCE 1980. 
- Vuchic, Vukan. 2000. Transportation for Livable Cities.

- Webber, M. (1976). The BART experience - What Have We Learned? [Monograph]. Institute of Urban and Regional Development and Institute of Transportation Studies, University of California, Berkeley, 26, 1-40.

- Weeks, J. (2002). Public Involvement by Minorities and Low-Income Populations. Removing the Mystery. TR News 220 May-Jun 2002. p. 25.

- Wohl, M. (1973). Public Transport Pricing, Financing, and Subsidy Principles. Traffic Quarterly, Vol. 27, Issue 4.

- Yang, H; Kong, H; Meng, Q. (2001). Value-of-Time Distributions and Competitive Bus Services. Transportation Research. Part E, Logistics and Transportation Review. 


\section{APPENDIX}

\section{A. The Case of COLUMBUS}

\section{Average Trip Characteristics By Income Group in Columbus}

- By Individual Trips (410):

\begin{tabular}{lccccc} 
Group & $\begin{array}{c}\text { Distance } \\
\text { (miles) }\end{array}$ & $\begin{array}{c}\text { Time } \\
\text { (minutes) }\end{array}$ & $\begin{array}{c}\text { Speed } \\
\text { (mph) }\end{array}$ & Min/Mile & $\begin{array}{c}\text { Fare/mile } \\
\text { (cents/mile) }\end{array}$ \\
\hline Lower-Income & 3.56 & 31.12 & 9.19 & 12.24 & 43.7 \\
Middle-Income & 4.52 & 33.44 & 9.93 & 9.58 & 31.3 \\
Higher-Income & 6.57 & 39.67 & 12.37 & 8.28 & 23.9
\end{tabular}

- By Transit User (221):

\begin{tabular}{lccccc} 
Group & $\begin{array}{c}\text { Distance } \\
\text { (miles) }\end{array}$ & $\begin{array}{c}\text { Time } \\
\text { (minutes) }\end{array}$ & $\begin{array}{c}\text { Speed } \\
\text { (mph) }\end{array}$ & Min/Mile & $\begin{array}{c}\text { Fare/mile } \\
\text { (cents/mile) }\end{array}$ \\
\hline Lower-Income & 7.98 & 61.51 & 9.60 & 10.72 & 33.0 \\
Middle-Income & 8.43 & 59.04 & 9.51 & 9.67 & 36.0 \\
Higher-Income & 11.16 & 62.88 & 11.51 & 8.52 & 25.0
\end{tabular}

- By Household (198):

\begin{tabular}{lccccc} 
Group & $\begin{array}{c}\text { Distance } \\
\text { (miles) }\end{array}$ & $\begin{array}{c}\text { Time } \\
\text { (minutes) }\end{array}$ & $\begin{array}{c}\text { Speed } \\
\text { (mph) }\end{array}$ & Min/Mile & $\begin{array}{c}\text { Fare/mile } \\
\text { (cents/mile) }\end{array}$ \\
\hline Lower-Income & 10.23 & 82.65 & 9.60 & 10.55 & 32.0 \\
Middle-Income & 9.86 & 67.96 & 9.28 & 9.35 & 36.0 \\
Higher-Income & 12.26 & 69.37 & 11.49 & 8.52 & 24.0
\end{tabular}




\section{Statistical Differences By Income Group, Using the T-Test Analysis in Columbus}

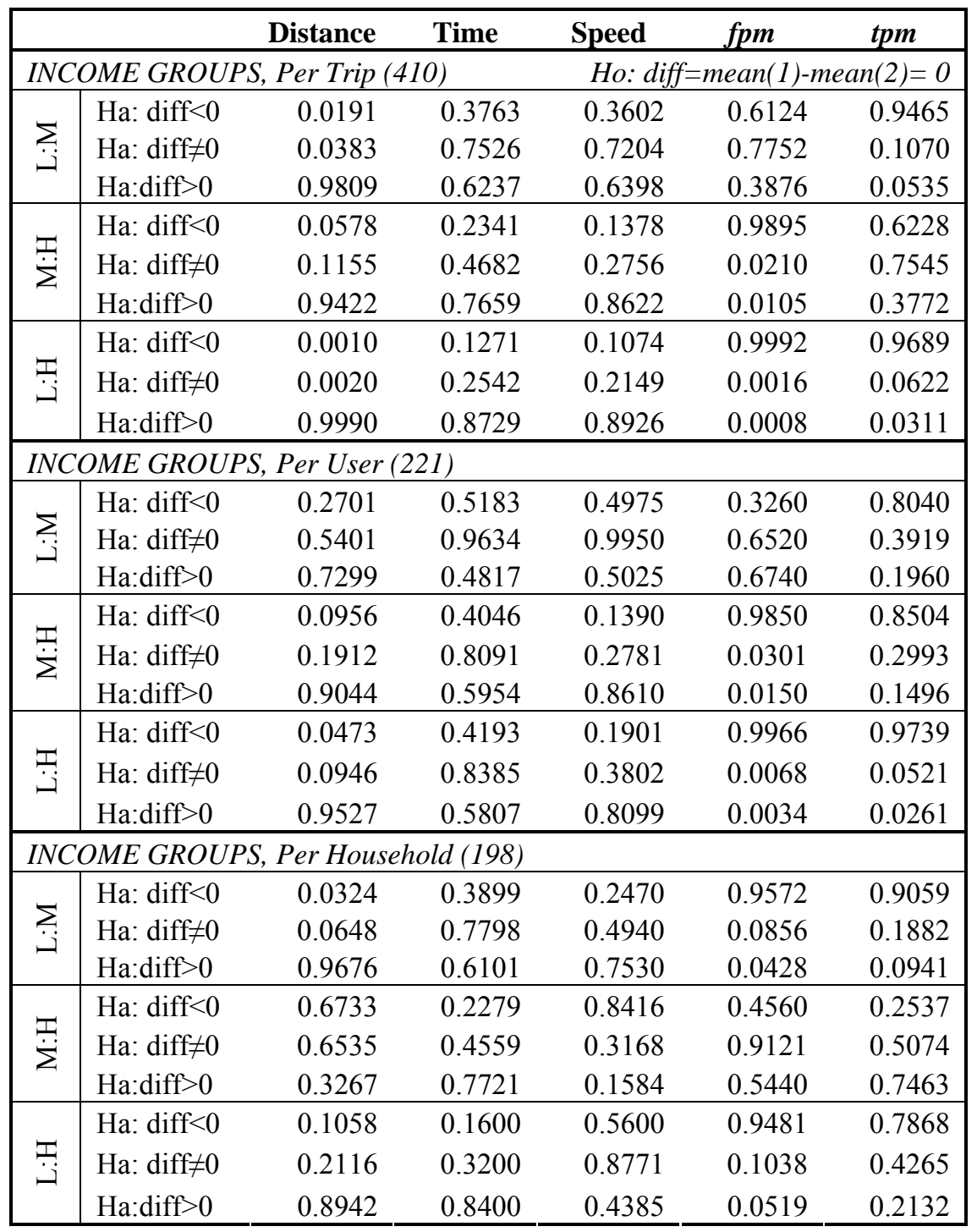




\section{Statistical Differences By Ethnic, Gender And Age Groups, Using the T-Test Analysis in Columbus}

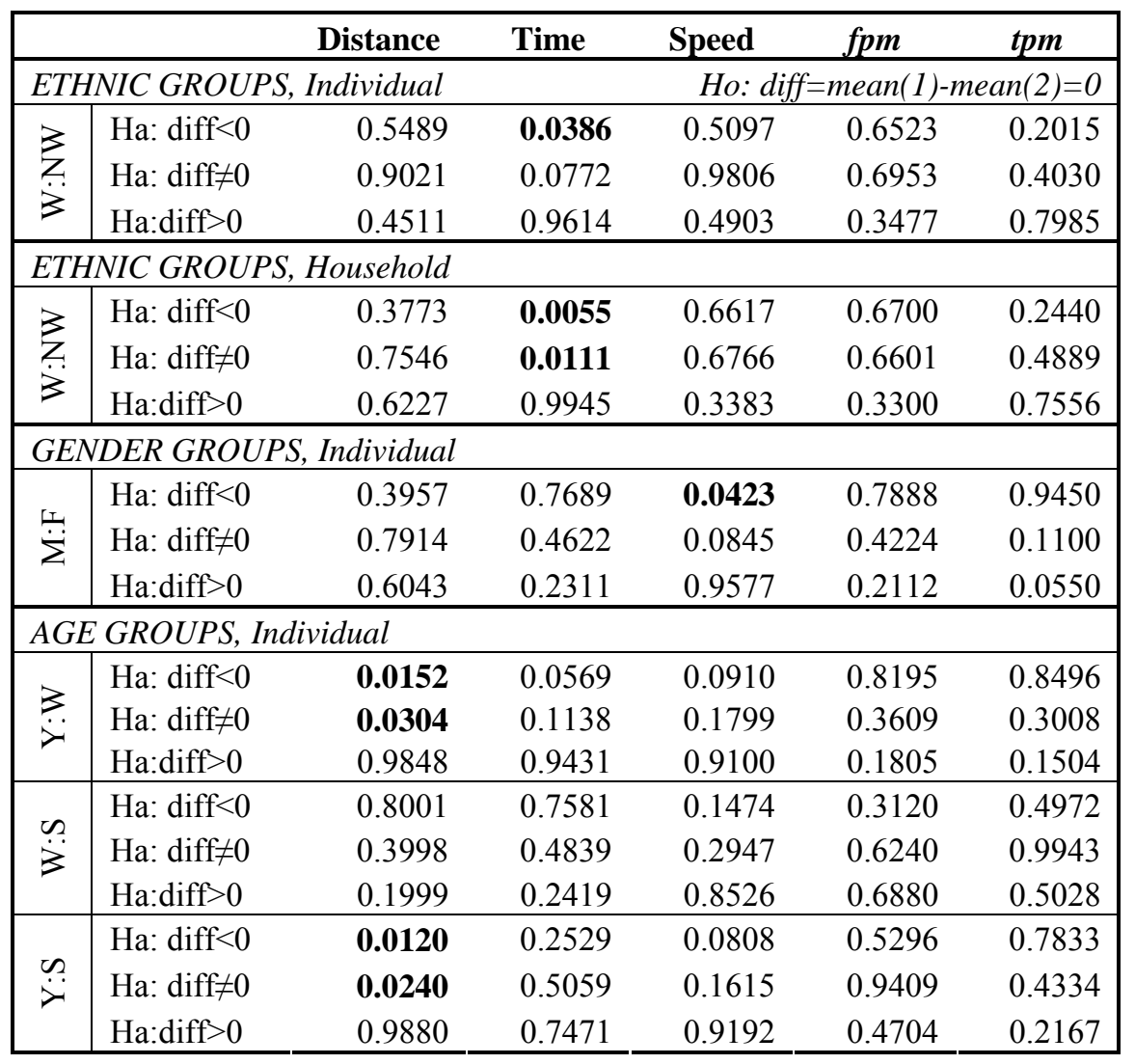




\section{Income Group Averages In fpm and tpm Per Income Category in Columbus}

- By trip average, per Income Code

\begin{tabular}{ccccc}
$\begin{array}{c}\text { Income } \\
\text { Code }\end{array}$ & $\begin{array}{c}\text { Income } \\
\text { Limits }\end{array}$ & $\begin{array}{c}\text { Population } \\
\text { (trips) }\end{array}$ & fpm & tpm \\
\hline 11 & $<10 \mathrm{~K}$ & 70 & 40.50 & 11.84 \\
12 & $10 \mathrm{~K}-20 \mathrm{~K}$ & 59 & 39.88 & 10.57 \\
13 & $20 \mathrm{~K}-30 \mathrm{~K}$ & 105 & 31.89 & 9.75 \\
14 & $30 \mathrm{~K}-40 \mathrm{~K}$ & 60 & 33.38 & 10.32 \\
15 & $40 \mathrm{~K}-50 \mathrm{~K}$ & 50 & 26.46 & 9.31 \\
16 & $50 \mathrm{~K}-60 \mathrm{~K}$ & 21 & 32.04 & 10.36 \\
17 & $60 \mathrm{~K}-75 \mathrm{~K}$ & 19 & 25.10 & 7.30 \\
18 & $75 \mathrm{~K}-100 \mathrm{~K}$ & 14 & 21.65 & 5.61 \\
19 & $>100 \mathrm{~K}$ & 12 & 18.85 & 10.10 \\
\hline \multicolumn{5}{c}{410} \\
\hline
\end{tabular}

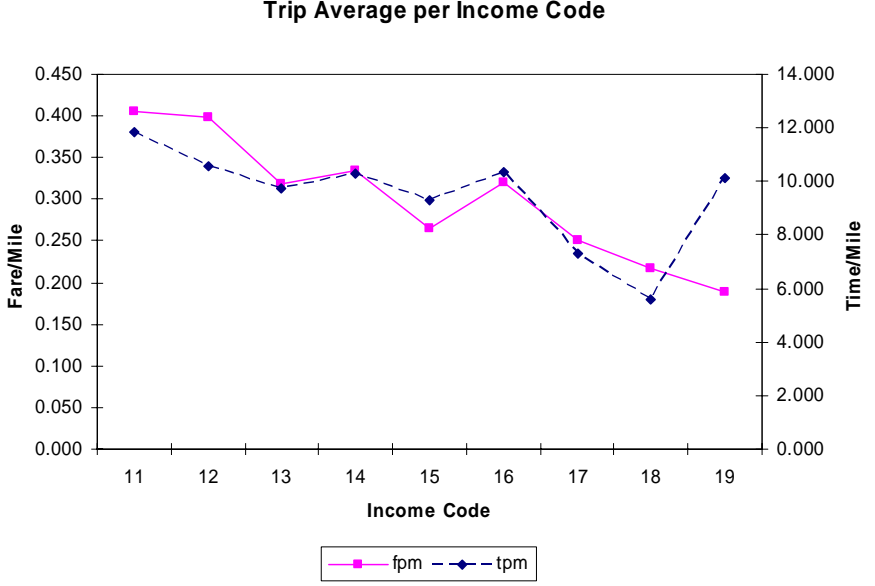

- By User average, per decile group.

\begin{tabular}{ccccc}
$\begin{array}{c}\text { Income } \\
\text { Deciles }\end{array}$ & $\begin{array}{c}\text { Income Limits } \\
\text { (in thousands) }\end{array}$ & $\begin{array}{c}\text { Population } \\
\text { (users) }\end{array}$ & Fare/Mile & Time/Mile \\
\hline 1 & $2-5$ & 22 & 39.17 & 10.68 \\
2 & $5-8$ & 22 & 35.33 & 12.85 \\
3 & $8-10$ & 22 & 28.53 & 9.64 \\
4 & $10-15$ & 22 & 43.03 & 9.03 \\
5 & $15-17.5$ & 23 & 30.65 & 9.57 \\
6 & $17.5-23.3$ & 22 & 36.01 & 10.48 \\
7 & $23.3-25$ & 22 & 28.77 & 7.75 \\
8 & $25-33.7$ & 22 & 23.09 & 8.93 \\
9 & $33.7-41.7$ & 22 & 25.08 & 9.44 \\
10 & $41.7-83.3$ & 22 & 23.25 & 8.04 \\
\hline \multicolumn{7}{r}{}
\end{tabular}




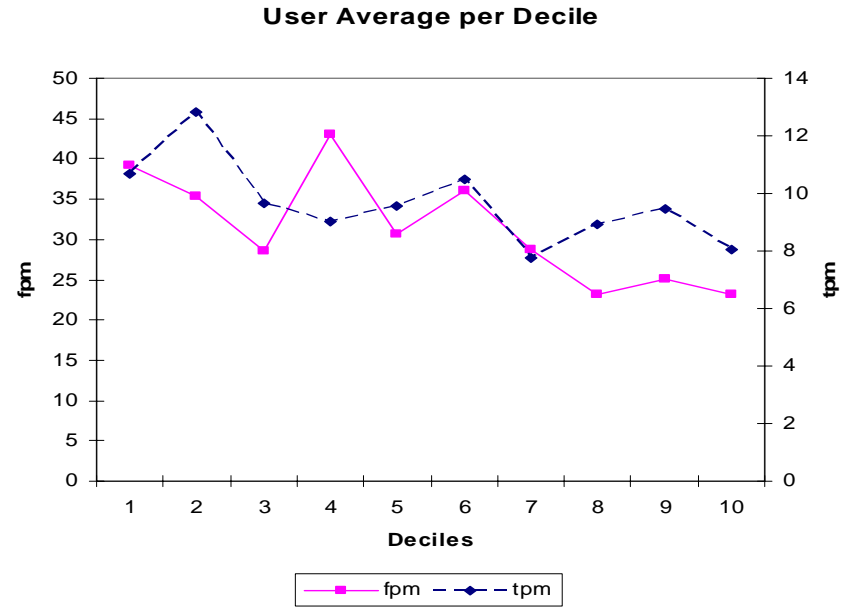

- By Household average, per decile group

\begin{tabular}{ccccc}
$\begin{array}{c}\text { Income } \\
\text { Deciles }\end{array}$ & $\begin{array}{c}\text { Income Limits } \\
\text { (in thousands) }\end{array}$ & $\begin{array}{c}\text { Population } \\
\text { (households) }\end{array}$ & Fare/Mile & Time/Mile \\
\hline 1 & $2-5$ & 20 & 34.29 & 12.07 \\
2 & $5-8.1$ & 20 & 35.32 & 10.95 \\
3 & $8.3-11.9$ & 19 & 26.22 & 8.33 \\
4 & $11.9-15$ & 20 & 47.65 & 9.71 \\
5 & $15-22$ & 20 & 42.54 & 12.40 \\
6 & $22-23.3$ & 20 & 21.34 & 6.22 \\
7 & $23.3-25$ & 20 & 29.78 & 9.12 \\
8 & $26-33.8$ & 19 & 24.38 & 8.53 \\
9 & $33.8-43$ & 20 & 24.04 & 9.31 \\
10 & $45-83.3$ & 20 & 23.92 & 8.18 \\
\hline
\end{tabular}

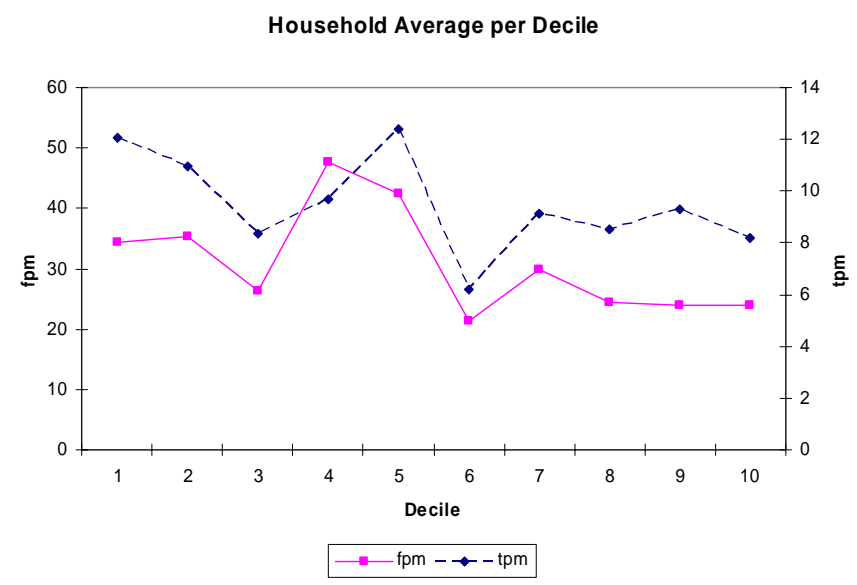


5. Gini, Theil And Atkinson Per Income Group in Columbus

\begin{tabular}{|c|c|c|c|c|c|c|c|c|}
\hline & Gini & & \multicolumn{2}{|c|}{ GE (a) } & \multicolumn{2}{|c|}{ Atkinson (e) } & & \\
\hline & \multicolumn{2}{|c|}{ Equivalent Income } & $\mathrm{W}$ & $\mathrm{B}$ & $\mathrm{W}$ & $\mathrm{B}$ & & \\
\hline \multirow{5}{*}{ 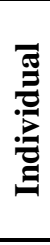 } & 0.338 & & \multicolumn{2}{|c|}{0.188} & \multicolumn{2}{|c|}{0.200} & $<=$ Overall & \multirow{10}{*}{$=$} \\
\hline & L.- $\quad 0.242$ & $\mathrm{GE}(-1)=$ & 0.211 & 0.159 & & & & \\
\hline & M.- 0.082 & $\operatorname{GE}(0)=$ & 0.074 & 0.149 & 0.071 & 0.381 & $=\mathrm{A}(2)$ & \\
\hline & H.- 0.161 & $\operatorname{GE}(1)=$ & 0.036 & 0.152 & 0.039 & 0.167 & $=\mathrm{A}(1)$ & \\
\hline & & $\operatorname{GE}(2)=$ & 0.027 & 0.170 & 0.019 & 0.079 & $=\mathrm{A}(0.5)$ & \\
\hline \multirow{5}{*}{ 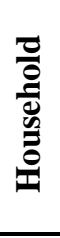 } & 0.354 & & \multicolumn{2}{|c|}{0.204} & \multicolumn{3}{|c|}{0.215} & \\
\hline & L.- 0.225 & $\mathrm{GE}(-1)=$ & 0.026 & 0.344 & & & & \\
\hline & M.- 0.093 & $\mathrm{GE}(0)=$ & 0.008 & 0.234 & 0.011 & 0.418 & $=\mathrm{A}(2)$ & \\
\hline & H.- $\quad 0.148$ & $\mathrm{GE}(1)=$ & 0.006 & 0.198 & 0.006 & 0.211 & $=\mathrm{A}(1)$ & \\
\hline & & $\operatorname{GE}(2)=$ & 0.007 & 0.199 & 0.003 & 0.103 & $=\mathrm{A}(0.5)$ & \\
\hline \multicolumn{9}{|c|}{ Equivalent Income } \\
\hline \multirow{5}{*}{ } & 0.385 & & \multicolumn{2}{|c|}{0.243} & \multicolumn{3}{|c|}{0.249} & \multirow{10}{*}{$\begin{array}{l}\infty \\
\vdots \\
0 \\
0 \\
0\end{array}$} \\
\hline & L.- $\quad 0.246$ & $\mathrm{GE}(-1)=$ & 0.031 & 0.421 & & & & \\
\hline & M.- $\quad 0.122$ & $\mathrm{GE}(0)=$ & 0.009 & 0.277 & 0.017 & 0.465 & $=\mathrm{A}(2)$ & \\
\hline & H.- $\quad 0.178$ & $\mathrm{GE}(1)=$ & 0.009 & 0.234 & 0.009 & 0.242 & $=\mathrm{A}(1)$ & \\
\hline & & $\operatorname{GE}(2)=$ & 0.021 & 0.241 & 0.005 & 0.120 & $=\mathrm{A}(0.5)$ & \\
\hline \multirow{5}{*}{ 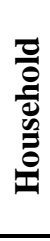 } & 0.375 & & \multicolumn{2}{|c|}{0.235} & \multicolumn{3}{|c|}{0.228} & \\
\hline & L.- 0.194 & $\mathrm{GE}(-1)=$ & 0.023 & 0.339 & & & & \\
\hline & M.- $\quad 0.222$ & $\mathrm{GE}(0)=$ & 0.011 & 0.248 & 0.023 & 0.407 & $=\mathrm{A}(2)$ & \\
\hline & H.- $\quad 0.084$ & $\mathrm{GE}(1)=$ & 0.012 & 0.223 & 0.012 & 0.219 & $=\mathrm{A}(1)$ & \\
\hline & & $\mathrm{GE}(2)=$ & 0.023 & 0.240 & 0.006 & 0.111 & $=\mathrm{A}(0.5)$ & \\
\hline \multicolumn{9}{|c|}{ Fare per Mile } \\
\hline \multirow{5}{*}{ 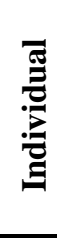 } & 0.386 & & \multicolumn{2}{|c|}{0.271} & \multicolumn{3}{|c|}{0.223} & \\
\hline & L.- 0.359 & $\mathrm{GE}(-1)=$ & 0.282 & 0.024 & & & & \\
\hline & M.- $\quad 0.433$ & $\mathrm{GE}(0)=$ & 0.228 & 0.024 & 0.365 & 0.024 & $=\mathrm{A}(2)$ & \\
\hline & H.- $\quad 0.324$ & $\mathrm{GE}(1)=$ & 0.246 & 0.025 & 0.211 & 0.015 & $=\mathrm{A}(1)$ & \\
\hline & & $\mathrm{GE}(2)=$ & 0.384 & 0.026 & 0.114 & 0.009 & $=\mathrm{A}(0.5)$ & 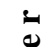 \\
\hline & 0.388 & & & & & & & $\infty$ \\
\hline 을 & L.- 0.329 & $\mathrm{GE}(-1)=$ & 0.276 & 0.030 & & & & \\
\hline$\stackrel{\mathscr{J}}{2}$ & M.- 0.409 & $\operatorname{GE}(0)=$ & 0.224 & 0.031 & 0.366 & 0.022 & $=\mathrm{A}(2)$ & \\
\hline 옾 & H.- $\quad 0.386$ & $\mathrm{GE}(1)=$ & 0.246 & 0.033 & 0.213 & 0.015 & $=\mathrm{A}(1)$ & \\
\hline & & $\operatorname{GE}(2)=$ & 0.401 & 0.035 & 0.115 & 0.011 & $=\mathrm{A}(0.5)$ & \\
\hline & Time per Mils & & & & & & & \\
\hline & 0.356 & & & & & & & \\
\hline$\stackrel{\pi}{3}$ & L.- $\quad 0.358$ & $\mathrm{GE}(-1)=$ & 0.302 & 0.017 & & & & \\
\hline 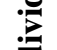 & M.- $\quad 0.360$ & $\mathrm{GE}(0)=$ & 0.208 & 0.017 & 0.366 & 0.037 & $=\mathrm{A}(2)$ & \\
\hline$\underline{\Xi}$ & 0.339 & $\mathrm{GE}(1)=$ & 0.210 & 0.018 & 0.191 & 0.013 & $=\mathrm{A}(1)$ & \\
\hline & & $\operatorname{GE}(2)=$ & 0.289 & 0.019 & 0.100 & 0.007 & $=\mathrm{A}(0.5)$ & a \\
\hline & 0.349 & & & & & & & $\infty$ \\
\hline 을 & L.- $\quad 0.316$ & $\mathrm{GE}(-1)=$ & 0.293 & 0.020 & & & & \\
\hline פ্ & M.- $\quad 0.352$ & $\mathrm{GE}(0)=$ & 0.198 & 0.020 & 0.362 & 0.036 & $=\mathrm{A}(2)$ & \\
\hline 옥 & H.- $\quad 0.367$ & $\mathrm{GE}(1)=$ & 0.202 & 0.020 & 0.187 & 0.011 & $=\mathrm{A}(1)$ & \\
\hline & & $\operatorname{GE}(2)=$ & 0.285 & 0.021 & 0.097 & 0.007 & $=\mathrm{A}(0.5)$ & \\
\hline
\end{tabular}


6. Gini, Theil And Atkinson, per Ethnic Group in Columbus

\begin{tabular}{|c|c|c|c|c|c|c|c|c|}
\hline & Gini & & & & & (e) & & \\
\hline & ivalent Income & & W & $\mathrm{B}$ & $\mathrm{W}$ & $\mathrm{B}$ & & \\
\hline & 0.338 & & & & & & $<=$ Overall & \\
\hline 苋 & NW.- $\quad 0.382$ & $\mathrm{GE}(-1)=$ & 0.363 & 0.007 & & & & \\
\hline 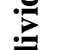 & W.- 0.326 & $\operatorname{GE}(0)=$ & 0.215 & 0.006 & 0.409 & 0.026 & $=\mathrm{A}(2)$ & \\
\hline$\underline{\mathbf{E}}$ & & $\operatorname{GE}(1)=$ & 0.182 & 0.006 & 0.192 & 0.009 & $=\mathrm{A}(1)$ & \\
\hline & & $\operatorname{GE}(2)=$ & 0.193 & 0.005 & 0.093 & 0.004 & $=\mathrm{A}(0.5)$ & 3 \\
\hline & 0.354 & & & & & & & u \\
\hline 을 & NW.- $\quad 0.376$ & $\mathrm{GE}(-1)=$ & 0.362 & 0.008 & & & & \\
\hline $\bar{\Xi}$ & W.- $\quad 0.344$ & $\mathrm{GE}(0)=$ & 0.235 & 0.007 & 0.415 & 0.016 & $=\mathrm{A}(2)$ & \\
\hline & & $\operatorname{GE}(1)=$ & 0.197 & 0.006 & 0.208 & 0.008 & $=\mathrm{A}(1)$ & \\
\hline & & $\operatorname{GE}(2)=$ & 0.201 & 0.006 & 0.102 & 0.004 & $=\mathrm{A}(0.5)$ & \\
\hline & ivalent Income & & & & & & & \\
\hline & 0.385 & & & & & & & \\
\hline 尔 & NW.- $\quad 0.381$ & $\mathrm{GE}(-1)=$ & 0.431 & 0.020 & & & & \\
\hline 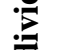 & W.- 0.361 & $\operatorname{GE}(0)=$ & 0.267 & 0.020 & 0.452 & 0.042 & $=\mathrm{A}(2)$ & \\
\hline$\underline{\Xi}$ & & $\operatorname{GE}(1)=$ & 0.224 & 0.019 & 0.232 & 0.022 & $=\mathrm{A}(1)$ & \\
\hline & & $\operatorname{GE}(2)=$ & 0.244 & 0.018 & 0.114 & 0.010 & $=\mathrm{A}(0.5)$ & é \\
\hline & 0.375 & & & & & & & $\infty$ \\
\hline 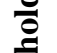 & NW.- $\quad 0.363$ & $\mathrm{GE}(-1)=$ & 0.356 & 0.007 & & & & \\
\hline 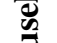 & W.- 0.375 & $\mathrm{GE}(0)=$ & 0.253 & 0.007 & 0.413 & 0.012 & $=\mathrm{A}(2)$ & \\
\hline 完 & & $\operatorname{GE}(1)=$ & 0.228 & 0.006 & 0.223 & 0.006 & $=\mathrm{A}(1)$ & \\
\hline & & $\mathrm{GE}(2)=$ & 0.257 & 0.006 & 0.114 & 0.003 & $=\mathrm{A}(0.5)$ & \\
\hline & per Mile & & & & & & & \\
\hline & 0.386 & & & & & & & \\
\hline 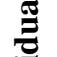 & NW.- 0.388 & $\mathrm{GE}(-1)=$ & 0.306 & 0.000 & & & & \\
\hline$\sum$ & W.- $\quad 0.382$ & $\mathrm{GE}(0)=$ & 0.252 & 0.000 & 0.380 & 0.000 & $=\mathrm{A}(2)$ & \\
\hline$\underline{\mathbf{E}}$ & & $\operatorname{GE}(1)=$ & 0.271 & 0.000 & 0.223 & 0.000 & $=\mathrm{A}(1)$ & \\
\hline & & $\operatorname{GE}(2)=$ & 0.409 & 0.000 & 0.122 & 0.000 & $=\mathrm{A}(0.5)$ & 2 \\
\hline & 0.388 & & & & & & & $\infty$ \\
\hline 을 & NW.- $\quad 0.390$ & $\mathrm{GE}(-1)=$ & 0.306 & 0.001 & & & & \\
\hline $\mathscr{\mathscr { S }}$ & W.- $\quad 0.383$ & $\operatorname{GE}(0)=$ & 0.254 & 0.001 & 0.380 & 0.000 & $=\mathrm{A}(2)$ & \\
\hline 胥 & & $\operatorname{GE}(1)=$ & 0.278 & 0.001 & 0.224 & 0.001 & $=\mathrm{A}(1)$ & \\
\hline & & $\operatorname{GE}(2)=$ & 0.436 & 0.001 & 0.124 & 0.000 & $=\mathrm{A}(0.5)$ & \\
\hline & e per Mile & & & & & & & \\
\hline & 0.356 & & & & & & & \\
\hline ש & NW.- $\quad 0.376$ & $\mathrm{GE}(-1)=$ & 0.319 & 0.001 & & & & \\
\hline 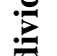 & W.- 0.339 & $\operatorname{GE}(0)=$ & 0.224 & 0.001 & 0.390 & 0.000 & $=\mathrm{A}(2)$ & \\
\hline$\underline{\Xi}$ & & $\operatorname{GE}(1)=$ & 0.228 & 0.001 & 0.201 & 0.000 & $=\mathrm{A}(1)$ & \\
\hline & & $\operatorname{GE}(2)=$ & 0.308 & 0.001 & 0.106 & 0.000 & $=\mathrm{A}(0.5)$ & é \\
\hline & 0.349 & & & & & & & $n$ \\
\hline 을 & NW.- $\quad 0.348$ & $\mathrm{GE}(-1)=$ & 0.312 & 0.001 & & & & \\
\hline 苞 & W.- 0.349 & $\mathrm{GE}(0)=$ & 0.218 & 0.001 & 0.384 & 0.012 & $=\mathrm{A}(2)$ & \\
\hline$\stackrel{0}{0}$ & & $\operatorname{GE}(1)=$ & 0.222 & 0.001 & 0.195 & 0.001 & $=\mathrm{A}(1)$ & \\
\hline & & $\mathrm{GE}(2)=$ & 0.305 & 0.001 & 0.103 & 0.000 & $=\mathrm{A}(0.5)$ & \\
\hline
\end{tabular}




\section{Gini, Theil And Atkinson per Gender Group in Columbus}

\section{GENDER GROUPS (2)}

\begin{tabular}{|c|c|c|}
\hline Gini & GE (a) & Atkinson (e) \\
& Within Between & Within Between \\
\hline
\end{tabular}

\begin{tabular}{|c|c|c|c|c|c|c|c|c|}
\hline \multicolumn{9}{|c|}{ Equivalent Income } \\
\hline \multirow{5}{*}{ 胥 } & 0.338 & & \multicolumn{2}{|c|}{0.188} & \multicolumn{2}{|c|}{0.200} & & \multirow{5}{*}{$\stackrel{\nabla}{0}$} \\
\hline & \multirow{4}{*}{$\begin{array}{cc}\text { M.- } & 0.333 \\
\text { F.- } & 0.342\end{array}$} & $\mathrm{GE}(-1)=$ & 0.370 & 0.000 & & & & \\
\hline & & $\operatorname{GE}(0)=$ & 0.222 & 0.000 & 0.424 & 0.002 & $=\mathrm{A}(2)$ & \\
\hline & & $\operatorname{GE}(1)=$ & 0.187 & 0.000 & 0.200 & 0.001 & $=\mathrm{A}(1)$ & \\
\hline & & $\mathrm{GE}(2)=$ & 0.197 & 0.000 & 0.096 & 0.000 & $=\mathrm{A}(0.5)$ & \\
\hline \multicolumn{9}{|c|}{ Equivalent Income } \\
\hline \multirow{5}{*}{ 预 } & 0.385 & & \multicolumn{2}{|c|}{0.243} & \multicolumn{2}{|c|}{0.249} & & \multirow{5}{*}{$\begin{array}{l}n \\
n \\
0 \\
0 \\
0\end{array}$} \\
\hline & \multirow{4}{*}{$\begin{array}{cc}\text { M.- } & 0.383 \\
\text { F.- } & 0.383\end{array}$} & $\mathrm{GE}(-1)=$ & 0.450 & 0.001 & & & & \\
\hline & & $\mathrm{GE}(0)=$ & 0.285 & 0.001 & 0.472 & 0.005 & $=\mathrm{A}(2)$ & \\
\hline & & $\mathrm{GE}(1)=$ & 0.242 & 0.001 & 0.248 & 0.002 & $=\mathrm{A}(1)$ & \\
\hline & & $\mathrm{GE}(2)=$ & 0.261 & 0.001 & 0.123 & 0.001 & $=\mathrm{A}(0.5)$ & \\
\hline & \multicolumn{8}{|c|}{ Fare per Mile } \\
\hline \multirow{5}{*}{ 矛 } & 0.386 & & \multicolumn{2}{|c|}{0.271} & \multicolumn{2}{|c|}{0.223} & & \multirow{5}{*}{$\begin{array}{l}n \\
1 \\
0 \\
n \\
0\end{array}$} \\
\hline & \multirow{4}{*}{$\begin{array}{cc}\text { M.- } & 0.412 \\
\text { F.- } & 0.366\end{array}$} & $\mathrm{GE}(-1)=$ & 0.305 & 0.001 & & & & \\
\hline & & $\operatorname{GE}(0)=$ & 0.251 & 0.001 & 0.380 & 0.000 & $=\mathrm{A}(2)$ & \\
\hline & & $\mathrm{GE}(1)=$ & 0.270 & 0.001 & 0.223 & 0.000 & $=\mathrm{A}(1)$ & \\
\hline & & $\mathrm{GE}(2)=$ & 0.408 & 0.001 & 0.122 & 0.000 & $=\mathrm{A}(0.5)$ & \\
\hline \multirow{6}{*}{ 胥 } & \multicolumn{8}{|c|}{ Time per Mile } \\
\hline & 0.356 & & \multicolumn{2}{|c|}{0.228} & \multicolumn{2}{|c|}{0.202} & & \multirow{5}{*}{$\begin{array}{l}n \\
\vdots \\
0 \\
n \\
0\end{array}$} \\
\hline & M.- $\quad 0.360$ & $\mathrm{GE}(-1)=$ & 0.316 & 0.004 & & & & \\
\hline & F.- 0.346 & $\operatorname{GE}(0)=$ & 0.221 & 0.004 & 0.378 & 0.018 & $=\mathrm{A}(2)$ & \\
\hline & & $\mathrm{GE}(1)=$ & 0.225 & 0.004 & 0.198 & 0.004 & $=\mathrm{A}(1)$ & \\
\hline & & $\mathrm{GE}(2)=$ & 0.305 & 0.004 & 0.104 & 0.002 & $=\mathrm{A}(0.5)$ & \\
\hline
\end{tabular}




\section{Gini, Theil And Atkinson per Age Group in Columbus}

\section{AGE GROUPS (3)}

\begin{tabular}{|c|c|c|c|c|}
\hline \multirow[t]{2}{*}{ Gini } & \multicolumn{2}{|c|}{ GE (a) } & \multicolumn{2}{|c|}{ Atkinson (e) } \\
\hline & Within & Between & Within & Between \\
\hline
\end{tabular}

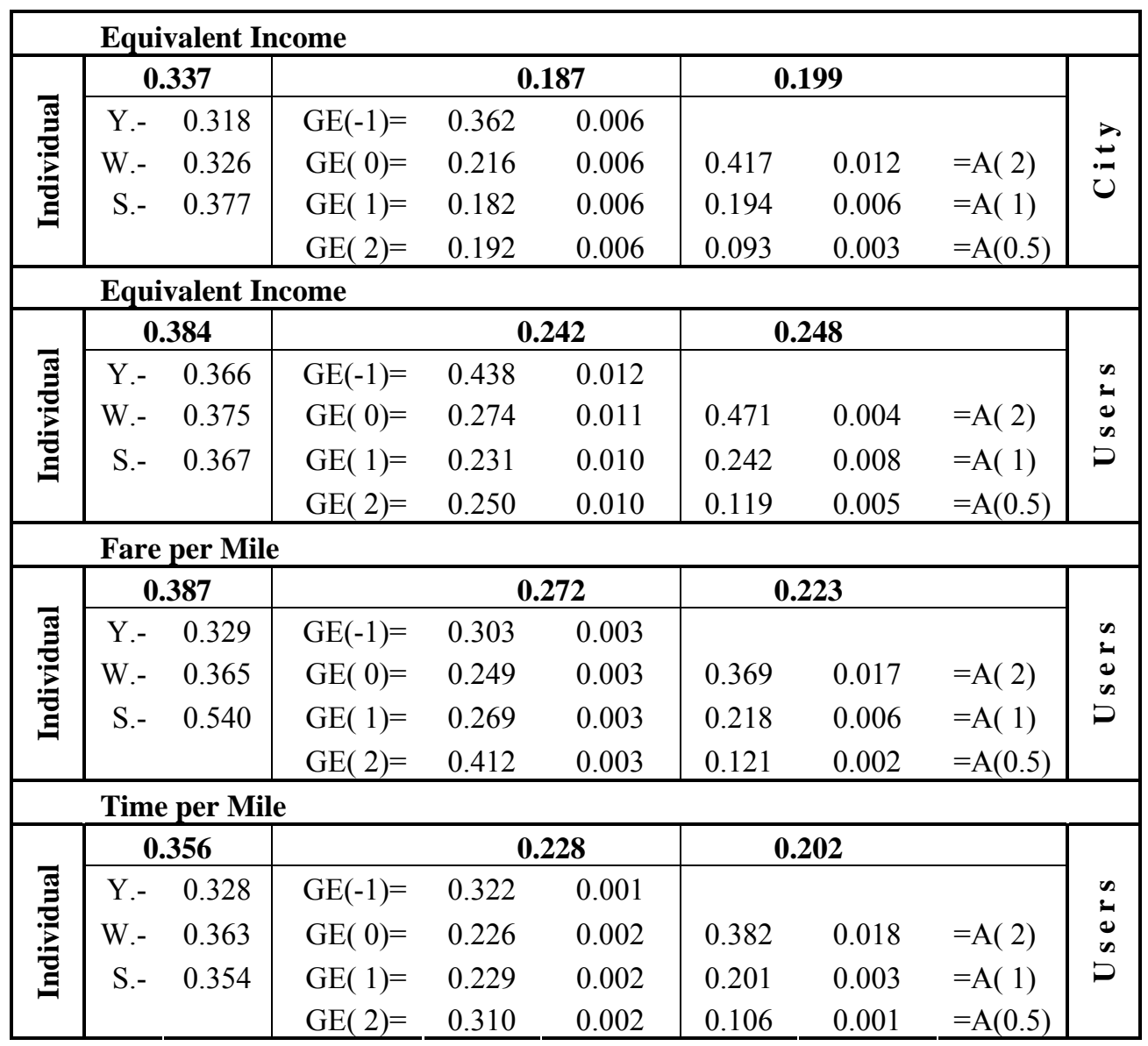




\section{B. The Case of SEATTLE}

\section{Average Trip Characteristics by Income Group in Seattle}

\begin{tabular}{lccccc} 
Group & $\begin{array}{c}\text { Distance } \\
\text { (miles) }\end{array}$ & $\begin{array}{c}\text { Time } \\
\text { (minutes) }\end{array}$ & $\begin{array}{c}\text { Speed } \\
\text { (mph) }\end{array}$ & $\begin{array}{c}\text { fpm } \\
\text { (cents/mile) }\end{array}$ & tpm \\
\hline Low-Income & 7.4 & 47.0 & 9.7 & 48.0 & 12.4 \\
Mid-Income & 8.2 & 44.7 & 10.7 & 38.5 & 10.5 \\
High-Income & 10.3 & 44.8 & 13.5 & 27.7 & 7.8
\end{tabular}

\section{Statistical Differences Using T-Test Analysis in Seattle}

Using the $t$-test procedure comparing high income (above 55K) versus low income (below $35 \mathrm{~K}$ ) groups, the following differences are found:

\begin{tabular}{cccccc} 
Distance & Time & Speed & Min/mile & Fare $/$ mile & Fare $/ \mathbf{m i n}$ \\
\hline Highly & Not & Highly & Significant & Significant & Not \\
Significant & Significant & Significant & at 5\% level & at 5\% level & Significant \\
$(<0.0001)$ & $(0.2069)$ & $(<0.0001)$ & $(0.0363)$ & $(0.0269)$ & $(0.3320)$ \\
\hline
\end{tabular}

\section{Gini Coefficient in Seattle}

The average fpm paid by each income group (as defined in the survey) is shown in the following table and graph. 22 records where users reported earning less than $35 \mathrm{~K}$ (but didn't report the specific range), were taken out of this analysis.

\begin{tabular}{cccc}
$\begin{array}{c}\text { Income } \\
\text { Code }\end{array}$ & $\begin{array}{c}\text { Income } \\
\text { Limits }\end{array}$ & Population & fare/mile \\
\hline 11 & $<10 \mathrm{k}$ & 72 & 91.96 \\
12 & $10 \mathrm{k}-15 \mathrm{k}$ & 38 & 36.50 \\
13 & $15 \mathrm{k}-25 \mathrm{k}$ & 113 & 30.08 \\
14 & $25 \mathrm{k}-35 \mathrm{k}$ & 119 & 47.75 \\
15 & $35 \mathrm{k}-45 \mathrm{k}$ & 172 & 38.85 \\
16 & $45 \mathrm{k}-55 \mathrm{k}$ & 180 & 36.18 \\
17 & $55 \mathrm{k}-75 \mathrm{k}$ & 211 & 26.26 \\
18 & $>75 \mathrm{k}$ & 196 & 29.23 \\
\hline & & 1,101 &
\end{tabular}




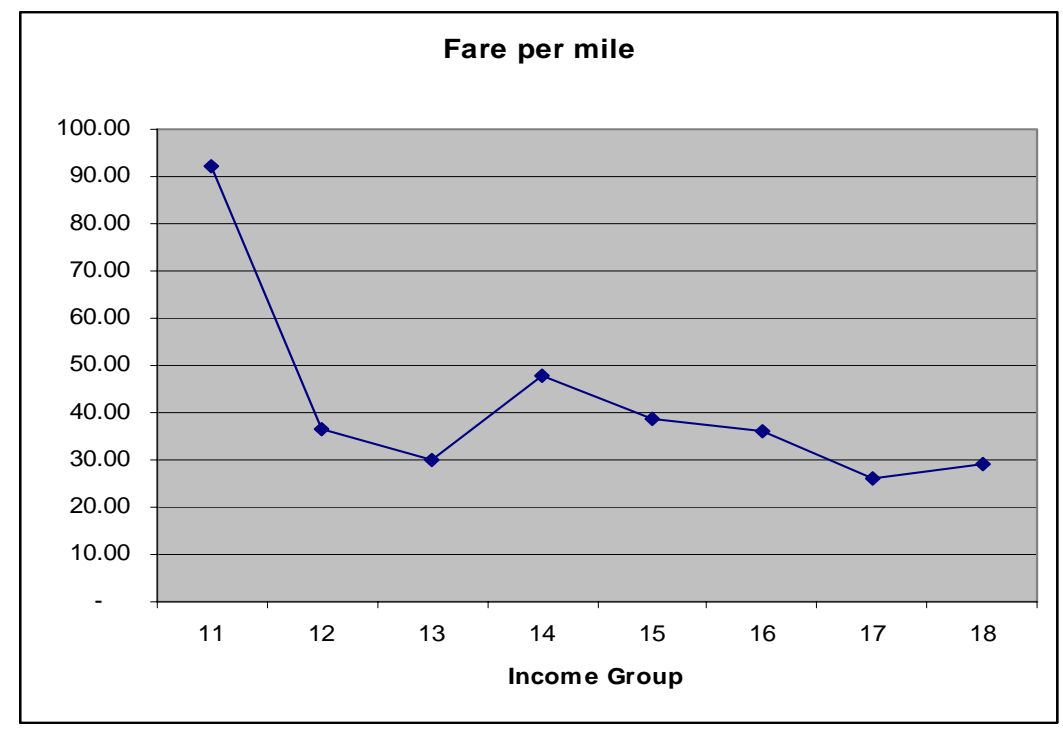

\begin{tabular}{cccc} 
Income Group & Population & $\begin{array}{c}\text { Average } \\
\text { fpm }\end{array}$ \\
\hline $11-12$ & $<15 \mathrm{k}$ & 110 & 72.80 \\
$13-14$ & $15 \mathrm{k}-35 \mathrm{k}$ & 232 & 39.15 \\
$15-16$ & $35 \mathrm{k}-55 \mathrm{k}$ & 352 & 38.51 \\
$17-18$ & $>55 \mathrm{k}$ & 407 & 27.69 \\
\hline \multicolumn{4}{c}{1,101}
\end{tabular}

*Considering these income groups, the Gini coefficient equals $\mathbf{0 . 4 1}$. 